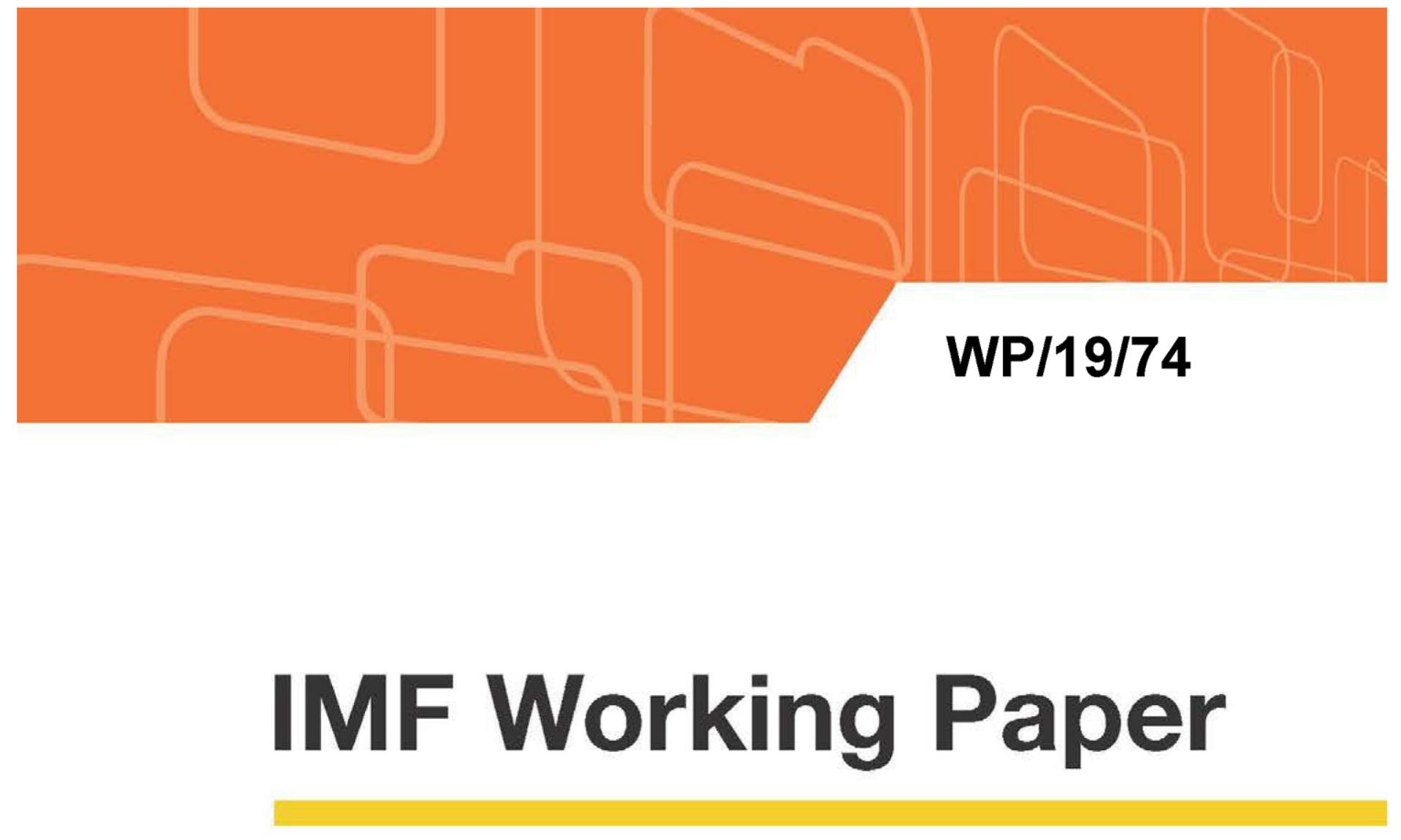

\title{
The Return of the Policy That Shall Not Be Named: Principles of Industrial Policy
}

\author{
by Reda Cherif and Fuad Hasanov
}

IMF Working Papers describe research in progress by the author(s) and are published to elicit comments and to encourage debate. The views expressed in IMF Working Papers are those of the author(s) and do not necessarily represent the views of the IMF, its Executive Board, or IMF management. 


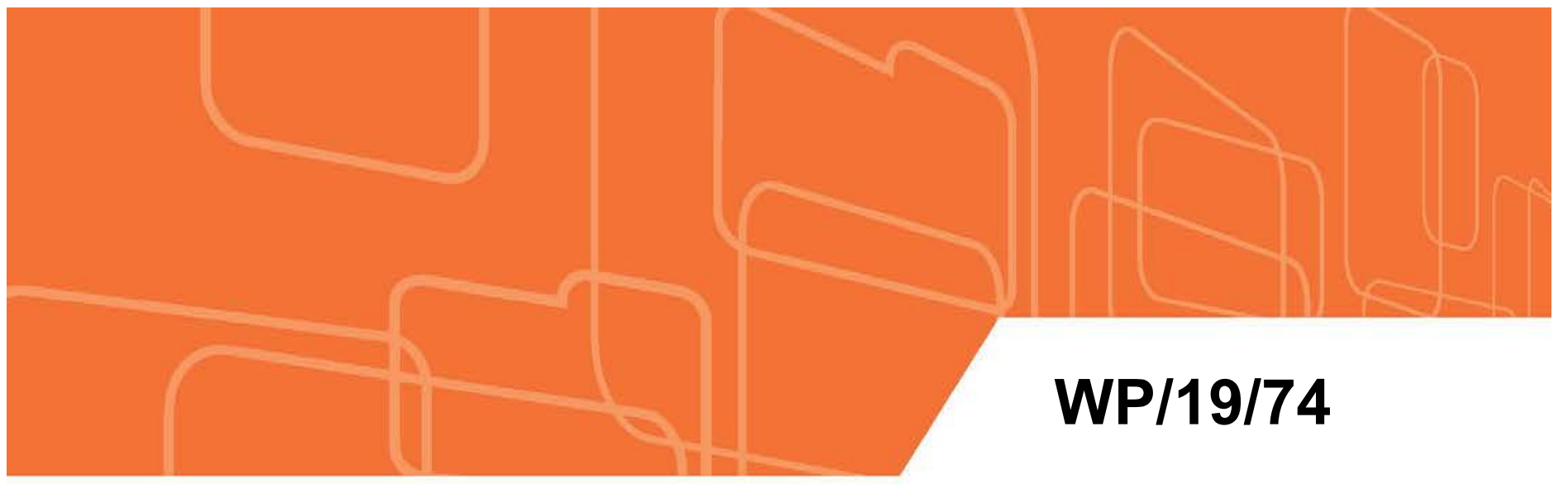

\title{
IMF Working Paper
}

\section{The Return of the Policy That Shall Not Be Named: Principles of Industrial Policy}

\author{
by Reda Cherif and Fuad Hasanov
}

IMF Working Papers describe research in progress by the author(s) and are published to elicit comments and to encourage debate. The views expressed in IMF Working Papers are those of the author(s) and do not necessarily represent the views of the IMF, its Executive Board, or IMF management. 


\title{
IMF Working Paper
}

Institute for Capacity Development

The Return of the Policy That Shall Not Be Named: Principles of Industrial Policy Prepared by Reda Cherif and Fuad Hasanov ${ }^{1}$

Authorized for distribution by Ralph Chami

March 2019

\section{IMF Working Papers describe research in progress by the author(s) and are published to elicit comments and to encourage debate. The views expressed in IMF Working Papers are those of the author(s) and do not necessarily represent the views of the IMF, its Executive Board, or IMF management.}

\begin{abstract}
Industrial policy is tainted with bad reputation among policymakers and academics and is often viewed as the road to perdition for developing economies. Yet the success of the Asian Miracles with industrial policy stands as an uncomfortable story that many ignore or claim it cannot be replicated. Using a theory and empirical evidence, we argue that one can learn more from miracles than failures. We suggest three key principles behind their success: (i) the support of domestic producers in sophisticated industries, beyond the initial comparative advantage; (ii) export orientation; and (iii) the pursuit of fierce competition with strict accountability.
\end{abstract}

JEL Classification Numbers: O25, O47, O57

Keywords: Industrial policy; technology; innovation; growth; diversification

Authors' E-Mail Addresses: acherif@,imf.org; fhasanov@,imf.org

\footnotetext{
${ }^{1}$ We are grateful to Ralph Chami and Alfred Kammer for valuable suggestions and discussions. We would also like to thank Bergljot Barkbu, Andrew Berg, Claudia Berg, Sascha Buetzer, Chris Colford, Dennis Essers, Jean-Marc Fournier, Chris Papageorgiou, Jiro Podpiera, Cyril Rebillard, Sidra Rehman, Alasdair Scott, Nikola Spatafora, Andrew Warner, and IMF seminar participants for helpful comments and discussions. We are grateful to Lopo De Castro Neto for assistance with some data and figures and to Claudia Cohen and Ravaka Prevost for help with formatting the paper. All errors are our own.
} 


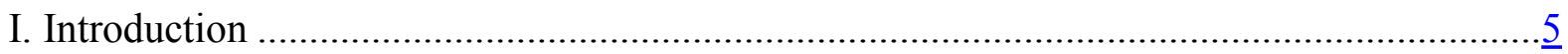

II. Rashomon's Witnesses of The Asian Miracles ....................................................................

III. Learning from Miracles vs. Failures .......................................................................

A. 50 Years of Development: Catching Up, Forging Ahead, and Falling Behind .......10

B. Can We Learn from Miracles? ............................................................................13

C. When Leo Tolstoy Meets Wassily Leontief: A Stylized Model of Long-Run Growth

IV. Technology and Innovation Policy as "True Industrial Policy" .......................................21

A. It is All About Productivity Gains: Innovation and Export Sophistication .............21

B. TIP: The Moonshot Approach to Development.....................................................22

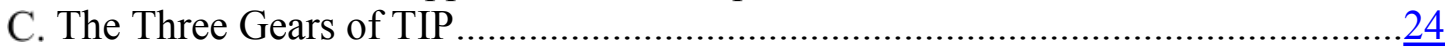

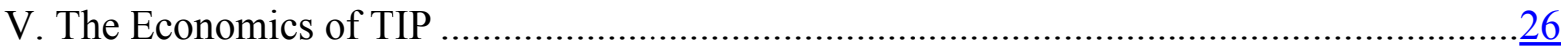

A. The Standard Growth Recipe is Not Enough.......................................................

B. Building Sophisticated Products .......................................................................

C. Beyond Comparative Advantage: Vegetables, Sewing Machines, or Microcircuits?

D. Not Manufacturing vs. Services, Rather Sophisticated Manufacturing and Services

$\ldots$

E. Creating Domestic Innovators: From Convergence to Growth at the Frontier ........ $\underline{45}$

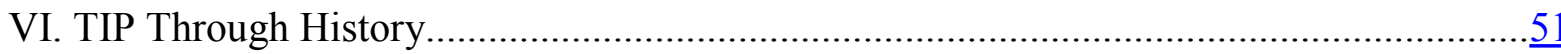

A. TIP Has Always Failed in the Past...Because It Was Not Tried .............................51

B. ISI in India: The State as a Micromanager...........................................................57

C. Export Orientation, not Tariffs, is the Secret Ingredient........................................

D. Can Laissez-Faire be Worse than Import Substitution?..........................................61

E. Earlier Miracles in Advanced Economies and the Forgotten Hand of the State ...... $\underline{62}$

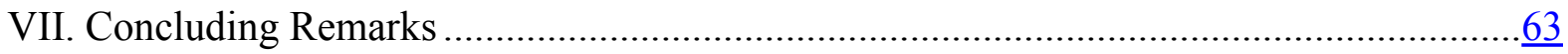

Figures

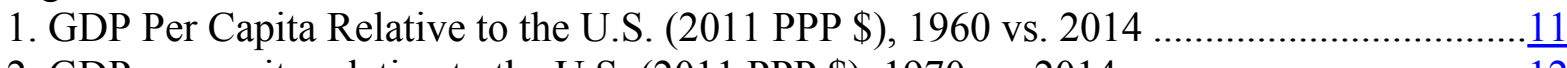

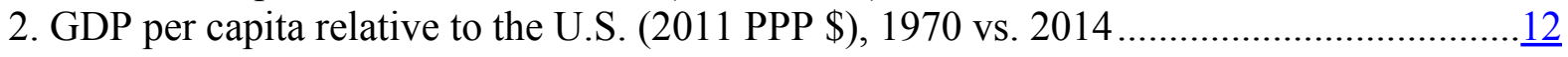

3. Average Investment Rate vs. Average TFP Growth (1970-90) ……................................

4. The Power Law Distribution of Gross Relative Growth Rates, 1964-2014........................17

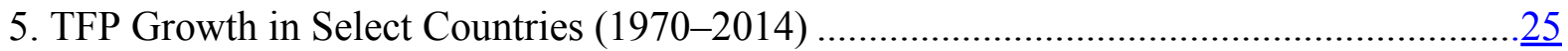

6. Doing Business and Competitiveness Indicators in Oil Exporters …………………….......29

7. Goods Export Sophistication .....................................................................................

8. Value-Added per Worker in U.S. Industries (2016) ........................................................

9. R\&D Intensity (Percent of GDP), OECD (2015) ……….................................................

10. R\&D Intensity and Personnel, USA (2015)..............................................................

11. Patents Issued by Different Industries, USA (2012)....................................................

12. Manufacturing Economy-wide Productivity Growth in Select Countries ........................... 40 
13. The Output Structure: Bahrain vs. Singapore ...............................................................

14. The Export Structure: Bahrain vs. Singapore …………………………………............ 43

15. Export Sophistication in Malaysia, Korea, and Taiwan Province of China …………….... 46

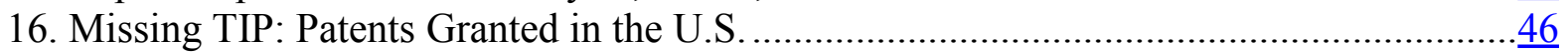

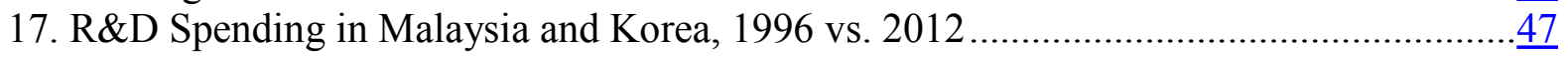

18. Patents Granted in the U.S.: When Korea Overtook Other Countries ................................ 49

19. Patents Granted in the U.S.: Korea vs. Other Countries (1990-2014) .............................49

20. Who Creates Technology?.....................................................................................

21. The Rise and Fall of Import Substitution Led Growth ................................................

22. Kernel Distribution of Structural Break Years ........................................................

23. Short-term Relationship Between Manufacturing Exports and Output.............................54

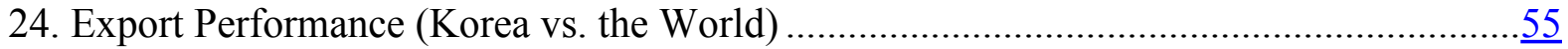

25. Manufacturing Export Market Share Change …………………………......................

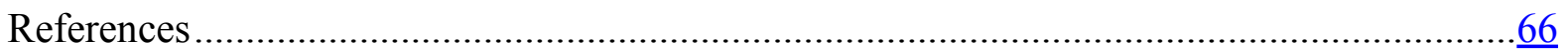

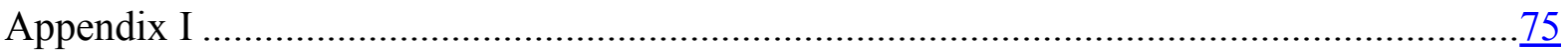

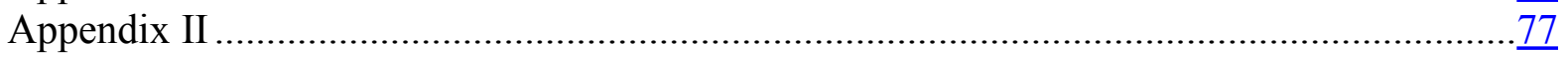




\section{INTRODUCTION}

How to achieve high and sustained growth is one of the most critical topics in macroeconomics, but it has remained an elusive holy grail. Over the past half a century, developing economies have treaded quite different paths, with a few like the "Asian Miracles"-Hong Kong (China), Korea, Singapore, and Taiwan Province of China - catching up, some forging ahead, and many falling behind, to use the description of Abramovitz (1986). Lucas (1988), observing cross-country growth experiences and their implications on social welfare, famously wrote that "once one starts to think about them, it is hard to think about anything else." The empirical evidence shows that the odds for poor or middle-income countries to reach high-income status within a couple of generations are very low. Over 19602014, less than 10 percent of economies (16 out of 182) have reached high-income status. In contrast to the Asian miracles, the others that made it either discovered large quantities of oil or benefitted from joining the European Union.

The contrasting views on the interpretation of the Asian miracles' success are akin to Kurosawa's Rashomon plot. In this masterpiece of Japanese cinema, every witness of a samurai's murder (that is, a peasant, a bandit, the samurai's wife, and lastly a soothsayer) has its own version of the same event. Similarly, many economists and policymakers call for a different mixture of the same standard growth policy recipe that includes financial deepening, openness to trade, ease of doing business, good infrastructure and institutions, macro-stability, good education, and capital accumulation. We argue for a distinct perspective on the success of the Asian Miracles (and perhaps play the role of the soothsayer in Rashomon).

Based on theoretical, empirical, and historical evidence (in the tradition of Friedrich List, Alice Amsden, Robert Wade, James Fallows, and Ha-Joon Chang), we argue that the development paths of the Asian Miracles as well as Japan, Germany, and the U.S. before them, provide us with important clues to their success. We contend that standard growth policy prescriptions are not sufficient. We find strong commonalities in policies pursued by the Asian Miracles, and one cannot ignore the preeminent role of industrial policy in their development. ${ }^{2}$ Not only did they succeed at catching up with the advanced world, the Asian miracles' economic model resulted in much lower market income inequality than that in most advanced countries. ${ }^{3}$

Distilling useful lessons from country experiences is a daunting task, not least because of the difficulty of disentangling the role of policies from luck in the absence of natural experiments. We contribute to this debate by arguing that many things could go wrong in the countries that diverged and there is a lot of valuable information in the countries that truly succeeded. First, we use a stylized model to show that it is not easy to distinguish between luck and policies in the countries that have diverged, adding more noise than signal to the uncovering of the

\footnotetext{
${ }^{2}$ In the paper, we do not examine China's policies (although there are many similarities to policies pursued by the Asian miracles) since China has not yet achieved the high-income status.

${ }^{3}$ See Luxembourg Income Study database.
} 
growth determinants. Second, we show that long-term growth follows a power law distribution suggesting that crucial information such as the experience of the Asian Miracles lies in the tail rather than the average. This approach contrasts with the standard approach in economics emphasizing averages such as growth regressions. In other words, according to the Nobel laureate in physics Phil Anderson, "Much of the real world is controlled as much by the tails of distributions as [by] means or averages...by the exceptional not the common place; by the catastrophe, not the steady drip... we need to free ourselves from 'average' thinking" (Ramalingam 2013).

We argue that the success of the Asian Miracles is based on three key principles that constitute "True Industrial Policy," which we describe as Technology and Innovation Policy (TIP). Although our paper is yet another attempt among many to discover the key ingredients for success in development, we are the first, to our knowledge, to articulate them into the following three key principles, which were applied at the onset by the Asian miracles: (i) state intervention to fix market failures that preclude the emergence of domestic producers in sophisticated industries early on, beyond the initial comparative advantage; (ii) export orientation, in contrast to the typical failed "industrial policy" of the 1960s-1970s, which was mostly import substitution industrialization (ISI); and (iii) the pursuit of fierce competition both abroad and domestically with strict accountability.

In addition, the extent of the technological leap to sophisticated industries early on and the extent of the technology creation by domestic firms would determine how successful the longterm growth outcome could be. Success depends on policies emphasizing innovation and technology at every stage of the development process. Those countries that manage this process would have a high chance of making it to the club of high-income countries in a relatively brief period. We contend that the Asian miracles implemented these principles, offering clues as to what other countries could do to follow in their footsteps. Indeed, "If we know what an economic miracle is, we ought to be able to make one" (Lucas 1993).

Economic diversification, which is on agenda of many developing countries, especially commodity exporters, is another outcome of TIP. It is consistent with the thesis of Breaking the Oil Spell, in which Cherif, Hasanov, and Zhu (2016) argue that to promote sustained growth, diversifying the tradable sector and increasing its sophistication are crucial for commodity exporters.

Both the state and the market have their roles to play in implementing TIP. The "Leading Hand of the State" has a role in steering labor and capital into activities the market would not necessarily undertake (Cherif, Hasanov, and Kammer 2016), but market-signal-based decision-making and an autonomous private sector are also crucial. Bill Gates, describing his and Mark Zuckerberg's efforts to finance green investments, said "the public led; we 
followed" (Rumbelow 2017). ${ }^{4}$ It is not the state against the market; rather "when the public takes the lead and is ambitious, not just facilitating or being meek, it can push the frontier" (Mariana Mazzucato in Rumbelow 2017).

We characterize a three-gear approach to implementing TIP. The state has to set the level of ambition of its goal, and then implement the right policies while imposing accountability and being able to adapt fast as conditions change-Ambition, Accountability, and Adaptability (AAA), or a triple A, of the "leading hand of the state." Mediocre growth is not necessarily a fatality; rather it depends on the right policies and the level of the gear selected. The Asian miracles - the highest gear - are the outcome of TIP in its moonshot approach version. The middle gear is a leapfrog approach and it may provide decent growth leading to the middleincome status, while the lowest gear is a snail crawl approach that results in relatively lower growth.

The three gears correspond to different sets of policies. We argue that a standard growth recipe such as improving business environment, institutions, and infrastructure, preserving macro-stability, investing in education, and minimizing government interventions is not sufficient to sustain high long-term growth and to a large extent, constitutes the lowest gear of TIP, or the snail crawl approach. These policies mostly fix "government failures" but not necessarily "market failures," especially in the development of sophisticated sectors. The standard policies to attract FDI in addition to state intervention to develop industries around comparative advantage sectors may result in leapfrogging and steady growth. By and large, however, these policies might not generate miracles. By intervening to fix market failures to develop sophisticated sectors and domestic or homegrown technology, the state could create conditions for high and sustained long-term growth. These ambitious policies pursued by the Asian miracles represent the moonshot approach.

The rest of the paper is divided into the following main parts: (i) a brief overview of the different sides of the debate on the nature of the Asian miracles' success; (ii) empirical evidence and theory showing why there is more information in the Asian miracles than in the "failures"; (iii) an outline of the principles of TIP; (iv) a justification of the principles of TIP from an economic perspective; (v) TIP in an historical perspective; and (vi) conclusion. A reader mainly interested in the principles of TIP can skip the second and third sections without loss of continuity.

\section{RASHOMOn's WitnesSes OF THE ASIAN MiRACleS}

The discussion of the Asian Miracles brings us to the taboo topic of the usefulness of industrial policy for development and growth. In one of the earliest work on the topic, the World Bank (1993), espousing the views of many economists, argues that the standard growth

\footnotetext{
${ }^{4}$ See, for example, Kavlak, McNerney and Trancik (2018) who show the importance of government funded $\mathrm{R} \& \mathrm{D}$ and policies that stimulate market growth in the dramatic cost reduction of photovoltaic modules.
} 
recipe such as enhancing macroeconomic stability, improving legal and regulatory structure and business climate, securing an effective financial system, liberalizing trade, and accumulating physical and human capital, was key to sustained growth of the East Asian countries. ${ }^{5}$ Although the World Bank (1993) acknowledges that state intervention to spur specific industries was successful in some cases, it suggests that in general industrial policy did not work and advises governments against using it. Many countries that tried have failed and a few that succeeded have pursued good fundamental policies and have been good at evaluating and monitoring the support provided. Nonetheless, the World Bank (1993) states that export-push strategies using standard growth policies hold the most promise. In other words, this view corresponds to the low gear of TIP or snail-crawl approach in our classification.

The example of Hong Kong illustrates well the contrasting views on what made the Asian miracles. Many argue that its success was due to free-market policies (e.g., Monnery 2017) rather than industrial policy. Chen (1987) and Weiss (2005) point to the prominent contribution of manufacturing exports to growth in the earlier period without state intervention in contrast to activist policies of Korea and Taiwan Province of China. However, the Trade and Industry Department of Hong Kong indicates that it provided various forms of support to industry, which can be classified as "soft" industrial policy. Hong Kong Productivity Council created in 1967 played an instrumental role in promoting technology and innovation, TIP in our definition (Boulton 1997).

The empirical growth literature suggests that many of the standard growth factors, by and large, are causal while at the same time considering the Asian miracles as mere statistical accidents. A few others, based on growth accounting exercises (e.g., Young 1995) believe the high growth of the Asian miracles is attributed to high investment rates in physical and human capital, increased labor force participation and higher working hours, or "perspiration" rather than high productivity gains or "inspiration." Others see in the Asian miracles the product of cultural traits and geography, which can neither be changed nor exported.

Yet many scholars have argued that a certain form of industrial policy in East Asia was instrumental in its rapid growth and catch up. Amsden (1989), Wade (1990), Woo (1992) and Chang (2002) have attributed this catch up to "the developmental state". Ricardo Hausmann, Jose-Antonio Ocampo, Dani Rodrik, and Joseph Stiglitz, among others, have also shown that policies play an important role in the structural transformation of developing economies. ${ }^{6}$ The state's priorities included high investment rates, promotion of some sectors either through creating state-owned enterprises (SOEs) or directing private firms to enter the sectors they would not otherwise enter, and strong export orientation (Wade 2018). Interestingly, some

\footnotetext{
${ }^{5}$ In addition, Bloom and Williamson (1997) argue that the demographic dividend contributed to the success of the Asian miracles.

${ }^{6}$ See for example Rodrik (2005), Ocampo, Taylor, and Rada (2009), Stiglitz and Greenwald (2014), and Hausmann, Espinoza, and Santos (2015).
} 
elements such as export orientation and high investment rates are common across the contrasting views on industrial policy in the earlier work.

The debate on industrial policy has been relatively confrontational in the recent past. Perhaps the consensus view among many economists is that industrial policy usually fails, so any resurrection of these ideas is taken with great skepticism. Wade (2018) mentions an interesting anecdote about the World Bank's view on industrial policy. In his account, only when Justin Lin arrived at the World Bank as Chief Economist in 2008, was there an attempt to bring back the banished phrase "industrial policy." In his speech in Pretoria, Vice President of the World Bank, Janamitra Devan citing The Economist's "Industrial policy is back in fashion," argues that "promoting industrial competitiveness is not back in fashion-because it never went out of fashion" (2011). ${ }^{7}$ Yet the term went underground after Lin left and the pilots "Competitive Industries Program" that were created were wound down. There are relatively few empirical studies on the causal effects of industrial policy, and some recent papers find a positive effect (e.g. Criscuolo et. al. 2019, Juhasz 2018, Kalouptsidi 2018, and Lane 2017).

Chang $(2009,2013)$ proposes to go beyond the confrontation and see what we can learn from this debate. He stresses the importance of export orientation as a common ground. He further argues that even such crucial problems as the lack of capabilities and political economy issues that tend to translate into advice for inaction, should not let "the best become the enemy of the good." In the same vein of surmounting the ideological confrontation, Benhassine and Raballand (2009) suggest that industrial policy may be most needed in low-income countries with undiversified industrial base. They argue that even if conditions for interventions are very weak, examples show that interventions can still succeed. Harrison and Rodriguez-Clare (2010) discuss theoretical and empirical work on industrial policy and suggest that there is an important role for a "soft" industrial policy, in which government and the private sector collaborate on interventions to increase productivity. ${ }^{8}$ IDB (2014) argues along the same lines based on the Latin American experience. Justin Lin (2012) suggests that the state could provide a facilitating role in identifying and helping develop industries around comparative advantage along with markets and firms leading the technological innovation.

Stiglitz and Greenwald (2014) argue that what separates advanced countries from developing countries is the gap in knowledge. They start with Arrow's (1962) seminal paper "Learning by Doing" and contend that markets will underprovide the production and diffusion of knowledge. Closing the knowledge gap would require a well-crafted industrial policy to encourage learning and create a learning society. Mazzucato (2013) shows how important the state's role is in promoting innovation and growth in advanced countries.

\footnotetext{
${ }^{7}$ We thank Chris Colford for bringing this speech to our attention.

${ }^{8}$ The OECD's Warwick (2013) also suggests "soft" industrial policy rather than heavy product market interventions. Chang and Andreoni (2016) discuss industrial policy in a changing world. Mazzucato (2013), World Bank's Hallegatte, Fay, and Vogt-Schilb (2013) and Harrison, Martin, and Nataraj (2017) propose green industrial policy.
} 
While academics have been debating about the practicalities and merits of industrial policy, most countries, whether intentionally or not, have been engaged in some form of industrial policy. Ha-Joon Chang has been arguing this point that by choosing to build a certain type of infrastructure (e.g., a railroad vs. a road or broadband internet) or encouraging a certain type of education (e.g., engineering schools vs. business schools), policies favor a certain type of industries. Moreover, many countries have been trying to promote explicitly tourism, finance, and logistics, and even if policies to promote these industries are not called industrial policies, effectively these policies have been industrial in nature. In many cases international financial institutions seem to have been less worried by this type of industrial policy. The key question is if many countries have been conducting industrial policy anyway, what should the right way to do this be.

\section{LEARNING FROM MIRACLES VS. FAILURES}

\section{A. 50 Years of Development: Catching Up, Forging Ahead, and Falling Behind}

A half-century of cross-country development experience indicates that the odds of reaching high-income status are low. Since high-income countries have also grown for the past 50 years, an important metric for assessing income convergence is relative growth. The standard methods to define low, middle, or high-income status using absolute levels of income need to be updated regularly to incorporate growth of other countries. Since the goal of economic development is to reach the living standards of the most advanced countries, the thresholds based on relative income capture how far an economy is from reaching that goal.

We use the distribution of GDP per capita in 2011 purchasing power parity (PPP) dollars relative to the U.S. in 2005 to compute the thresholds. ${ }^{9}$ We calculate this distribution's median and the seventy-fifth percentile, which help determine the thresholds for upper-middle-income and high-income countries, respectively. ${ }^{10} \mathrm{We}$ set the upper-middle income threshold at 20 percent of the U.S. income per capita and the high-income threshold at 50 percent (Figure 1). The thresholds are applied through time since they are expressed in relative income terms. In 2014, the upper-middle income threshold was about \$10,400, while the highincome threshold was about $\$ 26,000 .{ }^{11}$ These figures raise the bar for the countries to reach high-income status.

\footnotetext{
${ }^{9}$ We use data from Penn World Tables 9.0. The thresholds computed from the 2005 data are not substantially different from those computed using the data in the 2000s. In addition, these thresholds are not different from those in the earlier version of Penn World Tables 8.0. However, the thresholds based on the relative income distribution in earlier decades are much lower in PWT 9.0 than in PWT 8.0.

10 The median is about 18 percent while the 75 th percentile is about 47 percent in the relative income distribution.

${ }^{11}$ In 1960 , these thresholds were about $\$ 3500$ and $\$ 8800$, while in 1970 , they were about $\$ 4700$ and $\$ 11,700$, respectively.
} 


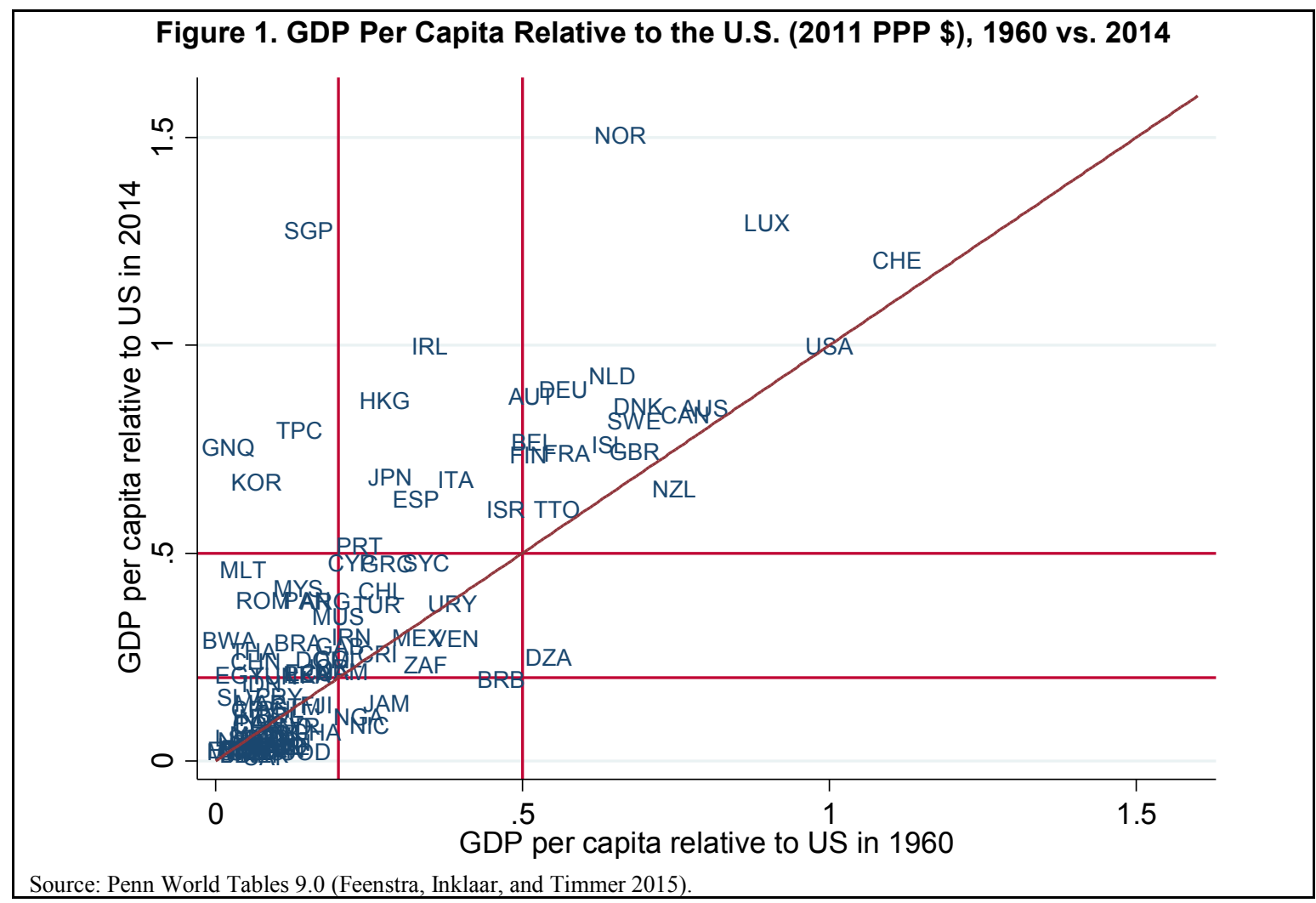

Some interesting patterns emerge. Many industrialized nations remained rich, with a few economies growing rapidly in the 1960s and passing the high-income threshold by 1970 (Israel, Italy, and Japan). Many oil-exporting countries witnessed a large fall in relative income over 1970-2014 despite the rise in oil prices in the 2000s (Cherif and Hasanov 2016). Low- and lower-middle income countries (with relative income of less than 20 percent of the U.S. GDP per capita) mostly stayed in the same relative positions. Only did a few countries rise to the upper-middle income status from the low-income status ${ }^{12}$ (Botswana, Egypt, China, Grenada, Mongolia, and Thailand). A few more countries rose to the upper-middle income level from the lower-middle income level (e.g., Brazil, Malaysia, and Romania). Many others lagged and fell in relative rankings (e.g., Jamaica and South Africa). ${ }^{13}$

\footnotetext{
12 The threshold for the low-income status is set at 10 percent of U.S. GDP per capita.

${ }^{13}$ For a survey, see Johnson and Papageorgiou (forthcoming).
} 


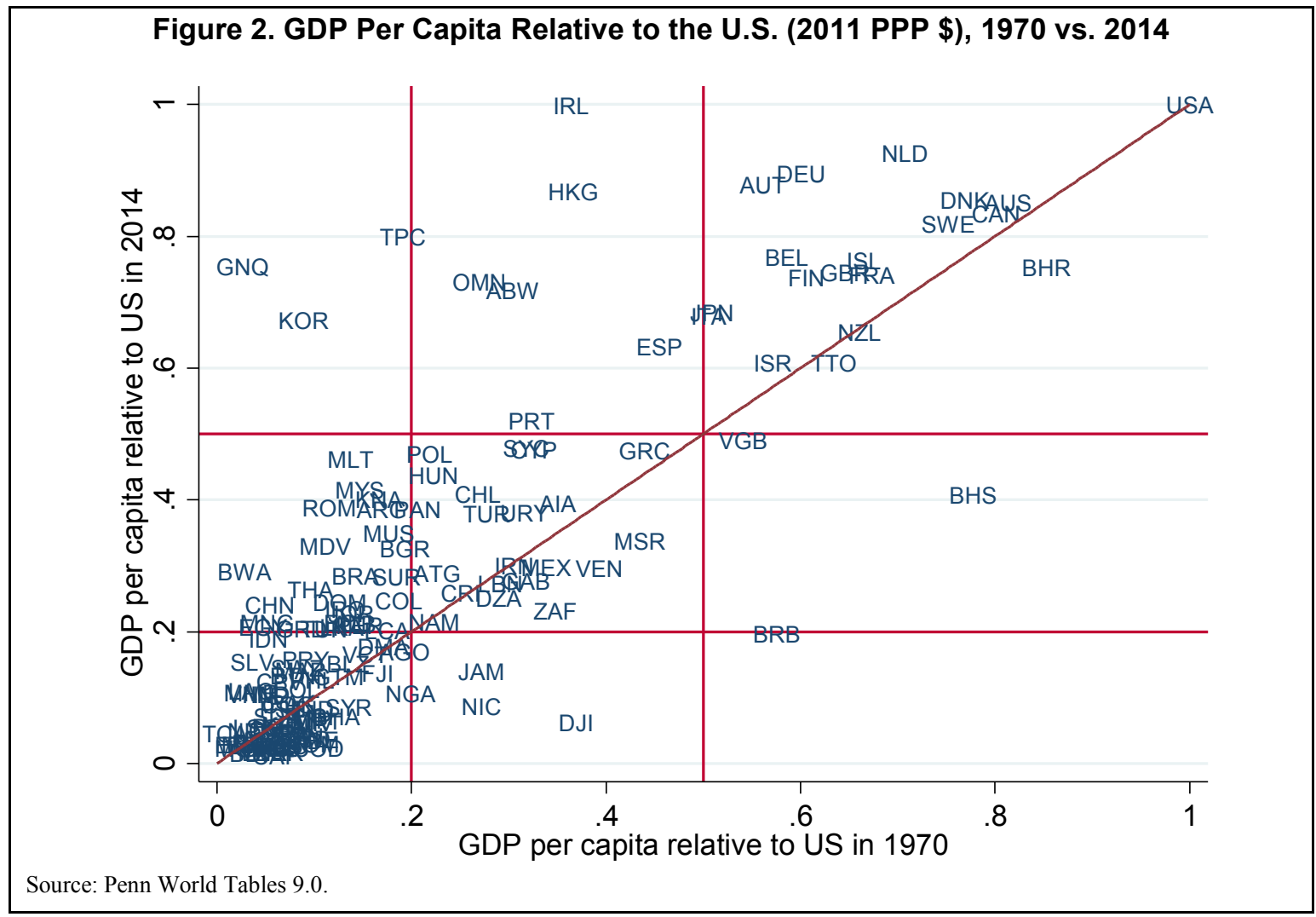

In the past one-half of a century (1960-2014), only a handful of economies, 16 out of 182 economies in the sample in 2014-Aruba, Czech Republic, Equatorial Guinea, Estonia, Hong Kong (China), Ireland, Israel, Italy, Japan, Korea, Oman, Portugal, Singapore, Slovenia, Spain, and Taiwan Province of China - have crossed the threshold of 50 percent of the U.S. GDP per capita. Examining a bit over 40 years of data (1970-2014), Israel, Italy, and Japan drop out from this sample as they reached the high-income status by 1970. Over the past 44 years, 7 economies out of 13 reaching the high-income status were European countries, which were already upper-middle income economies to begin with, and later became part of the European Union, including a small Dutch Caribbean island of Aruba. It is not surprising that these economies grew relatively fast. Other countries such as Equatorial Guinea, Oman, and in fact Aruba, grew fast due to oil discoveries. However, history may repeat itself as other oil exporters such as Kuwait and Saudi Arabia got rich with oil discoveries but then lost their relative income ranking over time.

The four economies reaching the high-income status without the proximity to advanced Europe or natural resource discoveries are the Asian Tigers-Hong Kong (China), Korea, Singapore, and Taiwan Province of China. Korea, Singapore, and Taiwan Province of China were below the upper-middle income threshold in 1960 (Figure 1). In 1970, only Korea was below the 10 percent threshold for low-middle income countries, while Taiwan Province of China was slightly below 20 percent threshold (Figure 2). Given the historic record of longterm growth and income convergence, reaching high-income status in $40-50$ years constitutes an economic "miracle" as Lucas (1993) observed. For instance, what took Malaysia more than 
50 years to reach about 40 percent of U.S. GDP per capita in 2014 (starting at around 15 percent of U.S. GDP per capita), took Korea only about 20 years. And for current and forthcoming generations, fast convergence is what matters.

\section{B. Can We Learn from Miracles?}

Our summary of 50 years of development showed that only a few countries made it from relative or absolute poverty to advanced economy status. While countries like Ireland and Spain do provide valuable lessons, their relatively high starting levels of income, the geographic proximity to the advanced economies of Europe and the substantial aid and development programs of the EU cannot be ignored as contributing factors. Meanwhile, the Asian miracles could be considered as the most relevant group and arguably the only true "miracles". One would naturally expect the Asian miracles to constitute a focal point for the students of development. Instead, and until recently, the experiences of the Asian miracles have been mostly considered as "accidents" that cannot and should not be emulated, at least from the point of view of standard development economics. ${ }^{14} \mathrm{~A}$ few exceptions are Murphy et. al. (1989) and Lucas (1993) who gave elegant and insightful views of the mechanism behind the Asian miracles but not necessarily the policies that led to them. As we will argue below, the success of the Asian miracles cannot be disentangled from that of their industrial policies.

As for why development economics in general ignored the Asian miracles, or rather the industrial policies behind them, there are roughly two schools. In the first school, the tendency is to interpret History so that it fits preconceptions about the role of policies and the type of institutions or projectionism in the words of Johnson (1982). Some consider the Asian miracles in their recent form, when it would be difficult to distinguish them from other advanced economies in terms of institutions, human and physical capital as well as policies, and in particular in terms of the extent of state intervention. Others document state intervention and sectoral policies during the fast growth periods but conclude that they had a minor effect and that the miracle would have happened without them (see World Bank 1993). In other words, there is no particular value extracted from their experiences beyond the usual prescription: financial deepening, openness to trade, infrastructure, institutions, macrostability, education, etc. ${ }^{15}$ This approach of course ignores History in the sense that it ignores the different metamorphoses performed by the Asian miracles and in particular the role of their ever-changing policies to take them from one stage of development to the next.

The second broad school is based on empirical studies, which either "de-mystify" the Asian miracles as the result of a rapid accumulation of labor and capital (see Krugman 1994) or consider them as statistical accidents or outliers with no meaningful information within the

\footnotetext{
${ }^{14}$ There are many studies emphasizing the role of unorthodox policies in the economic development of the Asian miracles, but their conclusions are not viewed as part of the standard economics textbook or the consensus among policy experts (e.g., Amsden 1989, Wade 1990, Woo 1991, Chang 2002, among others).

${ }^{15}$ See World Bank (1993) and Jomo (1997).
} 
context of growth regressions (see Easterly 1995). In a seminal paper, Young (1995) performed a careful and painstaking growth accounting exercise based on the data of Korea, Hong Kong, Singapore and Taiwan Province of China. His conclusion was that the contribution of productivity gains, i.e. Total Factor Productivity (TFP), had been exaggerated and once physical and human capital were correctly measured, TFP's contribution to growth decreased significantly. ${ }^{16}$ For some, this was the proof that the Asian miracles were the result of "perspiration", sheer hard work and sacrifices in the form of high saving and investment rates, rather than "inspiration". What needs to be done to imitate the Asian successes is to follow policies encouraging the accumulation of both physical and human capital ultimately meaning going back to the standard prescription.

Several facts contradict the theory that the secret of the Asian miracles is simply "perspiration". The main implication of this growth accounting exercise based on the neoclassical production function is that the end of the Asian miracles' era of sustained high growth should have been around the corner (see Krugman 1994). ${ }^{17}$ Young (1995) showed that TFP contribution was low for the period roughly between the 1950s and late 1980s. However, Singapore continued growing fast afterward and became one of the richest countries in the world by 2017. Meanwhile Korea and Taiwan Province of China have been following a similar path, essentially unaffected by the laws of diminishing returns.

Many countries had high rates of investment over 1970-90, that were in many cases comparable to those in the Asian miracles, while simultaneously displaying much lower average TFP growth rates (see Figure 3). Korea for example had an impressive average investment rate of about 30 percent between 1970 and 1990 but this was not exceptional. A diverse group of countries had similar or greater investment rates such as China, Iran, Jordan, Portugal, and Saudi Arabia over the same period and average TFP growth was negative in all these countries. Many of these countries did not succeed in achieving sustained high growth despite their high rates of accumulation of both physical and human capital (see Cherif, Hasanov and Zhu 2016 for some examples). Something fundamental must distinguish the experience of these countries over that period from the Asian miracles beyond the rate of accumulation of capital. ${ }^{18}$

Moreover, if one accepts that TFP contribution was low in the Asian miracles, one would have to put it in a cross-country perspective. The same method used by Young (1995) of "chipping away" the contribution of TFP by a more precise measurement of the quality of capital, human capital, labor participation, hours, etc. would also apply to many other

\footnotetext{
${ }^{16}$ Hsieh (2002) showed that the contribution of TFP growth could be significantly greater for Taiwan Province of China and Singapore.

${ }^{17}$ If one assumes a neoclassical production function, in the absence of sustained technological progress, the accumulation of physical and human capital alone would lead to stagnation.

${ }^{18}$ Interestingly, over the subsequent period 1990-2010, China's investment rate increased substantially and its TFP started growing much faster which corresponds to a move from a period of import substitution policies to policies more closely resembling TIP (see Appendix Figure 3).
} 
developing economies yielding even smaller, if not negative, TFP contributions to growth. ${ }^{19}$ In this case, the sustained growth of TFP over long periods of time in the Asian miracles would remain an oddity compared to most other countries. Senhadji (2000) shows that even though a country's TFP growth could be lower due to different assumptions and mismeasurement, the differences in TFP growth are robust across countries suggesting that many countries had lower TFP growth than that of the Asian miracles. More important, patents granted in the U.S. show that firms in the Asian miracles were already very active in terms of innovation at an early stage of development. In other words, something else than "perspiration" must have happened in these countries that led them to high and sustained growth.

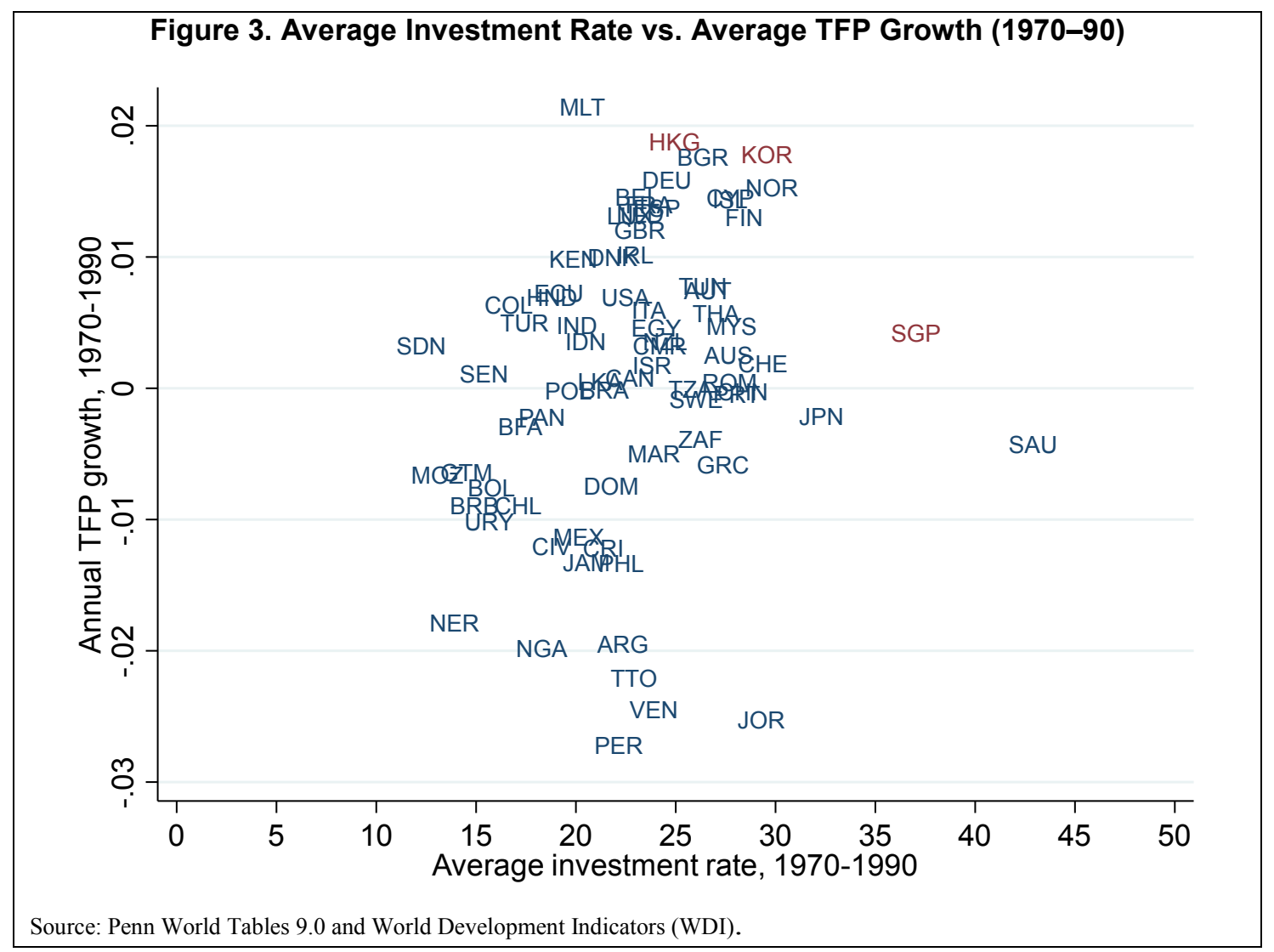

The Asian miracles were also ignored on methodological grounds in growth regressions. There is a large and rich literature based on cross-country growth regressions, but the common approach is to regress average growth rates (over 5 years, a decade or longer horizons) on a set of independent variables (e.g., measures of the quality of institutions, initial income per capita, and other economic variables). In this literature, the Asian miracles are in general considered outliers or statistical accidents with no relevant information to be gained from (see Easterly 1995). It is even recommended to exclude obvious outliers from the sample as they would bias the results. The implicit assumption in standard growth regressions is that the

\footnotetext{
${ }^{19}$ See Cherif and Hasanov (2016) showing that many oil exporting countries had negative TFP growth rates over past several decades.
} 
variable of interest should be well behaved. In particular, the error term of the linear model should follow a distribution with finite mean and variance. Although this could seem as a plausible assumption, we argue that in the case of growth regressions, at least over longer horizons, this critical assumption could be challenged. There is a myriad of criticisms against growth regressions including the endogeneity issue (see Bazzi and Clemens 2013), the difficulty of extracting policy recommendations from growth regressions (see Rodrik 2012), or the unreasonable assumption that all countries follow the same linear model (see Hausmann et al. 2005).

To our knowledge, the argument we develop below, namely that growth over the long term follows a Power Law constitutes a novel contribution to the literature. Our goal is not to discredit growth regressions; rather it is to argue that the Asian miracles should not be sidelined as mere anomalies with no informational content.

To illustrate our argument, we study the distribution of cross-country relative gross growth rates, which is the ratio of GDP per capita relative to the U.S. in 2014 to that in 1964. This measure is in fact the same as the one we used in Figure 1 to summarize 50 years of development. Our conjecture is that the relative gross growth rates follow a power law. Power law distributions exhibit fat tails such that extreme events (multiples of standard deviations) are much more likely than with normal distributions. ${ }^{20}$ Empirical studies have been uncovering such power laws in a wide spectrum of fields. The distribution of wealth, the sizes of cities in a country, and stock market returns are a few examples (see Gabaix 2009). The peculiarity of these distributions is that they could exhibit infinite means or variances depending on the exponent of the distribution. In the case of power laws, observations which are considered outliers under other distributions become an important source of information, if not most of the information.

We follow Clauset et. al. (2009) to test whether gross relative growth rates follow a power law. Figure 4 below illustrates the result. It shows the cumulative distribution function (CDF) of the variable of interest $x$ expressed on a logarithmic scale. The test detects the minimum threshold for $x$ as being around one, implying that only countries that have grown at least as fast as the U.S. over the period should be considered. The straight line represents the CDF of a power law with exponent equal to about 2.5 (estimated from the data). The distribution of the gross relative growth rates follows closely that of a power law with exponent 2.5 for observations greater or equal to one (Figure 4). The formal test confirms this observation as the null hypothesis cannot be rejected. We also use Kolmogorov-Smirnoff test to check if other distributions such as log-normal and exponential are good approximations to the data. The tests suggest that these distributions are not a good approximation to our data. We also use log-likelihood ratio tests, where the null hypothesis is that $\mathrm{x}$ follows a power law against these distributions. These tests indicate that one cannot reject that the distribution of gross relative growth rates follows a power law (although in the case of log-normal and Weibull

\footnotetext{
${ }^{20}$ See Gabaix (2009) for a detailed survey about power laws.
} 
distributions, the tests do not reject these distributions, either). Overall, power law seems to be a good approximation to long-run gross relative growth rates.

If cross-country gross relative growth rates follow a power law with exponent 2.5 , then it would mean that the Asian miracles should not be dismissed and instead they would constitute an important source of information. It would also mean that the mean of gross relative growth is finite while its variance is infinite (see Gabaix 2009). In turn, this would imply that statistical inference may not be applied to long-term cross-country growth regressions.

Estimating the exponent for shorter panels such as for $40,30,20,10$ years, ending in 2014, we note that the estimate increases in value. For the 20- and 10-year panels, it is above three, suggesting that variance is finite, and that inference may be valid Figure 4. The Power Law Distribution of Gross Relative Growth Rates, 1964-2014

in short panels. However, since in short panels we estimate the effects of variables on growth in the short to medium term, we could potentially miss what is key to long run sustained growth.

\section{When Leo Tolstoy Meets Wassily Leontief: A Stylized Model of Long-Run Growth}

\section{Can We Learn from Failures: Luck or Policies?}

For growth to happen, it is plausible to assume that a relatively large number of conditions must be satisfied simultaneously. For simplicity let us assume that the growth outcome takes the form of:

$$
g=G(P, X)
$$

Where $P$ represents an index of policy decisions and $X$ is an index summarizing exogenous factors lying outside the control of the government. Growth is the result of an interaction between policy and exogenous factors, i.e. policy decisions could magnify or mitigate luck (good or bad). In turn, let's assume that X is defined as follows: 


$$
X=\min \left(x_{1}, x_{2}, \ldots, x_{n}\right)
$$

where $x_{1}, x_{2}, \ldots, x_{n}$ are the exogenous factors. In other words, the binding constraint on growth could come from any of the exogenous factors (e.g., natural disaster, civil war, commodity prices, etc.). For simplicity, we assume that these factors lie in $[0,1]$, which means that at best a country would get the full benefit of its policies over a certain period, but its luck cannot make it grow beyond what its policies would yield over an extended period of time. We also assume that the exogenous factors are random variables. To simplify, let's assume that they are all randomly drawn from the same probability distribution, the CDF of which is $F$. It is straightforward to show that for any value y:

$$
\operatorname{Pr}(X>y)=(1-F(y))^{n}
$$

If the number of exogenous factors is large, the probability of being greater than y becomes small. Back to equation (1), we assume a simple multiplicative form for the interaction between policy and exogenous factors. We can rewrite equation (1) as

$$
g=G(P) * X
$$

We order $P$ on a continuum $[0,+\infty)$ corresponding to the ordering of the quality of the policy decisions, from worst to best respectively. $G$ is assumed to be an increasing function of $P$. Conditional on a policy decision $P$, the probability that growth, $g$, is greater than a certain value $z$ is:

$$
\operatorname{Pr}(g>z \mid P)=\left(1-F\left(\frac{z}{G(P)}\right)\right)^{n}
$$

If $G$ is an increasing function, then the probability that $g$ is greater than a certain threshold $z$ increases when $P$ increases such as better policies increase the chances of greater growth. To study the effects of policies on growth, we examine how $\operatorname{Pr}(g>z \mid P)$ is affected when $\mathrm{P}$ changes that is:

$$
\frac{\partial P r(g>z \mid P)}{\partial P}=n \frac{G \prime(P) z f(z / G(P))}{G(P)^{2}}\left(1-F\left(\frac{z}{G(P)}\right)\right)^{n-1}
$$

In turn, deriving with respect to $\mathrm{z}$ yields:

$$
\frac{\partial^{2} P r(g>z \mid P)}{\partial P \partial z} \propto f\left(\frac{z}{G(P)}\right)+\frac{z}{G(P)} f^{\prime}\left(\frac{z}{G(P)}\right)-(n-1) \frac{z}{G(P)} f\left(\frac{z}{G(P)}\right) f^{\prime}\left(\frac{z}{G(P)}\right)\left(1-F\left(\frac{z}{G(P)}\right)\right)^{-1}
$$

Given that each factor $x$ is in $[0,1]$, we assume that they follow a uniform distribution. The equation above becomes (for $z / G(P)$ in $[0,1]$ and given a positive factor of proportionality):

$$
\frac{\partial^{2} \operatorname{Pr}(g>z \mid P)}{\partial P \partial z} \propto 1
$$


This means that the marginal effect of policies is smaller when the threshold on growth is smaller. When the sample includes a lot of low-income countries, the marginal effect of policies is less distinguishable from the effect of luck.

According to this model, and for a fairly large $n$, conditional on a set of policies, fast and sustained growth is difficult to obtain even with the correct policies. More important, it also implies that an empirical investigator, curious about the effect of policies, should be mindful of the tradeoff between a larger sample containing more information and the noise introduced by low growth countries. The reason is that if the threshold $z$ in our notation is too low then it becomes very difficult to discriminate between bad policies and bad luck, which could spring from any of the exogenous factors.

Based on this model, one can build a narrative of the stylized facts shown in Figure 1. The group of countries which fell back (or grew less than the U.S.), can be characterized by bad luck and/or bad policies. Even if countries have tried to implement the right policies, bad luck could result in poor growth outcomes. The group of countries which maintained their relative income per capita (along the 45-degree line) probably did not encounter bad luck but most likely followed the snail-crawl approach to policy. The countries that grew a bit faster than the U.S. followed a leapfrog approach. Some countries that grew faster than the U.S., followed leapfrog policies and benefitted from good luck in the form of natural resources or proximity and support of the EU. Lastly, the Asian miracles, which did not encounter bad luck, had adopted the moonshot approach.

Paraphrasing Tolstoy, we argue that all rich countries are the same and every poor country is poor in its own way. For a large enough $n$, every low performing country could be considered unique in the sense that the sources of its bad luck are unique to it. The probability that the realization of exogenous variables $x$ is the same for all these countries, is very low. In other words, the experiences of bad performers may not hold useful information. Meanwhile, good performers could be said to be the same in the sense that they were not hit hard with bad luck and they adopted the best policies. As our stylized model suggests, and as argued in the following section, there are common patterns in policies among successful economies. ${ }^{21}$ These common patterns further reinforce the case that their successes are the result of policies rather than good luck (the probability of which is very small with large $n$ ), and therefore they can be replicated. ${ }^{22}$

\footnotetext{
${ }^{21}$ One could argue that other non-policy factors could set aside the Asian miracles and that by focusing on the successes, one may risk concluding that policies pursued were key to success. We argue that the Asian miracles were spared bad luck and thus managed to achieve success, and what was important for success was not necessarily the specific tools used or particular factors (e.g. geography, size, culture, political structure); rather, the principles of TIP were implemented in the relentless pursuit of achieving high income.

${ }^{22}$ See for example Henry and Miller (2009) for the importance of policies vs. geography, culture, and other similar characteristics. Acemoglu and Robinson (2012) argue that "inclusive" political and economic institutions are important for development. Although we agree that certain institutions are necessary, we argue that they are not sufficient and policies to solve market failures are crucial, as the cases of the Asian miracles and rich Gulf oil exporters illustrate.
} 


\section{The Power of Compounding}

We show that if the effect of policies is compounded over time, it can lead to a power law distribution of growth in the cross-section, the coefficient of which decreases with time. First, we assume that $G(P)$ is the compounding of the effects of $P$ over T periods such that:

$$
G(P)=P^{T}
$$

We further assume that $\mathrm{P}$ follows a broken Power Law with coefficient $\alpha^{\prime}$ over [0,1] and $\alpha^{\prime \prime}$ for $\mathrm{P}>1$. The p.d.f. of $\mathrm{G}(\mathrm{P})$ denoted $f_{G(P)}(\mathrm{y})$ is therefore:

$$
f_{G(P)}(\mathrm{y})=\frac{f_{P}\left(y^{1 / T}\right)}{T\left(y^{1 / T}\right)^{T-1}}
$$

which by definition is proportional to:

$$
\begin{gathered}
y^{-\frac{\alpha^{\prime \prime}+T-1}{T}} \text { for } \mathrm{y} \text { in }[0,1] \\
y^{-\frac{\alpha^{\prime}+T-1}{T}} \text { for } \mathrm{y}>1
\end{gathered}
$$

We turn to the unconditional distribution of $g$ denoted $h(g)$. Given (1), it can be written as:

$$
h(g)=\int_{-\infty}^{+\infty} \frac{1}{x} f_{G(P)}(g / x) f_{X}(x) d x
$$

Given that $\mathrm{x}$ is in $[0,1]$, for $\mathrm{g}$ greater than one:

$$
h(g)=\int_{0}^{1} \frac{1}{x} f_{G(P)}(g / x) f_{X}(x) d x \propto g^{-\frac{\alpha^{\prime}+T-1}{T}} \int_{0}^{1} x^{\frac{\alpha^{\prime}-1}{T}} f_{X}(x) d x
$$

and if $\mathrm{g}$ is in $[0,1]$ :

$$
h(g)=\int_{0}^{1} \frac{1}{x} f_{G(P)}(g / x) f_{X}(x) d x \propto g^{-\frac{\alpha^{\prime}+T-1}{T}} \int_{0}^{g} x^{\frac{\alpha^{\prime}-1}{T}} f_{X}(x) d x+g^{-\frac{\alpha^{\prime \prime}+T-1}{T}} \int_{g}^{1} x^{\frac{\alpha^{\prime \prime}-1}{T}} f_{X}(x) d x
$$

For g greater than one, the distribution of $g$ follows a power law with a coefficient (minus exponent):

$$
\frac{\alpha^{\prime}+T-1}{T}
$$

which decreases with T provided $\alpha^{\prime}>1$. This pattern of decline in the exponent with time horizon is consistent with what we observed in the data in the previous section. For the exponent found for the long horizon (50 years), the distribution is capable of producing black swans (see Newman et al. 2005). The coefficient declines with T (converging to one) which is the lower bound to have a defined mean. With an increasing horizon, the dispersion increases 
and the probability of observing "miracles" increases. Focusing on short term growth is not helpful in detecting policies that lead to the miracle growth outcome.

\section{Technology and Innovation Policy As "True Industrial Policy"}

\section{A. It is All About Productivity Gains: Innovation and Export Sophistication}

A theoretical explanation for the lack of sustained growth, especially in the "middle-income trap," relates to productivity slowdowns as gains from low-cost labor and foreign technology imitation diminish in moving through the stages of development. As a low-income country becomes a middle-income country, it needs to find new sources of growth as benefits of lowcost labor and productivity gains from sectoral reallocation from agriculture to manufacturing and easy foreign technology adoption fade away. Wages rise, and competitiveness is eroded. Moving away from labor-intensive manufacturing to sustain increases in productivity and per capita income requires innovation - the use of new ideas, methods, processes, and technologies in production - rather than imitation (Romer 1990, Aghion and Howitt 1992).

Innovation-driven growth is key to sustaining productivity gains and achieving high-income status. Acemoglu, Aghion, and Zilibotti (2006) argue that if countries do not switch from an investment-based strategy to an innovation-based strategy when approaching the frontier, they may get stuck in a "non-convergence trap" without reaching the world technology frontier. Similar to Gerschenkron (1962), the authors suggest that government intervention to increase investment and adopt existing technologies is desirable at the early stage of development to increase growth, but ironically, this policy may be costly in the long run and result in a "nonconvergence trap." To move to an innovation-based strategy, competition policy and checks and balances on political interests are needed to ensure convergence to the frontier.

To sustain growth, a country needs to constantly introduce new goods and adopt and develop new technologies. Constantly introducing new goods rather than learning only on a fixed set of goods is what is needed to generate productivity gains for a sustained growth miracle (Lucas 1993). Learning-by-doing or learning-on-the-job is one of the most important channels of accumulating knowledge and human capital in this process. Producing the same set of goods or doing the same set of tasks would rapidly lead to stagnation in productivity. In contrast, introducing new goods and tasks would allow managers and workers to continually learn and move up the "quality ladder" (Aghion and Howitt 1992).

To introduce new goods and tasks, the country must be a large exporter (Lucas 1993), and empirically, export sophistication is one of the major determinants of growth. Hausmann, Hwang, and Rodrik (2007) and Cherif, Hasanov, and Wang (2018) in cross-country panel growth regressions show that export sophistication is an important explanatory variable while accounting for initial conditions, institutions, education, financial development, and trade openness. Eichengreen, Park, and Shin (2013) show that countries with a high share of population with secondary and tertiary education as well as a large share of high-technology exports are less likely to experience growth slowdowns. The authors emphasize the importance of moving up the "quality ladder" to sustain growth. Bulman, Eden, and Nguyen 
(2012) suggest that escapees from the middle-income trap experienced rapid structural transformation from agriculture to industry, higher human capital and innovation, and greater export orientation while preserving macroeconomic stability with inflation of less than 10 percent and experiencing small increases in inequality. Berg, Ostry and Zettelmeyer (2012), using an unknown-structural-break methodology to identify growth spells (periods of high growth), also find that growth duration is correlated with export orientation - a manufacturing focus, openness to FDI, and avoidance of exchange rate overvaluation - in addition to macroeconomic stability, democratic institutions, and lower inequality.

Examining empirically growth acceleration episodes, Hausmann, Pritchett and Rodrik (2005) find that most accelerations (with growth sustained for at least 8 years) are highly unpredictable and are not preceded or accompanied by improvements in standard determinants of growth and economic reform. Most instances of economic reform do not produce growth accelerations although positive political changes and economic reform are statistically significant predictors of sustained accelerations, that is, those persisting beyond the 8-year horizon. Positive terms of trade shocks and financial liberalization tend to be related to accelerations that are not sustained. The authors find that growth accelerations episodes are not a rare occurrence (with an unconditional probability of 25 percent in a decade) and that accelerations tend to be correlated with increases in investment and trade and real exchange rate depreciations. Despite finding that positive economic and political changes have some predictive power in identifying growth accelerations, the authors conclude that most growth accelerations are caused by idiosyncratic changes.

\section{B. TIP: The Moonshot Approach to Development}

We argue that TIP had helped the Asian miracles achieve sustained growth, thanks to its effect on export sophistication and innovation. Based on their experiences, we attempt to uncover what constitutes TIP. In defining a policy, it is best to start by defining its main goal. There is a striking pattern among the Asian miracles as well as Germany and Japan before them. At the onset of the acceleration of their growth, the governments set for themselves an extremely ambitious goal - to catch-up swiftly with the advanced world technologically and economically. In their eyes, development was not an abstract concept vaguely referring to the improvement in the standards of living. It was about joining the select club of industrialized nations, or the First World in the words of Lee Kuan Yew, the founder of Singapore. To do so, they had the models of Germany and Japan to follow.

The leaders of the Asian miracles stated explicitly this ambition on many occasions. In an emblematic episode in 1964, General Park Chung Hee, who became president of South Korea a year before, gave an emotional speech in Duisburg, West Germany. He addressed a group of 400 Korean miners who came to work as "Gastarbeiter":

"Looking at your tanned faces, my heart is broken. All of you are risking your lives every day as you go down thousands of meters underground to make ends meet... What poor people you are! You go through these trying times just because Korea is so impoverished...Although we are undergoing this trying time, we are not 
supposed to pass poverty onto our descendants. We must do our part to end poverty in Korea so that the next generation doesn't experience what we are going through now...About 150 years ago, the industrial revolution was in full swing in Germany, whereas Koreans had no idea of how the world outside was changing. Koreans stuck to their traditional way of life without knowing what was going on outside the country. We were like frogs in a well. How can a country like Korea, which was not fully prepared for the upcoming era, be as rich as Germany now?" 23

It is striking that General Park did not only aim at eradicating poverty within one generation (which Korea succeeded at) or becoming a "good" middle-income country but sought to discover how to make his country, one of the poorest in the world at the time, an equal to Germany.

One could cite many examples of speeches and political announcements to back the description above. However, the concrete decisions taken at the time by the state (or the private sector under the encouragement or coercion of the state) show clearly how Korea of the early 1970s was serious about these objectives. At the time, the country had no meaningful experience, skills (abroad or at home) or physical capital in industries such as steel, shipbuilding and automotive. Yet, it set up in each of these industries a large-scale production, leaving no doubt about the importance of exporting. Korea went from no experience in running an integrated steel mill to building one of the biggest mills in the world in Pohang; despite having no experience in modern shipbuilding, Hyundai (which was a construction company at the time) built the largest shipyard in the world (and simultaneously its first ship); and finally, the same company moved to the auto industry with no prior experience, and early on decided to build a factory the annual capacity of which would exceed the total annual sales of the whole country and set up its own networks of dealerships in the U.S., the largest and most competitive market in the world.

The ambitious policy goal to catch up was directly translated into precise objectives to develop select industries. This is the "leading hand of the state" at work (Cherif, Hasanov, and Kammer 2016) with its triple-A principles of ambition, accountability, and adaptability. The political leadership at the highest level decided that to catch-up it must compete with the richest nations on its own turf, i.e., export markets of manufacturing industries. To do so, the state played an active role, although the type and extent of the intervention depended on the circumstances.

\footnotetext{
${ }^{23}$ As recollected by one of the miners in attendance, Kwon Yi-chong, who became a professor of education at the Korea National University of Education. See http://www.koreatimes.co.kr/www/news/nation/2013/12/116_147609.html.
} 
The strategy of the Asian miracles' industrial policy/state intervention can be summed up as follows:

- Intervene to create new capabilities in sophisticated industries: Pursue policies to steer the factors of production into technologically sophisticated tradable industries beyond the current capabilities to swiftly catch up with the technological frontier.

- $\quad$ Export, export, export: A focus on export orientation as any new industrial product was expected to be exported right away with the use of market signals from the export market as a feedback for accountability. As conditions changed, both the state and the firms adapted fast.

- $\quad$ Cutthroat competition (at home and abroad) and strict accountability: No support was given unconditionally although performance assessment was not necessarily based on short term profits. While specific industries may get support, intense competition among domestic firms was highly encouraged in domestic and international markets.

\section{The Three Gears of TIP}

In creating lasting productivity gains, solving market failures is key. We classify the approach to fixing market failures into three types or gears - snail crawl, leapfrog, and moonshot. A snail crawl, or gradual, approach to solving market failures - or "evolution by creeps" (Ramalingam 2013, 219) — would not implement radical changes and would involve, for example, fixing skill imbalances, providing incentives to private firms to locate in certain areas, setting up export promotion agencies, etc. Many standard policies may fall under this category.

A leapfrog approach—or "evolution by jerks" (Ramalingam 2013, 220)—may go beyond standard intervention measures such as Malaysia's intervention to support rubber, palm oil (both natural comparative advantages) and electronic assembly industries (comparative advantage in terms of availability of cheap labor in the Heckscher-Ohlin sense). It may also step a little outside comparative advantage sectors, which the state would attempt to promote. Hausmann's (2015b) arguments on building on productive capabilities in existing industries to move to technologically similar industries is indicative of the gradual approach, while identifying new diversification opportunities, is closer to the leapfrogging approach.

A moonshot approach would pursue ambitious goals and radical changes. It would call for creating industries and providing all the necessary ingredients to help domestic firms grow and export way beyond existing comparative advantage sectors. It would require adopting a long-term view and the ability to take risks. The industries or sectors would be "wicked hard" to enter, as Pritchett (2017) called it, and much of the required skills and infrastructure might not even exist. This approach implies that the state would play a "leading hand" in development rather than leave the market to an invisible hand or a visible but slow-moving hand (Callen, Cherif, and Hasanov 2016). The moonshot approach relates to the "missionoriented" approach of Mazzucato (2013). She challenges the state to go beyond fixing market failures and to create and shape markets in addressing technological and societal challenges- 
from putting a man on the moon in the past to addressing climate change or tackling plastic pollution in the oceans today. Whether in developing or advanced economies, the state that pursues ambitious goals, has to pull the necessary resources to lift binding constraints to attain socially beneficial goals such as helping develop a new sector or pursuing cross-sectoral "missions." 24

These three approaches to solving market failures may explain how the Asian Tigers managed to reach the high-income status relatively fast while many other countries improved only marginally, if any. The three key parameters in identifying the gears of TIP are productivity growth, export sophistication, and innovation. For instance, despite converging toward highincome status, Chile has had stagnant productivity and export sophistication. Its approach can be described as a snail crawl. Many oil exporters would most likely fall into this category as well. Malaysia, instead, has witnessed positive productivity growth and improved export sophistication but limited innovation. Its approach could be described as leapfrogging. Lastly, high productivity growth, increasing export sophistication, and high innovation define the moonshot approach of the Asian miracles (Figure 5).

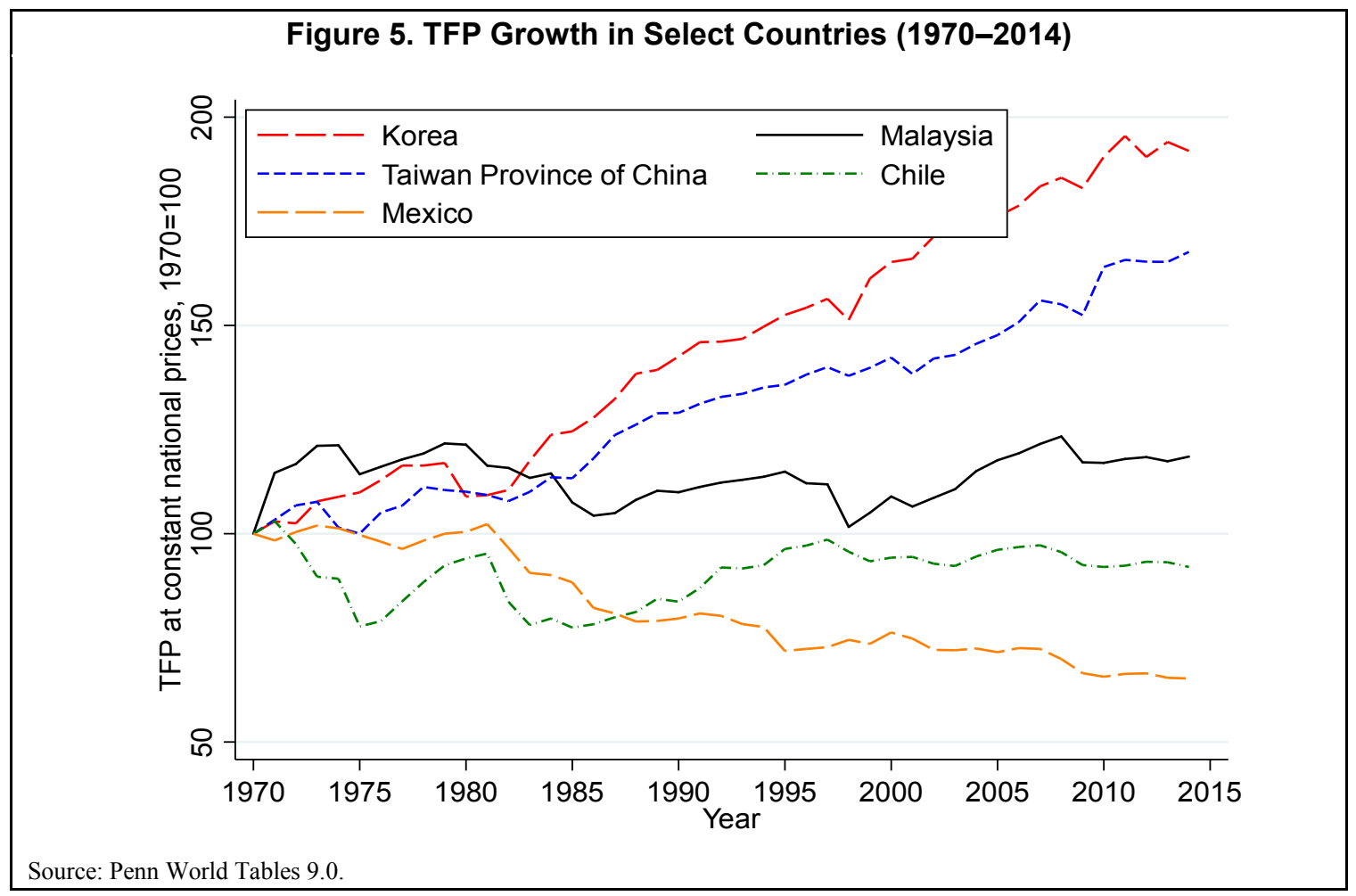

One could argue that the snail crawl and leapfrogging approach to keep sustained growth is a less risky strategy than the moonshot approach. Surely, Malaysia and Chile's growth

${ }^{24}$ Going beyond market failures to create and shape markets as Mazzucato argues is not necessarily inconsistent with fixing market failures. In general, market failures also relate to positive externalities such as learning-bydoing and spillovers or coordination failures related to firms not entering a market. The market would thus underprovide the optimum allocation or might not even exist. In this sense, fixing a market failure would imply creating new markets and new sectors. 
performance reaching the upper-middle-income status over several decades is better than slow or no convergence observed in many developing countries (see Johnson and Papageorgiou, forthcoming). But Malaysia and Chile, at their current trend of growth, are still many decades away from the levels of income in the Asian miracles although these countries started at relatively similar levels of development one-half century ago. In addition, the strategies implemented by Chile and Malaysia have not been risk-free, which relied on commodities and entailed a vulnerability to commodity price volatility. It is difficult to argue that tackling market failures to develop industries beyond existing comparative advantage sectors is much riskier than accepting the fatality that the price of a country's main export could collapse by say 30 percent in a matter of weeks. A passive management of commodity price volatility, through well managed sovereign wealth funds for example, would entail huge savings without necessarily achieving sustained growth, as shown by Cherif and Hasanov (2013).

To desire much higher welfare for a country's citizens by reaching high-income status in a relatively short period of time should be the ultimate goal of inclusive development. From the experience of the Asian miracles, the moonshot approach has been a key ingredient to their success. However, different countries can pick their gear depending on their circumstances such as political and social conditions. Moreover, these three approaches or gears are not necessarily mutually exclusive and could be applied simultaneously to various sectors, around existing industries or comparative advantage sectors and those beyond the comparative advantage sectors. What is important is that the other conditions of TIP, that is, export orientation and enforcement of competition, are ensured.

\section{THE ECONOMICS OF TIP}

\section{A. The Standard Growth Recipe is Not Enough}

Although theoretical and empirical growth literature has not yet found the "holy grail" of economic development, sustained productivity gains are key to catch-up high growth. Moving from an investment-based growth strategy to an innovation-led one, adopting and developing new technologies, introducing new products, promoting competition and reducing misallocation of resources, improving education and research capabilities, and increasing sophistication of production and exports are identified paths to spur productivity gains. All that is needed then is the design of relevant policies and their implementation. And yet as the history of the past one-half century shows that only a handful of countries have caught up with the advanced world. The typical explanation is that many developing countries have not followed through the growth policy advice prescribed. First, what is the right growth policy? Second, have countries failed implementing this policy? Or, has there been another big obstacle in preventing developing countries to catch up with the advanced world? We argue that there is a missing element in many growth policy discussions. This missing element is tackling "market failures."

The standard growth recipe mainly tackles "government failures" but does not alleviate much "market failures." Implementing structural reforms in product and labor markets, improving 
institutions and business environment, maintaining macroeconomic stability, investing in infrastructure and human capital, privatizing state assets, and reducing business regulations are the main ingredients of the standard growth policy prescriptions. These prescriptions tackle mostly what is described as "government failures" (Rodrik 2005). Such failures could arise from high inflation, excessive government spending, unprofitable state-owned enterprises, monopolies, investment impediments such as red tape and corruption, uncertainty about property rights, unwarranted rules and regulations on labor, and other types of government-driven distortions. The state should not intervene in the workings of the market and should fix these problems, leaving the rest to lassies-faire.

Although many developing countries have a room to improve their business environment and regulatory regimes, can the lack of progress in catching up with high-income countries be attributed to government failures alone? Tackling government failures, that is, the standard growth recipe, may not be enough to spur sustained growth.

We argue that the binding constraint to high sustained growth in many countries is market failures. ${ }^{25}$ Economies could be trapped in a suboptimal or low-productivity state not only as a result of distortions arising from government failures but also as a result of market failures due to learning externalities or coordination failures (Rodrik 2005).

The market failure based on a learning externality implies that firms do not internalize productivity gains, leading to a lower allocation of resources into high-productivity sectors. As argued by Matsuyama (1992), some activities, typically manufacturing, entail higher productivity gains for an economy compared to other traditional activities such as nontradable services or agriculture. Firms may not be fully aware of these productivity gains, which lead to lower output in high-productivity sectors and lower relative incomes over time. The learning externality could also involve spillover effects in which productivity in other sectors increase, while firms are unable to extract the pecuniary benefit from the spillover effect (e.g., manufacturing's spillover effect on agriculture). In this case, the resource allocation into the traditional sector would also be higher than the socially optimal level (Rodrik 2005). Moving from an investment-based strategy to an innovation-led one may not be straightforward even if all other distortions, due to heavy or no government intervention, are minimal.

The coordination failure is based on the idea that a critical size of the modern (e.g., manufacturing) sector is needed for a firm to enter it. It would be profitable for a firm to invest in a modern sector only if there are enough firms investing simultaneously in other modern sectors. The mechanisms proposed to explain spillovers in the literature differ (e.g., demand spillovers) but could be summed up as related to reaching a critical market size to justify investment in complex technologies (e.g., automotive and aircraft). If many firms

\footnotetext{
${ }^{25}$ We acknowledge the importance of political economy factors in tackling market failures (e.g., Pritchett, Sen, and Werker 2018). This discussion is left for the follow-up paper (Cherif and Hasanov, forthcoming).
} 
invest together in modern sectors, described as the "big push," economy reaches a higher level of productivity and development (Rodrik 2005).

The example of Chiapas in Mexico shows how market failures result in a lagging economy. Despite a similar macroeconomic and institutional environment, income per capita of Mexico's regions has evolved quite differently (Hausmann 2015a). The major reasons are the lack of productive capabilities and dynamic export industries (Hausmann 2015b). In the case of Chiapas that has the lowest income per capita in Mexico, its growth rate was the lowest in the 2000s. This is a dismal performance, especially since the gap within Mexico in years of schooling, infrastructure, and access to credit improved and Mexico experienced relative macroeconomic and institutional stability in the 2000s. Chiapas mostly exports agricultural commodities. It is effectively stuck in the low-productivity trap. The modern production has not emerged due to coordination failures - a chicken-and-egg problem. Private investment is low and many complementary inputs for modern production are missing. It is highly likely the market and the private sector would not be able to create high sustained growth. To correct these market failures and promote the development of more complex industries, the state needs to intervene to act as a catalyst (Hausmann, Espinoza, and Santos 2015).

The oil-exporting Gulf Cooperation Council (GCC) countries such as the United Arab Emirates (UAE) do not have significant government failures, and yet largely lack the non-oil tradable sector. The GCC countries, especially the UAE, have achieved high scores in the measures of infrastructure quality and business environment. In comparison, oil exporters such as Indonesia and Mexico, which lagged in regulation and business indicators, have performed better in developing non-oil tradables and promoting export sophistication (Figures 6-7). This observation suggests that to develop the tradable sector, countries do not have to have institutions and business indicators at the level of advanced countries. Malaysia's bureaucratic quality index (from the International Country Risk Guide) did not change much in the 1980s-1990s as it was developing its more sophisticated tradable sector, and this indicator was similar to that of Saudi Arabia (Cherif and Hasanov 2016).

The argument that market failures preclude the development of the non-oil tradable sector in the GCC oil exporters is further illustrated by the business activities of large conglomerates. These activities are mostly in the nontradable sector such as construction and services including finance and tourism (most of the activities in these service sectors are nontradable). The conglomerates have access to land, financing, government bureaucracy, and world markets, and the ability to import skills if needed. Most forms of government failures and some forms of market failures such as coordination failures should not have significant impact on the operations of these firms. Yet most conglomerates have not diversified into the non-oil tradable sector unlike their Korean counterparts, chaebols, or Japanese zaibatsus, a few decades ago. 
Figure 6. Doing Business and Competitiveness Indicators in Oil Exporters
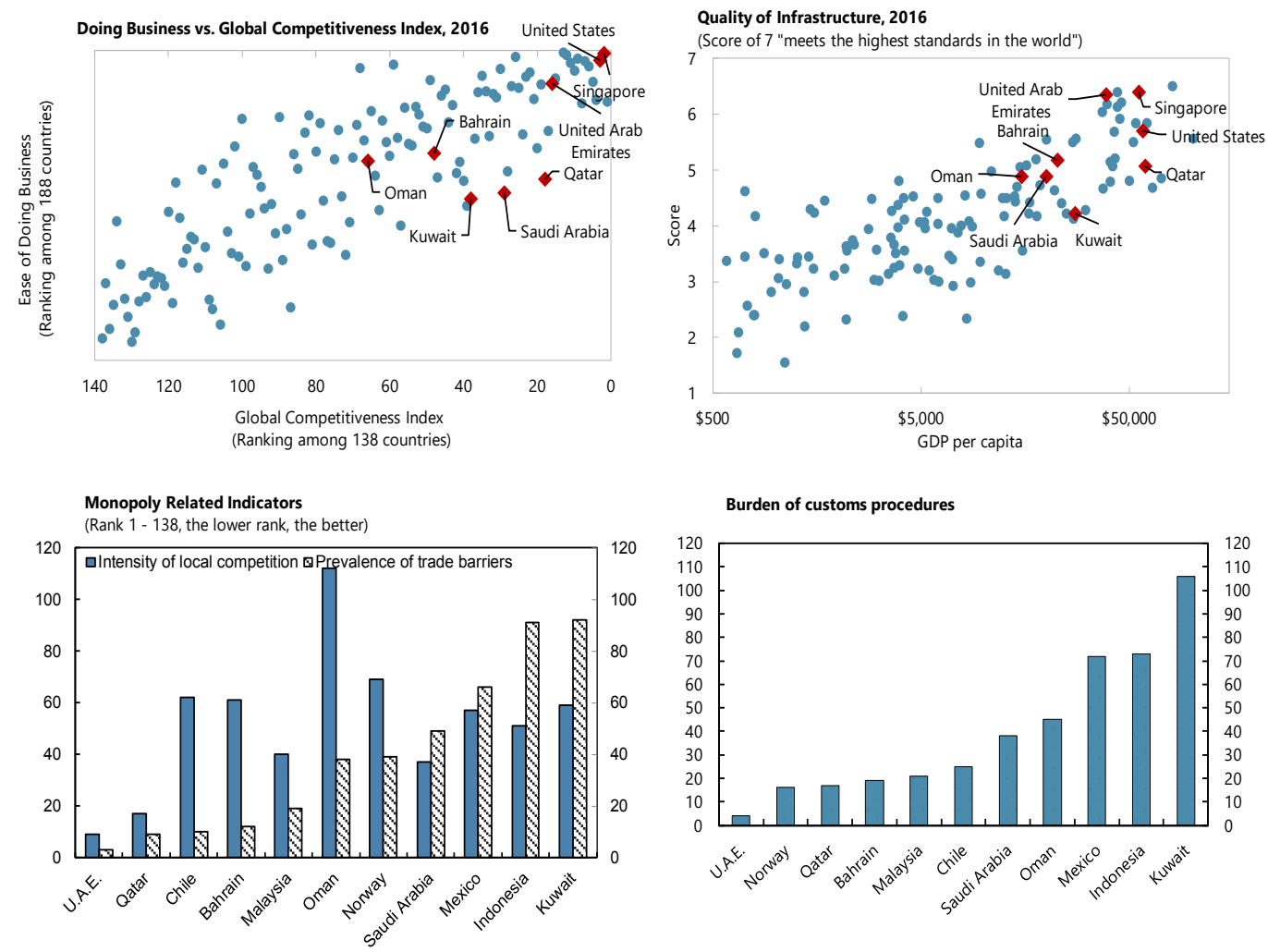

Source: World Economic Forum and World Bank's Doing Business Indicators.

\section{Figure 7. Goods Export Sophistication} (Adjusted for Commodity Exports)

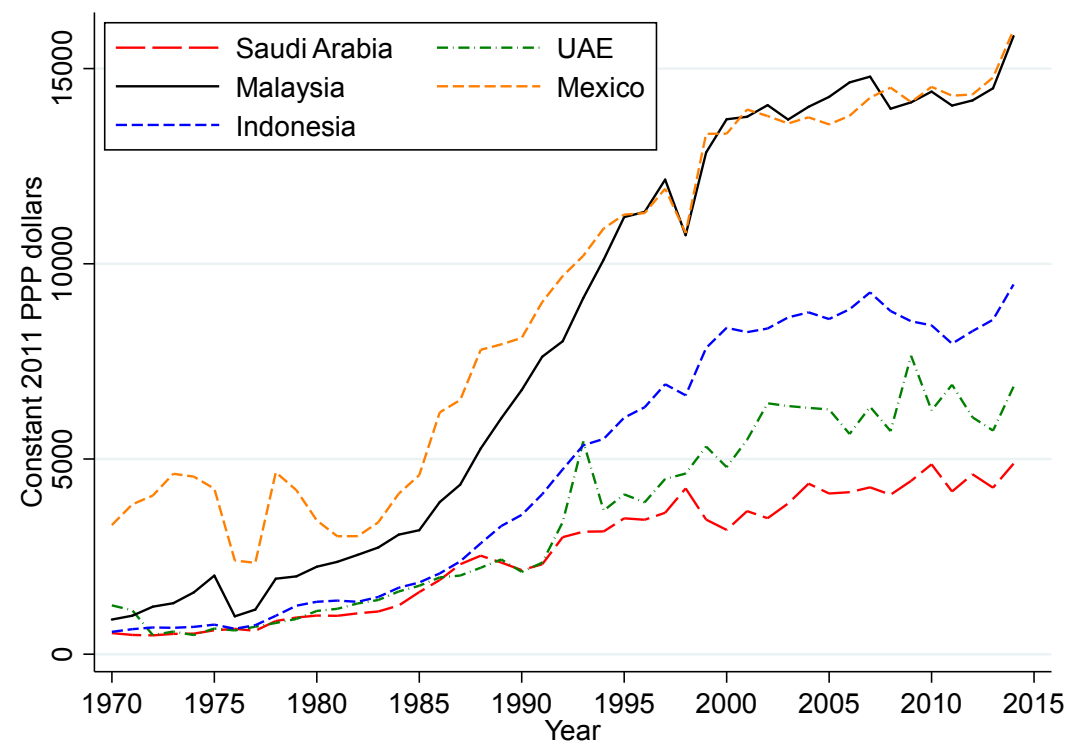

Source: Cherif, Hasanov, and Wang (2018); based on Hausmann; Hwang and Rodrik (2007); and World Trade Flows (Feenstra and Romalis 2014). 
Even in advanced oil-exporting countries such as Norway and Canada, market failures have slowed down the growth of the non-oil tradable sector. These countries have fallen prey to Dutch disease - broadly defined as the crowding out of the tradable sector due to oil income flows - although to a lesser extent compared to less technologically advanced oil-exporting countries (Cherif 2013). Dutch disease would lead to a market failure if firms do not fully internalize the fact that the non-oil tradable sector offers higher potential for productivity gains. And with the shrinking or slow-growing non-oil tradable sector, the prospect for continuous productivity gains is shrinking as well. Norway and Canada do not suffer from government failures and yet, they have not been immune to Dutch disease and resulting market failures (Cherif and Hasanov 2016). For instance, in 2012, manufacturing hourly wages in Norway were the highest in the world and about double that of the U.S. or Japan, according to the U.S. Bureau of Labor Statistics. Unit labor costs increased by 50 percent in the 2000s, whereas they declined in Sweden and have not changed substantially in Germany. It is not surprising that the measure of export sophistication adjusted for commodity exports in Norway has not increased much since the late 1970s in contrast to that of its neighbor Denmark.

In developing an oil and gas suppliers' cluster in the 1970s, Norway has understood that the existence of market failures and the lack of government failures would not necessarily result in a rush of domestic firms to the fledgling oil and gas industry. The state policies were quite interventionist to create and grow the local cluster of firms. First, the government intervened directly in the procurements of oil operators. The Norwegian Petroleum Code imposed that operators communicate their lists of bidders to the government, which in turn had the authority to impose Norwegian firms and even to change which firm was awarded the bid (Leskinen et. al. 2012). Second, the licensing process required foreign operators to come up with plans to develop the competencies of local suppliers (Heum 2008). Third, starting in the late 1970s, the government imposed a minimum of 50 percent of R\&D needed to develop a field to take place in Norwegian entities (Leskinen et. al. 2012). Although the restrictions were lifted in 1994 when Norway signed trade agreements with the EU, the government continued to support the suppliers though the INTSOK foundation to encourage them to internationalize their activity. Eventually the suppliers' cluster became highly successful, including globally, spanning a large array of sophisticated industries such as subsea, geology, and seismic, developed the required skills, and employed directly about 114,000 workers in 2009 , or more than five times the employment of the operators in the oil and gas sector (Sasson and Blomgren 2011).

The success of several EU countries, based on FDI-led growth, could suggest that tackling government failures is sufficient. IMF (2016) shows that high TFP growth was sustained through FDI-technology transfers, mostly from more advanced EU countries, supported by improvement in business environment. However, it is unlikely that such circumstances would arise outside the EU. These policies and convergence outcomes, especially for larger economies, are akin to the leapfrogging of Malaysia and Thailand. 
The existence of market failures requires state intervention to correct them although many might argue that the state intervention would only make matters worse. Intervening to correct market failures would allow the economy to reach a socially superior outcome. At the same time, even if market failures exist, the benefits of state intervention could be outweighed by the costs of intervention, exacerbating government failures such as rent-seeking and corruption. In fact, the post-WWII doctrine of "ordoliberalism" calls for the minimum role of the government to enforce contracts and ensure competition while avoiding interfering with the workings of the economy (Eichengreen 2016). Even though the state intervention in certain cases could prove to be counterproductive, it does not imply the state should only fix government failures and should not interfere to correct market failures. Being paralyzed into inaction or by the fear of potential mismanagement cannot be the correct policy option. This trade-off suggests that the way the state intervenes in the economy is crucial as the examples above illustrate. And this intervention needs to be cognizant of exacerbating government failures, or "doing no harm."

\section{B. Building Sophisticated Products}

The key question in the industrial policy debate is what should be produced. In fact, the three approaches to fixing market failures shed light on what could be produced. The snail crawl approach suggests producing goods and services around the existing industries (e.g., tourism and agriculture) and moving up the quality ladder. The leapfrogging approach suggests venturing into other sectors that may be a bit beyond the existing capabilities of the economy, perhaps with the support of FDI. The moonshot approach calls for building "sophisticated products" by domestic firms.

We argue that to create sustained growth to catch up and keep up with the frontier, the economy has to produce "sophisticated products." We need to define what we mean by "sophisticated" and "products." Now "products" are not necessarily only goods but also could be services although we argue below that most services probably would not qualify since they are not sophisticated and nontradable. "Sophisticated" would essentially mean that the product or service is conducive to high productivity gains and spillovers to the tradable sector (not only the nontradable sector). In addition to forward linkages, the sector could have a high content of intermediate goods to create backward linkages in the production process. The spillovers and high linkages could result in agglomeration effects and clusters feeding back into productivity gains. Linkages and spillovers, productivity gains, and agglomeration and clusters should support high sustained employment, which is a key goal in the development process.

From innovation-led growth theory, sustained productivity gains can be generated by the introduction of new goods/sectors, development of new technologies, and quality upgrading (Aghion and Howitt 1992, Lucas 1993). The new goods and technologies would also increase the scope of the goods produced and further support productivity growth. Sophisticated sectors with linkages and spillovers are more likely to be conducive to new technologies and sustained productivity gains than other sectors. And these sectors tend to be the tradable 
sectors. Herrendorf and Valentinyi (2012) show that a large part of aggregate TFP differences across countries are driven by productivity differences in the tradable sector, especially in tradable investment goods such as machinery and equipment.

Less sophisticated sectors, in contrast, may not be as conducive to sustained productivity gains as sophisticated industries. For instance, developing a tourism industry by building the necessary infrastructure such as hotels, roads, restaurants, sightseeing places, etc. could produce some productivity gains and growth. It has spillovers mostly to the nontradable sector. Yet whether it could be sustained for a long time is less likely since tourism activities are not conducive to the introduction of new goods and development of new technologies. Eating in restaurants and walking down the city streets are not going to be any different tomorrow than it is today, and these activities entail mostly cooking, serving, and street performances. And even if there is any innovation in providing tourist services such as wearing augmented reality goggles in museums or on city streets, the activity of watching artifacts or adoring medieval or modern architecture is still much the same. Efficiency can be improved in cooking and serving, and as Baumol said, performers can play music faster, but it is unlikely tourists would demand these more "efficient" services.

Spillovers to the tradable sector are an important characteristic of sophisticated products. Many activities could have spillovers to the nontradable sector. In fact, tourism qualifies. However, it would not result in a lot of spillovers to the tradable sector. In contrast, for instance, the semiconductor sector would produce spillovers to downstream sectors such as computers, phones, and other electronics products. The backward linkages that exist in the automobile and aircraft industries with many input components, which are part of the tradable sector, are other examples of linkages in the tradable sector.

The literature on industry linkages and spillovers emphasizes their importance. Hirschman (1958) advocated forward and backward linkages as a strategy for development. Liu (2017), in a model of production networks and market imperfections, shows that it is optimal for the government to intervene in "upstream" sectors, which supply to many other sectors. In this production network economy, downstream sectors buy less-than-optimal amounts of inputs from their suppliers, and these distortions propagate in the network upstream through backward demand linkages. Liu (2017) provides examples of heavy chemical and industry (HCI) drive (steel, metals, machinery, petrochemicals, electronics, and shipbuilding) in South Korea in the 1970s and metal, chemical, and machinery-producing industries in China in the 2000s. These industries are upstream suppliers of intermediate goods to producers in other sectors. Lane (2017), in a comprehensive empirical analysis of the HCI drive in South Korea, shows that the targeted industries grew much more than non-targeted ones. The author finds strong positive spillovers from the supported industries to downstream industries, which increased the purchase of intermediate goods and invested more. Interestingly, the effects of industrial policy persisted even after the support to the targeted sectors was reduced or terminated. 
Bartelme and Gorodnichenko (2015) also document a robust and strong relationship between industry linkages and aggregate productivity. Interestingly, even in the U.S., the tradable sector, in particular, electronics and auto industries and professional services, contributed about one-half to the real value-added recovery after the 2008 crisis although it accounted for only a third of the total value added (Hlatshwayo and Spence 2014). In sum, spillovers and linkages in the tradable sector provide opportunities for agglomeration and clustering of firms, fostering knowledge accumulation, knowledge sharing, and innovation. These activities fuel productivity gains and sustained growth.

Sophisticated products do not necessarily mean high value-added goods and services. Krugman (1994a) argues that high value-added industries are not necessarily high-tech ones. In particular, he cites cigarettes and petroleum refining as high value added per worker industries in the U.S. Electronics and aircraft industries have about the average value added per worker. Essentially, Krugman argues that high value-added industries are mostly capitalintensive industries such as petroleum refining, steel, and autos, which have to charge higher markups over labor costs to earn a normal return on large investments. In addition, some service industries fall into the high value-added category. Some are capital intensive like transportation and others may generate some rents like finance and real estate. Using the latest Bureau of Economic Analysis (BEA) data, industries such as parts of finance (funds, trusts, and other financial vehicles), real estate, petroleum and coal products have the largest value added per worker in 2016 (Figure 8). High-tech industries such as computers and electronics have smaller value added per worker than that of mining or utilities and are similar to those for broadcasting and telecoms, water transportation, and movie production. With its strong bend toward heavy manufacturing such as oil and gas production and chemicals, and service industries such as finance, real estate, and broadcasting and telecom, high value-added industries are not necessarily the industries that countries might want to promote. The question arises as to which industries would be considered high-tech, high-productivity-gain, and high-spillover industries.

To measure sophisticated products, we propose a measure of "sophisticated" goods and services based on R\&D intensity and patents issued. Using the data from the National Science Foundation (NSF) and OECD on R\&D intensity (a share of R\&D spending in net sales or value added), we identify industries that have high R\&D intensity (Figure 9). These are computer/electronic/optical products, pharmaceuticals, transport equipment except for motor vehicles, information technology services, motor vehicles, electrical equipment, machinery and equipment, chemicals, and scientific/professional/technical services. Metals, furniture, and textiles in manufacturing and telecom, publishing, and finance/real estate in service industries have much lower R\&D intensity. A similar picture emerges when examining the U.S. data (Figure 10). Scientific R\&D services, pharmaceuticals, computer and electronic products, aerospace products, and IT services have relatively high R\&D intensity and a share of R\&D personnel in total industry employment. Interestingly, some industries that have highvalue added per worker end up on a lower end of R\&D intensity spectrum, e.g., metal production, telecoms, and finance/real estate. 
Figure 8. Value-Added per Worker in U.S. Industries (2016)

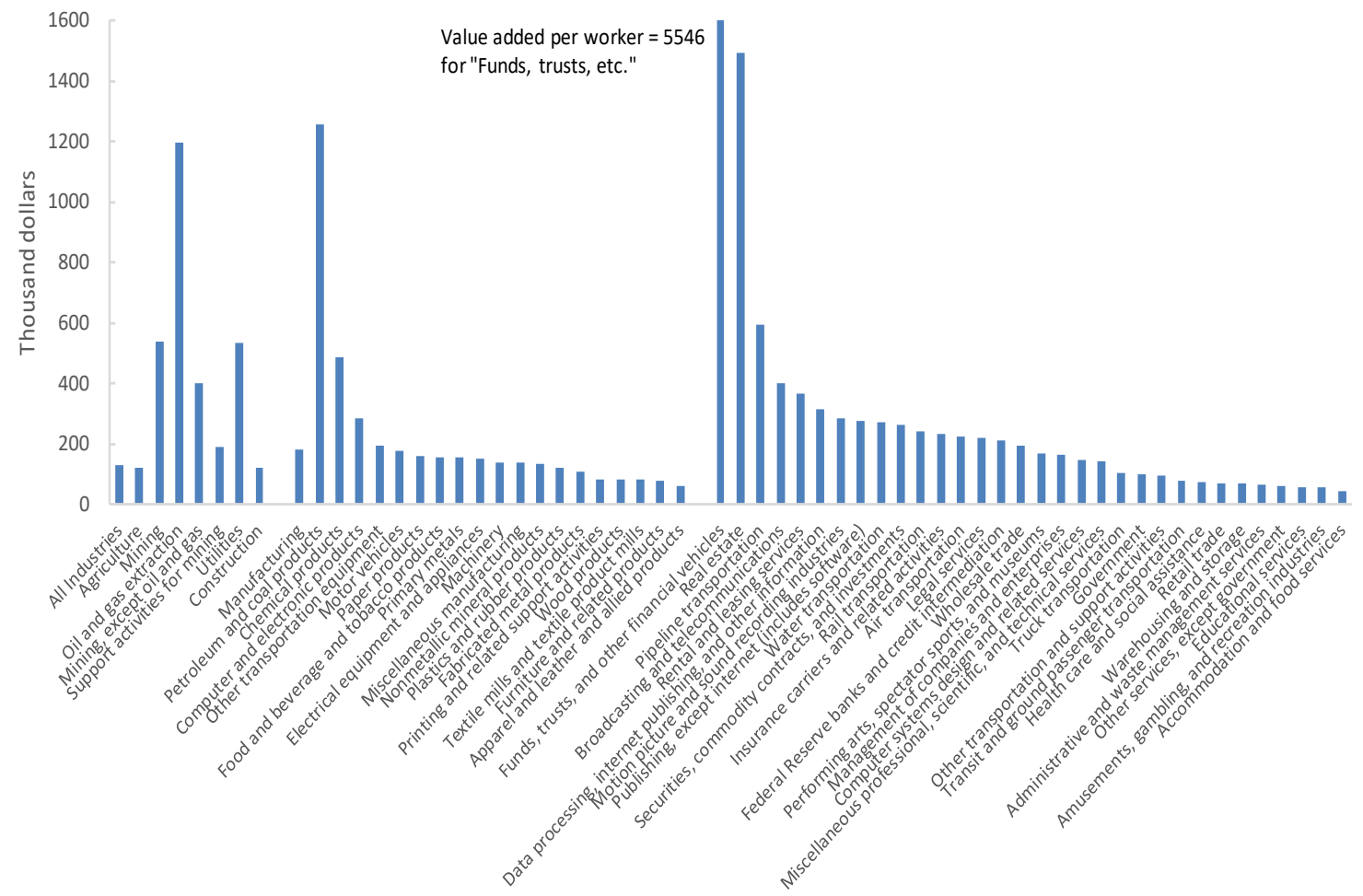

Source: BEA.

Figure 9. R\&D Intensity (Percent of GDP), OECD (2015)

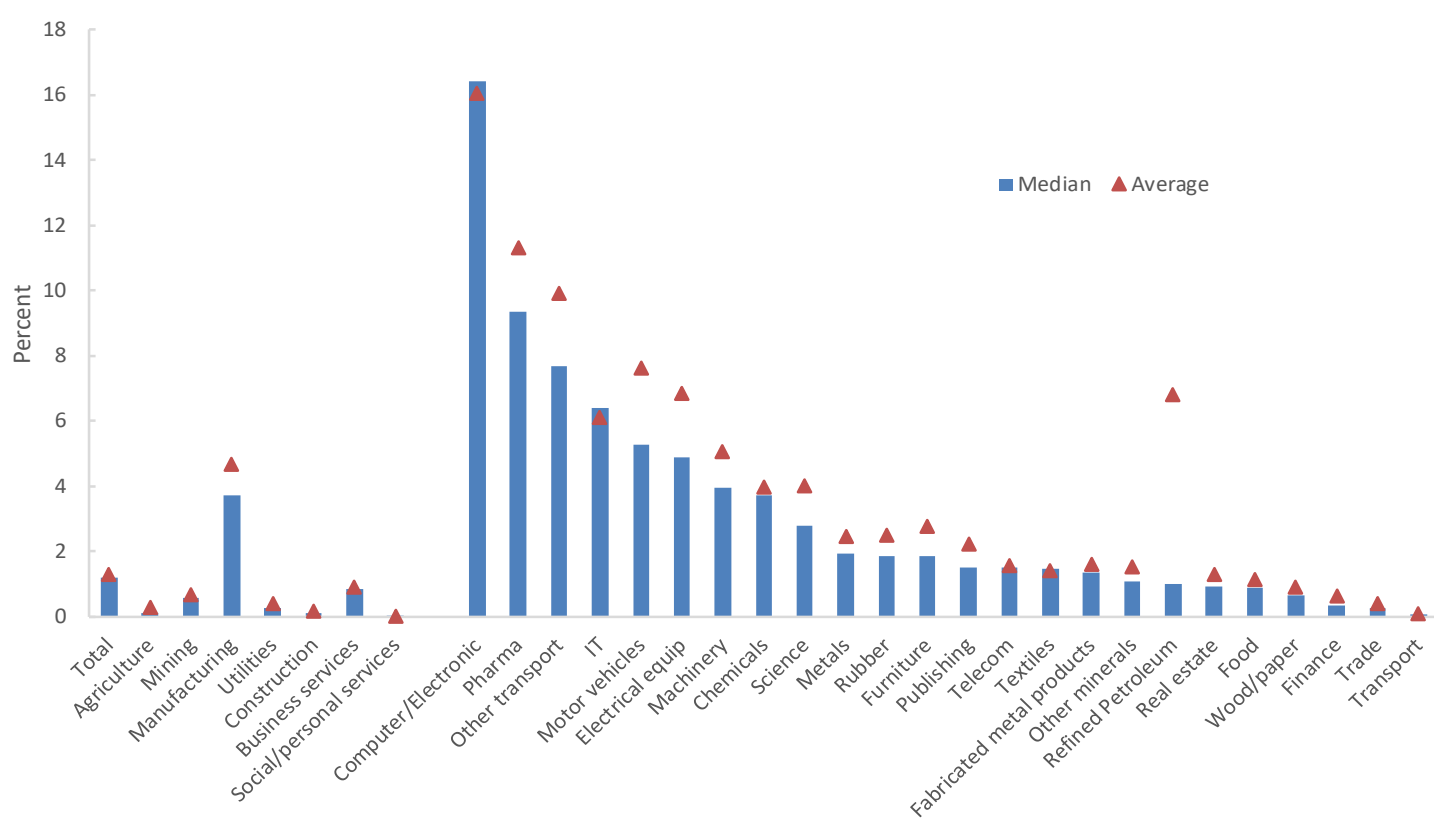

Source: OECD. 
The patents data corroborate the above measure of "sophisticated" goods and services. Of course, $R \& D$ and patents are correlated, and we find that in 2012 , out of about 84,000 patents issued in the U.S., about 57,500 were issued in manufacturing and 26,500 were issued in nonmanufacturing industries. In manufacturing industries, most patents were issued in computer and electronic products, chemicals (pharma), machinery, transportation equipment, and medical equipment (Figure 11). In nonmanufacturing industries, patents are basically produced by software and scientific/professional services (see Appendix Figure 5).

These measures suggest that "sophisticated" products are not only manufacturing goods but also certain services. Electronics, machinery, pharma, aerospace, motor vehicles are key manufacturing products with high $R \& D$ intensity and patent production. In services, these are software/IT and various scientific and technical services. Essentially, these industries comprise the high-tech sector.

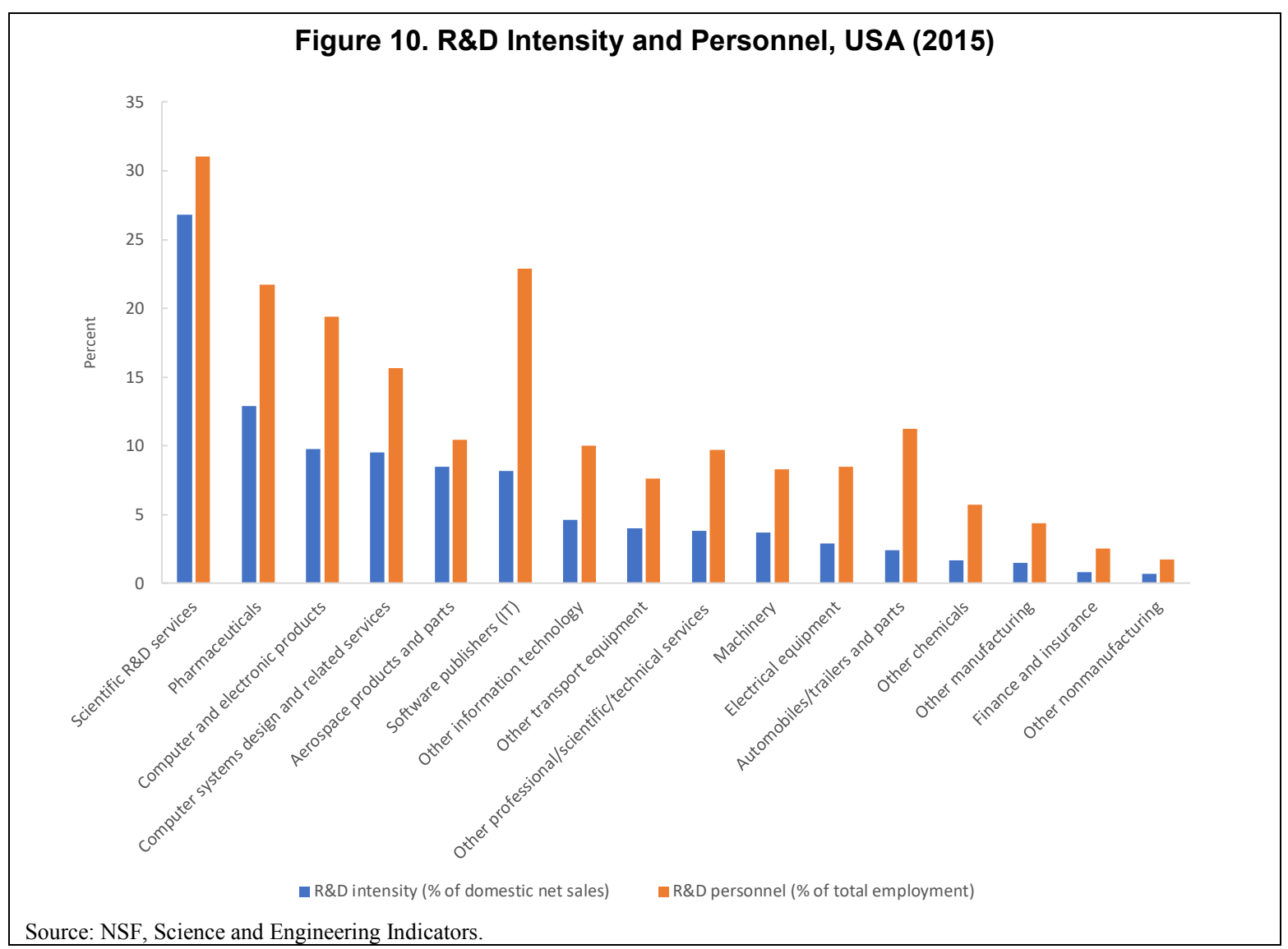




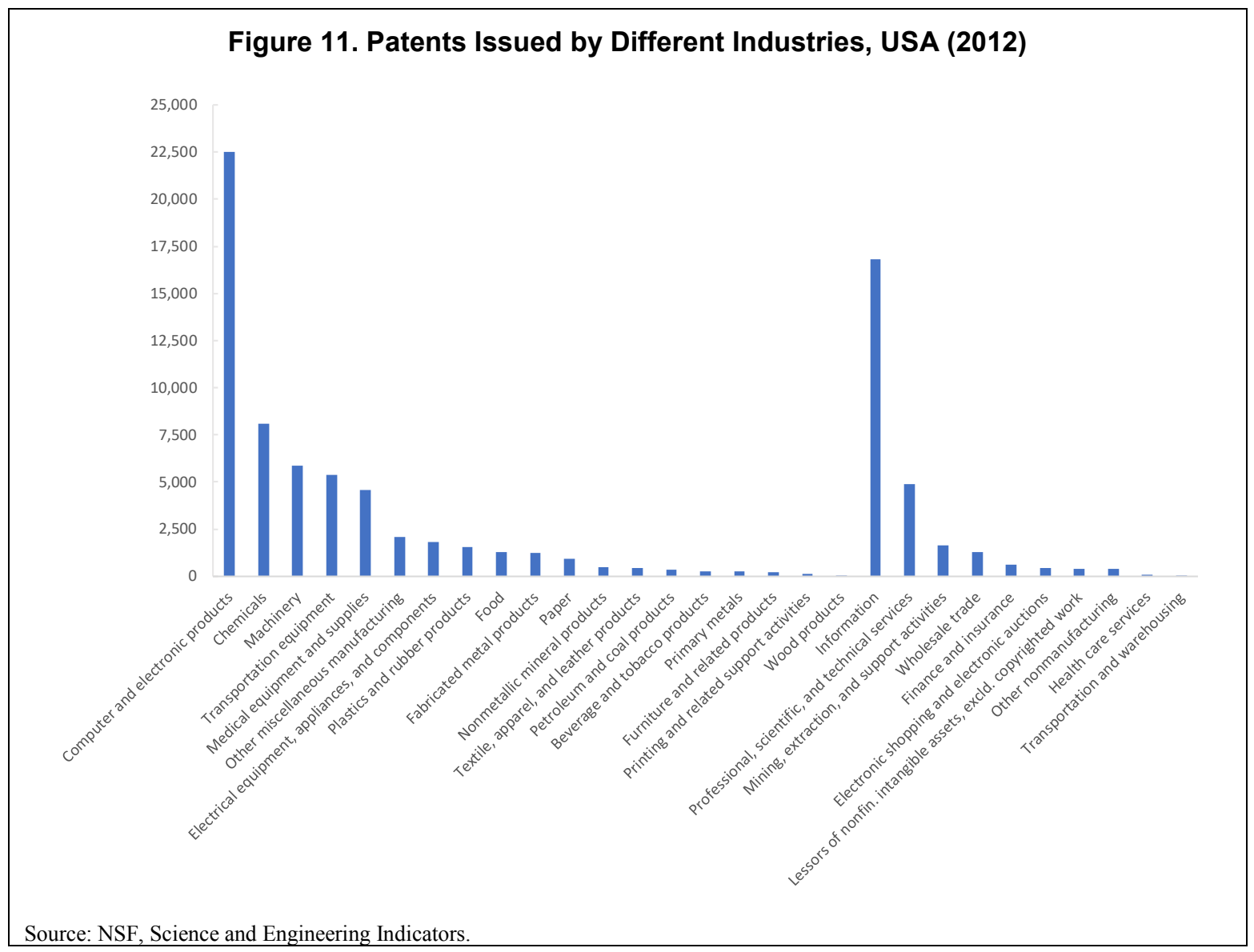

\section{Beyond Comparative Advantage: Vegetables, Sewing Machines, or Microcircuits?}

One of the key ingredients of the Asian miracles' policies was their push into technologically sophisticated sectors, which were sectors beyond their comparative advantage at the time. Many argue that this goes against one of the tenants of economic theory explaining why it is doomed to fail in general. ${ }^{26} \mathrm{~A}$ central assumption of the modern version of the theory (Heckscher-Ohlin-Samuelson) ignores the fact that to develop new industries, a country needs to accumulate industry specific capital and knowledge. In other words, it assumes that technology is freely available to every country. The only barrier for the poorest developing economies to produce, say aircrafts, robots, or satellites, is the capital-labor ratio. Moreover, relying on comparative advantage, and implicitly on Ricardian or Heckscher-OhlinSamuelson type of models, ignores the importance of experience in the technology acquisition process, or learning by doing, and the fact that capital accumulation in general does not necessarily imply developing new industries. In other words, it is based on theories ignoring externalities such as learning-by-doing or Marshallian externalities (increasing returns to scale) stemming from clustering.

\footnotetext{
${ }^{26}$ See Chang and Lin (2009) for an excellent debate summing up the key issues around comparative advantage and the role of the state in development.
} 
Even in a standard Ricardian comparative advantage framework, Krugman (1987) shows that in the presence of learning externalities (learning-by-doing), there is a justification for infant industry support policies. Young (1991) further shows that in a growth model with learning by doing, a country starting with a lower initial level of knowledge would grow less in free trade equilibrium than in equilibrium without trade. Essentially, producing goods in the sector in which learning by doing has been exhausted without attempting to produce goods with learning externalities, would lead to lower growth outcome.

Another potent critique of development strategies solely based on comparative advantage is that in most cases, developing countries that succeeded at technological leapfrogging held no initial obvious advantage and their later success came mostly as the result of a conscious decision to succeed in specific sectors (see Chang and Lin 2009). To paraphrase Ha-Joon Chang, Japan's relatively limited experience in the automotive industry, lack of natural resources like rubber to make tires or oil to run these cars, and even the limited surface to drive cars should have precluded the emergence of the car industry in the 1950s and 1960s. Korea's example is even starker as its main export in the 1960s consisted of rice, silk, wigs (made of human hair) and tungsten, and yet it embarked in developing shipbuilding, electronics and car industries. Korea's path would have been quite different if it followed the advice it was given at the time to focus on these sectors instead of following its "reckless" industrial policy in shipbuilding, for example (Woo 1991, p. 132).

To illustrate our argument, we study the dynamics of the Revealed Comparative Advantage (RCA), which is a standard measure of comparative advantage in the export sectors (see for example Balassa and Noland 1989), ${ }^{27}$ of Korea and Taiwan Province of China between 1970 and 1990. This period corresponds to a thoroughly documented and extensive state intervention to push strategic sectors such as electronics, along the lines of TIP (see Wade 1990, Chang 2002, Woo 1991, Amsden 1989, and Cherif and Hasanov 2015). In terms of exports, in 1970, these two economies were dominated by relatively unsophisticated industries. For example, food exports represented 27 percent and 22 percent of total exports in Taiwan Province of China and Korea respectively. ${ }^{28}$ The industries with the highest revealed comparative advantage index included vegetables (Taiwan Province of China), cork and wood products (Taiwan Province of China and Korea) and raw silk (Korea). It is difficult to imagine how far these economies would have gone by focusing on silk and vegetables instead of their moonshot to highly sophisticated sectors.

We illustrate further with a subtler approach of relying on RCAs. We assume that one would focus on the more sophisticated manufacturing industries that were nascent in these economies at the time and verify whether it could have helped us predict their evolution.

\footnotetext{
${ }^{27}$ The RCA is an index defined for a good $j$ in a country $i$ as $R C A_{i, j}=\sigma_{i, j} / \sigma_{w, j}$ where $\sigma_{i, j}$ is the share of export $\mathrm{j}$ in country i's total export and $\sigma_{w, j}$ is the share of world export of good $\mathrm{j}$ in total world export. If RCA is greater (smaller) than one, the country is considered to hold a comparative advantage (disadvantage) in that good.

${ }^{28}$ Adding up categories "0", "1" and " 2 " in SITC Revision 2 classification.
} 
In 1970, there were 13 industries that had an RCA greater than one in Taiwan Province of China in the industry category "machinery and transport equipment", representing 13 percent of total exports (see Appendix Tables). These industries were mostly in the subcategories of "machinery specialized for particular industries" (SITC "7"), in particular in "textile and leather machinery", typically sewing machines, and none in the subcategories that include electronics and other sophisticated machinery. This is not a surprise as the electronic industry did not even exist at the time in Taiwan Province of China and the direct intervention to create the industry was in its early stages (see Wade 1990 and Cherif and Hasanov 2015). In other words, this indicator "revealed" that relatively less sophisticated machinery and transport equipment were where this economy should have focused its energy, and electronics was not one of these sectors. Fast forward to 1990, there were 63 industries with RCAs greater than one, representing about 34 percent of total exports, mostly in the electronics and electric machinery industries based on the export shares (see Appendix Tables). More striking, the 13 initial comparative advantage industries in 1970, not only did not achieve RCAs greater than one by 1990 , but they all simply vanished as export industries.

The same exercise yields even more dramatic results for Korea. In 1970, only three export industries (SITC 4-digits) within the "machinery and transport equipment" category had an RCA greater than one (see Appendix). These industries resemble those found in Taiwan Province of China at the time, that is, textile and leather machinery and mechanical parts. In 1990, the top 10 exports of Korea were in much more sophisticated industries such as electronics and shipbuilding. As in the case of Taiwan Province of China, the industries that became the top exports did not even exist in 1970 as the state was just starting its effort to develop shipbuilding, automotive and electronics. Moreover, the industries that had an RCA greater than one in 1970, which were supposed to be the most promising, according to this measure, disappeared as export industries by 1990 .

The same pattern could be observed in Malaysia. Few relatively unsophisticated industries could be considered as within their comparative advantage (three in 1970 according to the same method applied for Korea and Taiwan Province of China). In 1990, microcircuits alone represented 10 percent of Malaysia's total exports which did not exist as export industries twenty years earlier. Although the microcircuit industry in Malaysia was dominated by multinational corporations, MNCs (as in 2017), their move to Malaysia was influenced by a strategic decision and consistent effort by the government to attract FDI in this specific sector way beyond their initial comparative advantage (see Cherif and Hasanov 2015). In contrast, Chile, which also had no sophisticated industry with a revealed comparative advantage in 1970, had still no industry within this category with an RCA greater than one by 1990, while its structure of exports remained relatively stable relying on products such as copper, natural sodium nitrate and pulpwood. More important, exports of machinery and transport equipment remained marginal hovering around 1 percent of total exports over these two decades.

In the description of Chang and Lin (2009), the question is not whether comparative advantage should be defied or not, but how far from comparative advantage the state should push. Given the chosen sectors, some would argue that the state should only play the role of a 
facilitator while others see the state as playing an active role in initiating the development of certain industries.

Based on the experience of the Asian miracles, we argue that a comprehensive strategy should take simultaneously different approaches in different sectors, fully benefitting from current comparative advantage while at the same time building the expertise for tomorrow's industries. Let us assume that a certain developing economy has $n$ sectors where its factors' endowment or its experience represents a clear comparative advantage (e.g., fertile land for agriculture, cheap labor for low-skilled manufacturing such as textiles, beautiful beaches for tourism, or natural resources). For a typical developing economy, these are sectors of low sophistication and limited spillovers. If these comparative advantages are real and not imaginary, ${ }^{29}$ these industries should not require any significant sectoral state intervention and would flourish provided major government failures are tackled and public goods are provided, which would be summarized as horizontal policies ${ }^{30}$ (e.g., transportation for agricultural products, electricity for textile factories, and safety for tourists). In this case the state should act as a facilitator and results should materialize relatively quickly in the form of export revenue and employment. In such sectors the state should avoid an active risk-taking role such as subsidies, state owned enterprises or directed/guaranteed credit. There are two rationales for this approach. If these sectors are truly comparative advantage sectors, then an active role of the state would only discourage competition and create opportunities for cronyism and inefficiencies. Moreover, the opportunity cost of state intervention in low-skill, low-spillover and low productivity gain sectors (such as tourism), as opposed to intervention in high-skill, high-spillover and high productivity gain sectors (such as electronics), is large.

In parallel, we assume there are $n$ ' sectors for which the standard analysis would not reveal a comparative advantage. Notable examples of such sectors in the 1960s and 1970s would be the automotive industry in Korea, the semiconductor industry in Taiwan Province of China, and the aircraft industry in Brazil (EMBRAER), all of which turned out to be major commercial successes, large employers and represent a significant share of the exports of these economies. These sectors could also include backward linkages with existing sectors such as those in oil rich countries. As discussed earlier, Norway used very aggressive policies to spur the growth of its oil service industry in the 1970s and until the mid-1990s, the result of which was the emergence of a high-tech and successful oil service cluster that had not existed before (see Cherif and Hasanov 2015). These policies included the interference in tenders by oil companies to the benefit of local firms and laws requiring oil companies to perform onehalf of their R\&D in Norway. The common features among the policies pursued to develop these sectors in these countries included an appetite for risk-taking, emphasizing technological development, and encouraging competition in domestic and international markets. More important, these policies were pursued over decades.

\footnotetext{
${ }^{29}$ Another issue is the regional crowding-out, where neighbors invest heavily in the same sectors, typically tourism, logistics and finance.

${ }^{30}$ See Aghion (2016).
} 


\section{Not Manufacturing vs. Services, Rather Sophisticated Manufacturing and Services}

Rodrik (2016) shows that many developing countries have been undergoing premature deindustrialization. In most developing countries, with an exception of some Asian countries, manufacturing shares in employment and output have been falling since the 1980s. More important, manufacturing started shrinking at much lower levels of income than what advanced countries and early industrializers experienced in the past. Rodrik argues that many developing countries have been turning into service economies without going through a full industrialization process.

Premature deindustrialization could be a daunting challenge if manufacturing is key to sustained growth. Rodrik (2016) argues that since high sustained growth in early industrializers has been driven by manufacturing - a technologically dynamic sectordeveloping countries today could miss out on this opportunity to industrialize and sustain growth. Manufacturing industries have experienced high productivity growth for decades and exhibit unconditional convergence (Rodrik 2013). In addition, other features of manufacturing such as spillovers and learning by doing, tradability, and innovation suggest that manufacturing is important for sustained growth. Indeed, Korea's manufacturing economywide productivity (manufacturing real value added per capita) has increased 45 -fold for the past 45 years while that of Chile or Mexico barely doubled. Indonesia and Malaysia have done better than Chile or Mexico, but not as well as Korea (Figure 12).

Figure 12. Manufacturing Economy-wide Productivity Growth in Select Countries (1970-2014)

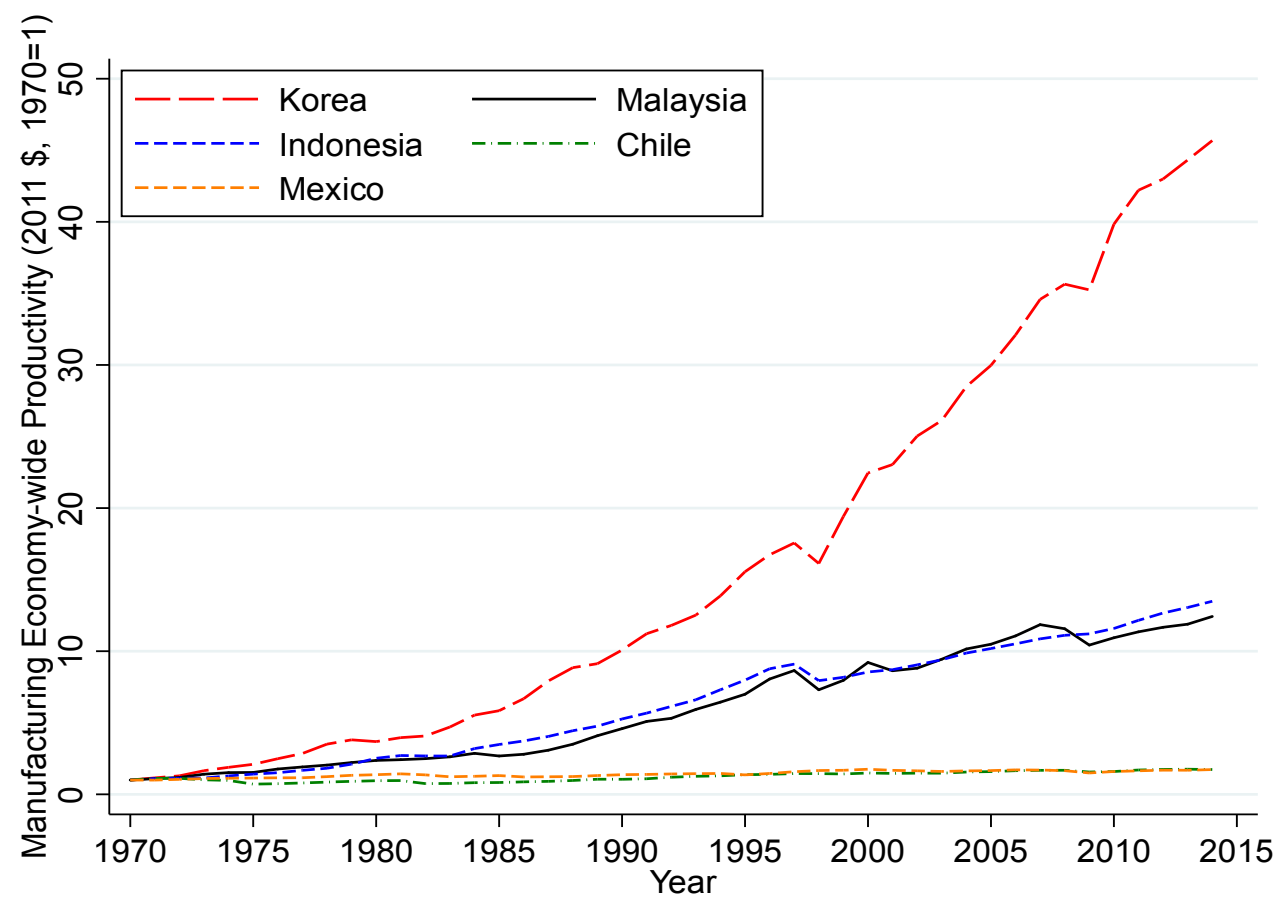

Source: WDI.

With the decline of manufacturing in developing countries, the debate ensued whether countries should still pursue manufacturing or leapfrog toward services. Ghani and Kharas 
(2010), Ghani, Goswami, and Kharas (2011), Ghani and O'Connell (2014) argue that "modern" services could be a catalyst for growth in developing countries as these services exhibit increasing sophistication and tradability. Hallward-Driemeier and Nayyar (2017) also suggest that key characteristics of manufacturing such as tradability, scale, innovation, and learning-by-doing are becoming features of services too. IMF (2018) proposes that perhaps services could replace manufacturing as an engine of growth going forward as the shift from manufacturing to services does not have to lead to lower productivity growth.

Although a focus on services may stem from the idea that a large part of the output structure is usually services, in many instances, the export structure would paint a different picture. Singapore and Bahrain illustrate this point (Figures 13-14). Bahrain has a higher share of mining and a little lower share of services than Singapore does, but overall the output structure of the two countries is relatively comparable. Services make up a big part of both countries' output. In contrast, goods exports in Bahrain are mostly concentrated in oil and metals (about 90 percent of goods exports, excluding re-exports), which is vastly different from the diversified export base of Singapore, which has about 40 percent of goods exports (excluding re-exports) in machinery and other industrial products (Figure 14). Interestingly, services account for about one-half of each country's total exports. Bahrain mostly exports services in insurance and travel industries, and although travel exports in Singapore are not small, the bulk of Singapore's service exports are in transport, business services, and finance. Exports are a good proxy of tradable production, and even for small open economies like Bahrain and Singapore, tradable services do not capture a large share of total exports. Since Singapore has maintained high growth rate for decades (with services accounting for a much smaller export share in the past), the types of tradable goods and service sectors existing in the economy are important.

The discussion about the rise of services is mostly centered on "modern" services. IMF (2018) indicates that two types of services - transport and communications and financial intermediation and business services - tend to exhibit labor productivity growth similar to or higher than manufacturing. The IMF study also finds that these types of services show patterns of unconditional convergence to the frontier. These industries include land, water, and air transport, post and telecommunications, financial intermediation, insurance and pensions, real estate, and business services such as rentals of machinery and equipment, software and data processing, $\mathrm{R} \& \mathrm{D}$, and professional services.

However, it is not a clear-cut case that these "modern" services would be sufficient for sustained growth and employment generation. Most of the services included in transport and communications and financial intermediation and business services are not going to be considered "sophisticated" according to our measure of sophistication. Only scientific, R\&D and professional services would fall into this category. Other service categories such as financial intermediation may require high skills and pay high wages but may not support employment on a large scale. Bahrain's finance sector, about 17 percent of GDP, directly employed less than 10 percent of Bahraini nationals in 2012, similar to London's share of the finance and insurance sector (Cherif and Hasanov 2016). Moreover, it is not clear what higher 
value added implies in many of these industries such as post and telecommunications, financial intermediation, and transport - whether these are higher rents and profits or "true" contribution to production.

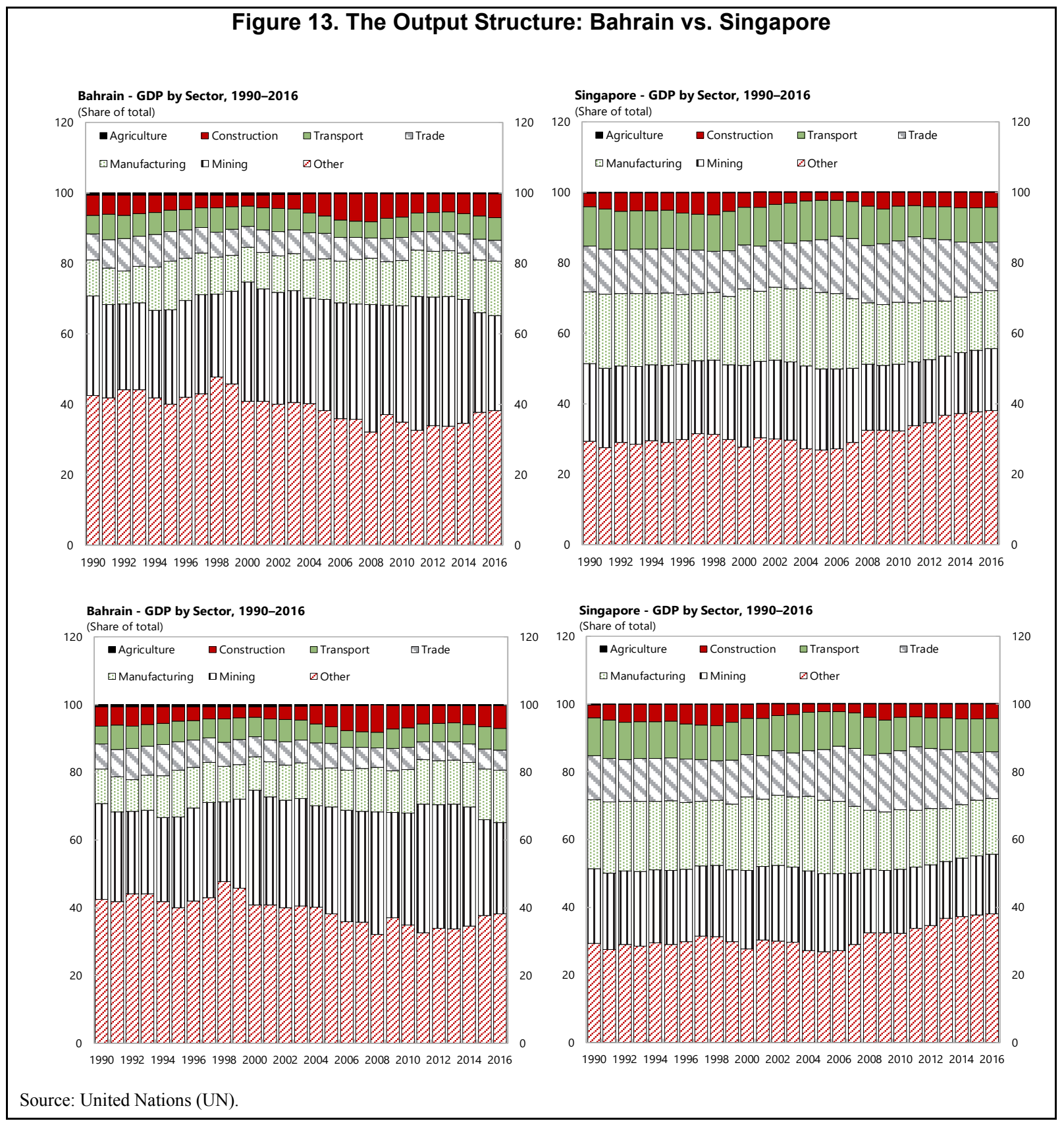




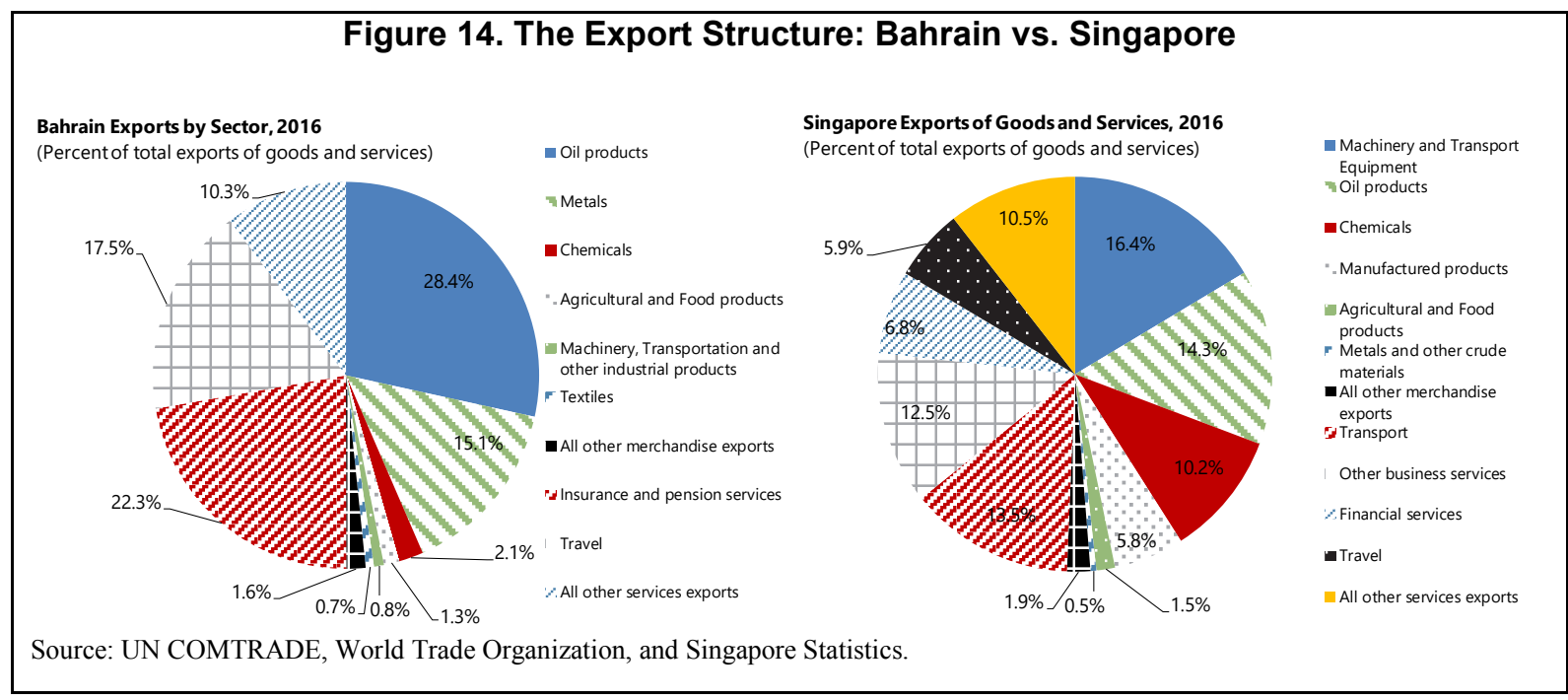

These service categories may not be that easy to scale up and trade on a large level, and for large countries that manage this, it is not going to be a long-term growth strategy. India and Philippines are some examples of countries that managed to achieve scalability and tradability in telecommunications and information technology services. In fact, Philippines overtook India in call centers, which employ more than a million people, account for about 8 percent of GDP, and bring in huge export earnings (The Economist 2016). These types of industries could constitute "quick wins" or a snail crawl approach although it is not sufficient as a longterm growth strategy. And for large countries such as India that focus on services-led exports, the counterexample is China with its focus on manufacturing that has had higher sustained growth and employment generation than India.

Other services such as tourism are also "quick wins" but do not qualify as key to long-term growth. These industries may generate some export earnings, growth and employment. But as shown in Arezki, Cherif, and Piotrowski (2009), specialization in tourism yields limited growth benefits. An increase in the tourism sector share of exports by 8 percent (one standard deviation in a sample of more than 80 countries over 1980-1990) increases growth by only one-half percentage points a year. To generate growth, a country has to attract more tourists every year (as real spending per tourist is mostly constant), putting an exponentially higher strain on public services such as security, utilities, and waste management. In addition, tourism comprises low productivity activities such as trade and hotel/restaurants. Even in small open economies with a focus on service exports, the generated export earnings are not sufficient to cover enough of goods imports. The case of Bahrain with its large financial sector and tourism illustrates that the country's positive net service balance only covered about a third of goods imports in 2011 (Cherif and Hasanov 2016).

Business services - which are sophisticated services - could support productivity growth and employment, and in fact, may be related to manufacturing industries. This spurred the debate on "servicification" of manufacturing. IMF (2018) shows that value-added of services in manufacturing gross output increased by about 6 percentage points between 1995 and 2011, accounting for about one-third of gross manufacturing output in a median country in 2011 . 
Although services account for a larger share of manufacturing output now than before, it is not a significant share yet (although for some countries it is larger than 50 percent).

Alternatively, knowledge-intensive business services seem to have sprung up in disappearing manufacturing clusters (Cermeño 2018a, 2018b). The share of knowledge-intensive business services in gross value added of GDP in constant dollars since the 1950s in the U.S. increased from under 20 percent to over 35 percent, while the share of manufacturing and other services stayed roughly the same. Cermeño (2018a, 2018b) shows that knowledge-intensive business services tend to be concentrated in densely populated areas although they could be done remotely. She argues that large local markets largely explain the localization of these services. Essentially, there are increasing returns to scale in this sector with spillover effects, economies of scale and proximity to skills, competitors and providers. And these knowledge hubs were originally related to the proximity to manufacturing clusters (Marshall 1880, Hall 1902).

Hong Kong's experience illustrates the fine line in the measurement of manufacturing and services. Manufacturing played an important role in Hong Kong's development. Employment in manufacturing peaked in the early 1980s with about 1 million workers out of 5 million total population (Trade and Industry Department 2018). Subsequently, manufacturing production relocated outside of Hong Kong as labor costs were much lower in mainland China. For example, in 2008, Hong Kong enterprises employed about 10 million workers in the Pearl river delta region while Hong Kong's total population stood at about 7 million (Trade and Industry Department 2018). Although most of the manufacturing activities of these enterprises are not carried out in Hong Kong, the value they generate are classified under the services sector instead, blurring the true contribution of manufacturing to Hong Kong's economy.

Our discussion on manufacturing as an important driver of sustained growth has come a full circle. Berger (2011), a co-chair of MIT's Production in Innovation Research Commission argues that the next wave of technological innovations is tied to production processes and in which R\&D is harder to separate than in IT and electronics industries of the past. In fact, Berger contends that innovation in manufacturing in some of these emerging industries like solar is key. Andrew Liveris, the executive chairman of DowDuPont, echoes the same point that manufacturing, in particular advanced manufacturing, is essential to the knowledge economy (Knowledge@Wharton 2017). According to Liveris, manufacturing is crucial for innovation: "If you have the shop floor, if you make things, you have the prototype for the next thing, so you can innovate." (Knowledge@Wharton 2017). Based on Cohen and DeLong (2016) that studied Alexander Hamilton's (one of the early architects of industrial policy) approach to catapult the U.S. to the technological frontier, DeLong has emphasized that manufacturing creates engineering communities of technological competence that help spread knowledge, generate spillovers, and sustain productivity growth. And sophisticated products are more likely to be in manufacturing than service industries.

A recent work by Diao, McMillan, and Rodrik (2017) examining growth episodes in developing countries in the past couple of decades suggests that none of these episodes has been driven by rapid industrialization observed in East Asian countries. In particular, in Africa, structural change from low to high productivity activities have been mostly driven by 
increased demand for goods and services in modern sectors rather than productivity improvements in those sectors. Manufacturing in Africa has also performed quite poorly. In contrast, in Latin America, which has experienced some within-sector productivity growth, structural change has made negative contribution to overall growth as labor moved from highproductivity sectors to low-productivity activities. McMillan and Rodrik (2011) argue that the pattern observed in Latin America is mostly due to commodity dependence, overvalued exchange rates, and deindustrialization. East Asia, which has experienced sustained growth, has seen both within-sector productivity growth and structural change as new industries were born, and resources moved from traditional to new industries. These papers cast doubt whether recent growth experiences in Latin America and Africa could be sustained.

\section{E. Creating Domestic Innovators: From Convergence to Growth at the Frontier}

We argue that the key to long-run sustained growth to reach the advanced country status and then keep up with the frontier growth is to promote technology and innovation at each stage of development. And the way to create technology and generate innovation is to produce sophisticated products. In fact, doing so and competing with other firms requires R\&D and innovation in the first place. The first key element of the growth strategy is thus straightforward - produce sophisticated products to catch up with the frontier and keep producing sophisticated products, although not necessarily the same products, to keep up with the frontier. And it is not only producing sophisticated products, but also producing it by domestic firms. This is the second key element. Only then creating own technology would be possible. Creating and growing domestic innovators should be the focus of TIP.

The middle-income trap exemplifies the importance of creating own technology. Cherif and Hasanov (2015) show that Malaysia did follow the standard growth recipe but was not able to generate enough innovation to support productivity growth needed to escape the middleincome trap. The standard growth determinants such as infrastructure, macroeconomic stability, strength of institutions and governance, trade openness, and FDI did not seem to be the binding constraints, especially in comparison to Korea in the 1980s, which was at a similar level of development. The inflow of FDI and the arrival of large MNCs did result in a large boon to exports, increasing export sophistication considerably (Figure 15). However, manufacturing economy-wide productivity and TFP productivity growth lagged those of Korea of the 1980s (Figures 5 and 12).

The missing link in Malaysia compared to Korea and Taiwan Province of China is own technology creation. When Korea overtook Malaysia in 1985-86, its patents granted in the U.S. per 1000 people was about one per year while Malaysia stood at a quarter of that number (Figure 16). Both countries had relatively low number of patents in the early 1980s. However, since then, Korea's patents have skyrocketed. The number of Malaysia's patents per 1000 people granted in 2014 (about 9) was still much below Korea's when it had a comparable level of income around 2000 (about 75). In this regard, Korea's remarkable growth is driven by its remarkable innovation. When Korea's chaebols started investing heavily in cutting-edge DRAM chips, with government support, in the mid-1980s, its GDP per capita relative to the 
U.S. only stood at around 25 percent (Kang 2001). By the early 1990s, Korean firms were already dominating the market. And when they started other sophisticated industries in the early 1970s like electronics and shipbuilding (HCI drive), the country's relative income was only about 12 percent, just above the low-income threshold of 10 percent.

\section{Figure 15. Export Sophistication in Malaysia, Korea, and Taiwan Province of China}

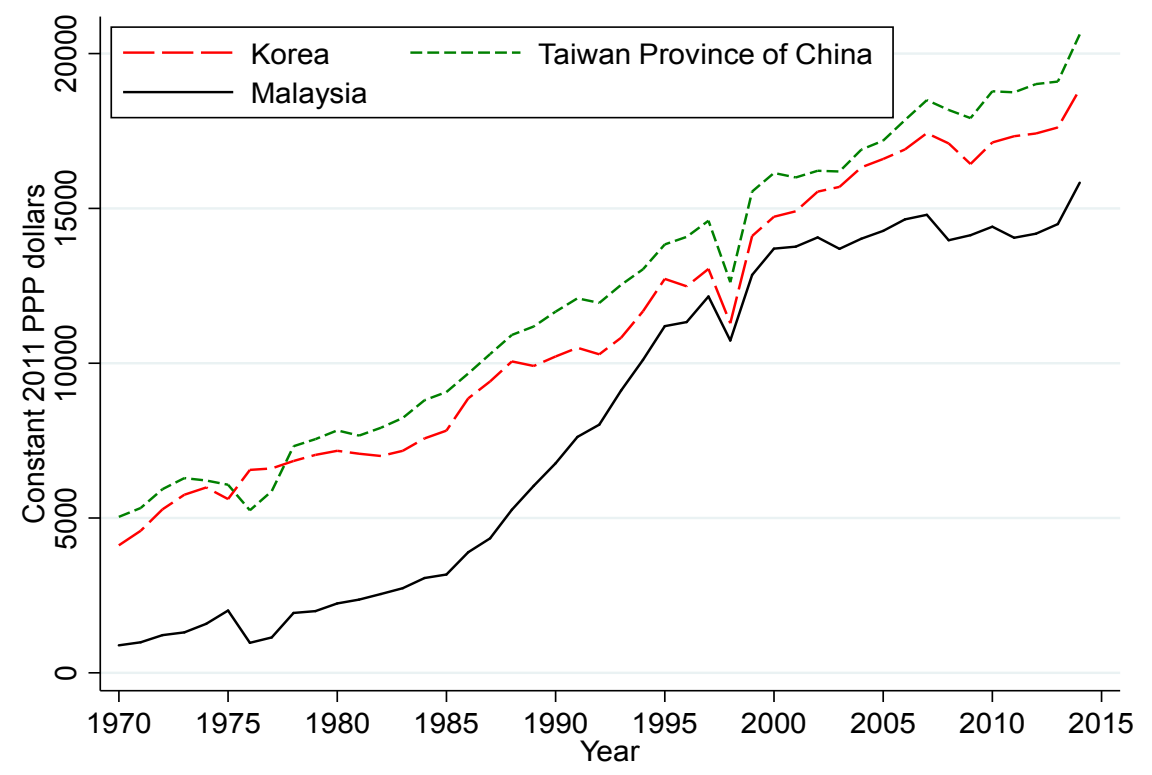

Source: Cherif, Hasanov and Wang (2018).

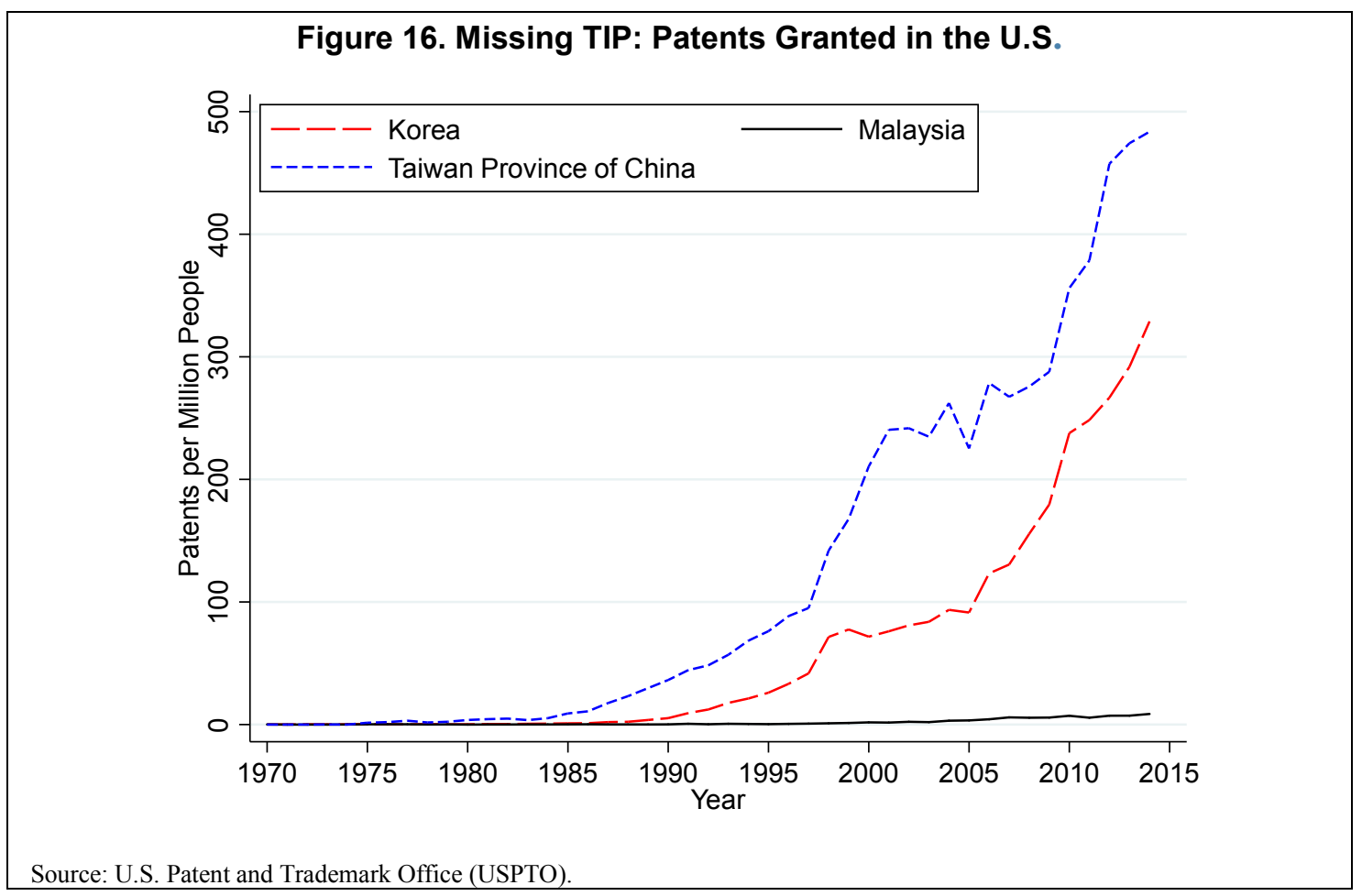

CInternational Monetary Fund. Not for Redistribution 
Lower R\&D spending in Malaysia contributed to a smaller number of patents granted (Figure 17). R\&D expense was much lower in Malaysia in 2012, a little over 1 percent of GDP, than it was in Korea of the 1990s, more than 2 percent of GDP, and even of the mid-1980s, 1.3 percent in 1984 (Tran 2013). This could partially be explained by a higher share of graduates in engineering, manufacturing, and construction in Korea (about 35 percent of tertiary graduates) in the 1990s than that in Malaysia in the late 2000s (about 25 percent). The figures were reverse for social science graduates, 21 vs. 33 percent (Tran 2013).

A focus on MNCs and technology transfer rather than growing domestic innovators contributed to the lack of innovation in Malaysia as compared to Korea and Taiwan Province of China. Cherif and Hasanov (2015) argue that although Malaysia recognized the importance of technology creation and provided various incentives for MNCs to diffuse technology and support local firms, it was not very successful at doing so. The country had some success with Vendor Development Program that had local content requirements (Felker 2001), but it was not sufficient. The Malaysian electronics cluster lacked the "packaging and integrating" capabilities of Singapore and product development and technology management capabilities of Taiwan Province of China (Best 2007). Rasiah (2007), using a sample of auto parts firms, showed that foreign ownership helped increase exports in East Asian countries, but R\&D intensities were mostly driven by local firms. In Taiwan Province of China, which had much higher patent production than Malaysia, local electronics firms had higher technological intensity than foreign firms, opposite of the pattern observed in Malaysia (Rasiah 2004).

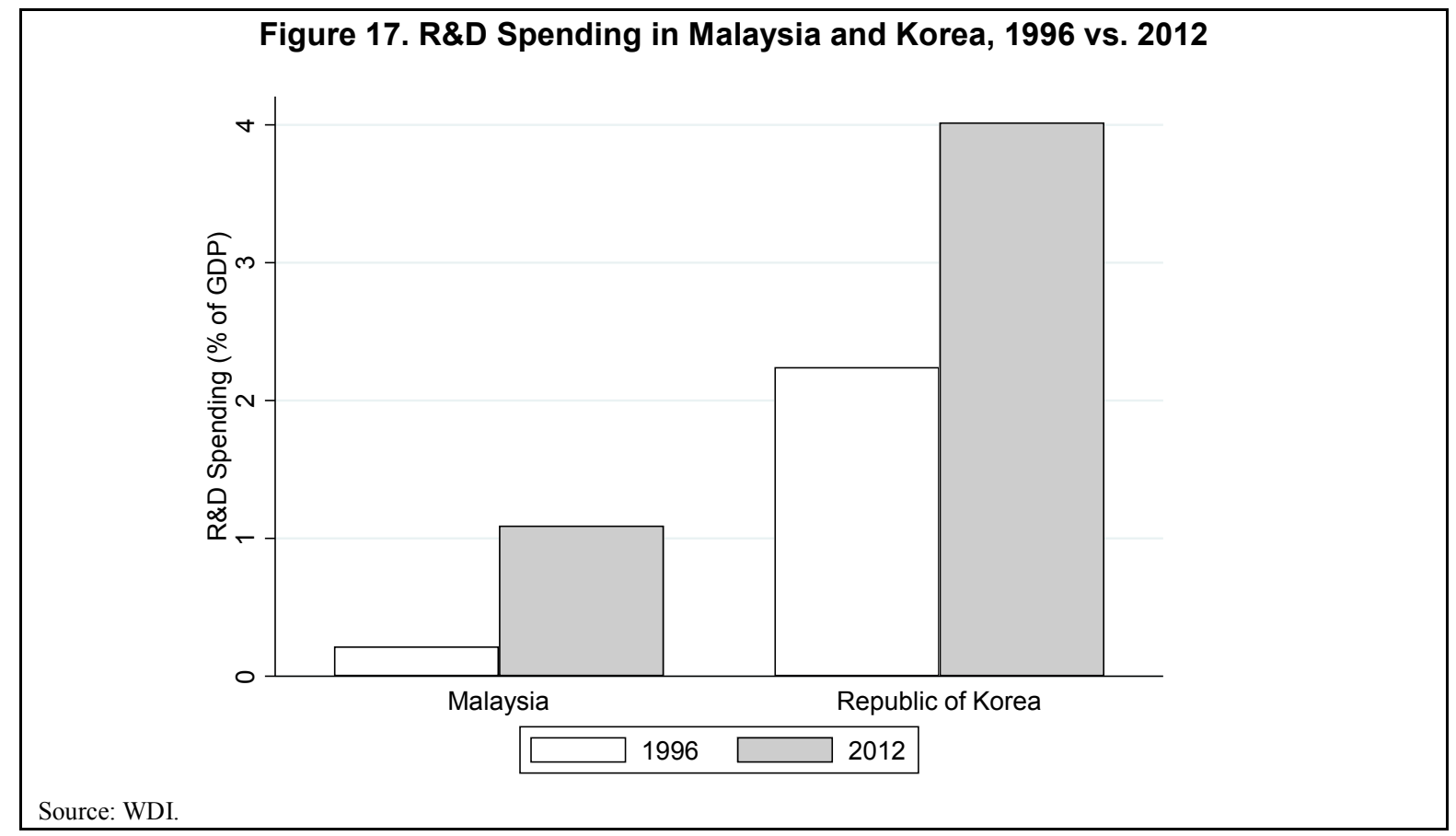

Singapore was more forceful in creating local firms and technology despite the large inflow of FDI and the presence of MNCs. Initially, Singaporean SOEs engaged with MNCs as subcontractors, but the Ministry of Finance was keen on creating local non-state-owned MNCs (Low 2001). The cluster-based industrialization in the 1990s led by Singapore's 
Economic Development Board involved many stakeholders, including MNCs. For instance, the electronics cluster was spearheaded by the Singapore Technologies Group, an SOE, working in tandem with government research institutes, universities, and MNCs (Low 2001). Unlike the Malaysian electronics cluster that continued to engage in relatively low skill production, the Singaporean electronics cluster moved up the quality ladder as low-cost manufacturing was becoming no longer viable (Best 2007).

Korea and Taiwan Province of China did not rely on MNCs in technology creation and instead, were determined to create their own technologies led by local firms. Taiwan Province of China's electronics sector has been its pillar of stellar growth in the past decades, while Korea's venture into automotive, shipbuilding and electronics is equally impressive. In both cases, the state played a key role in promoting these sectors (Cherif and Hasanov 2015).

Building domestic capabilities and creating own technology in sophisticated sectors are key elements to achieving innovation and sustained growth. In many instances, it would imply to enter sectors with little or no comparative advantage, lack of skills, experience, and resources, and high risk of losing money. The bigger the technological leap is (or the farther away from its comparative advantage the country is), the bigger the risk is and the longer it could take to discover the true outcome of initial investment (Rodrik 2005 and Chang and Lin 2009). However, in the long run, these sectors offer high returns and are the ones that could catapult the country into the high-income status. This high risk-high return tradeoff is exemplified by Nokia's mobile unit (part of a Finnish logging company at the time) that had incurred losses for about 20 years and had to be cross-subsidized (Chang and Lin 2009).

The case of Korea offers strong support to the principle of innovation at early stages of development to generate sustained growth. Figure 18 shows patents granted in the U.S. for Korea and other countries at comparable levels of development. For instance, in the early 1970s, when Korea's GDP per capita was similar to that of Tunisia and Philippines, the countries had a similar number of patents granted. Starting in 1980, as Korea had comparable levels of GDP per capita with Brazil, Chile, Malaysia, and Mexico, it was already receiving a higher number of patents. And the gap has been increasing with time. Looking at 2014, we observe that some countries increased their patents but not as dramatically as Korea had done. Even advanced countries at about same level of development in 2014 were patenting much less than Korea. Figure 19 shows actual patents, and the gap is enormous even with many advanced countries, which in fact have been experiencing relatively lower growth rates.

In fact, sustaining innovation at the frontier requires producing sophisticated products. Examining business R\&D in OECD countries, one finds a striking pattern (Figure 20). The patents per capita in top innovator nations such as Korea, Japan, Finland, Switzerland, and the U.S. indicate that most of business R\&D is done in high-tech manufacturing by large domestic firms. As discussed earlier, most of $R \& D$ is done in manufacturing and software/scientific services. Producing sophisticated products should lead to higher R\&D and innovation. In venturing into these sectors, countries and firms would have no other option but to invest in $\mathrm{R} \& \mathrm{D}$ and innovate to compete. 
Figure 18. Patents Granted in the U.S.: When Korea Overtook Other Countries (1970-2014)

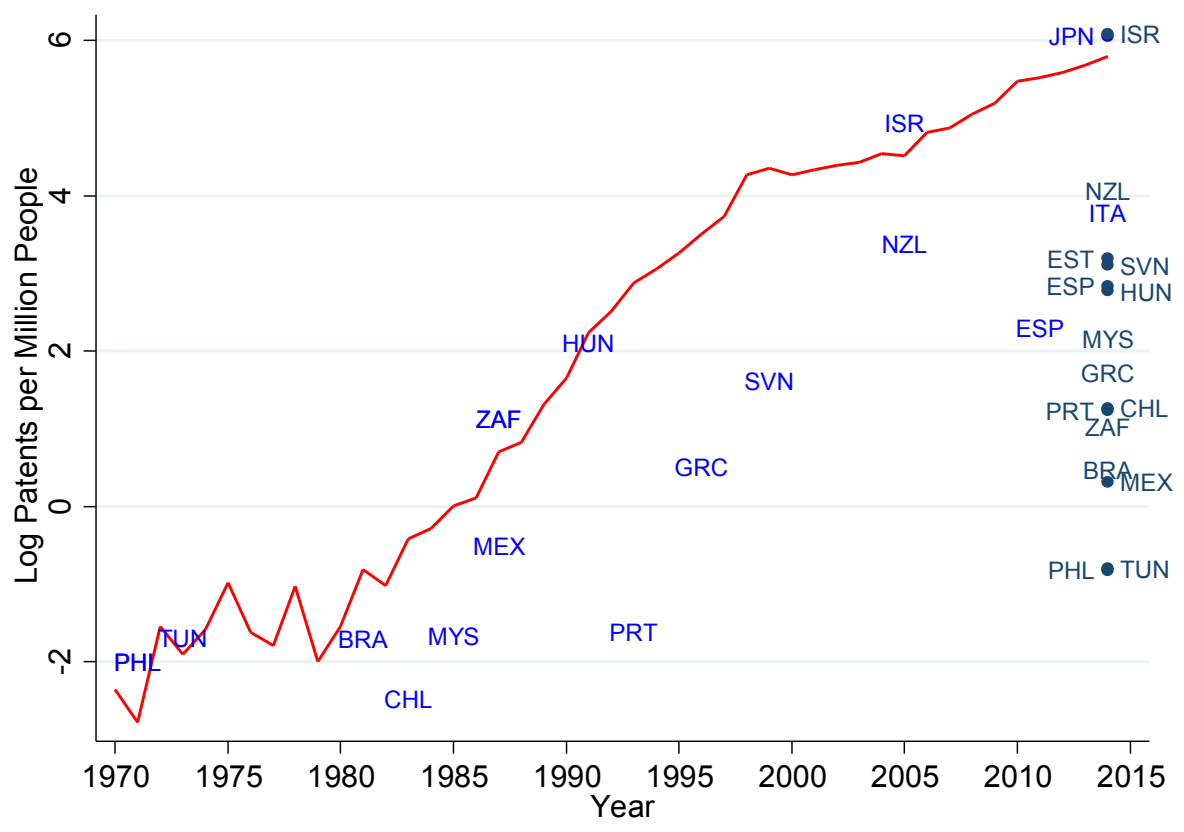

Source: USPTO.

Figure 19. Patents Granted in the U.S.: Korea vs. Other Countries (1990-2014)

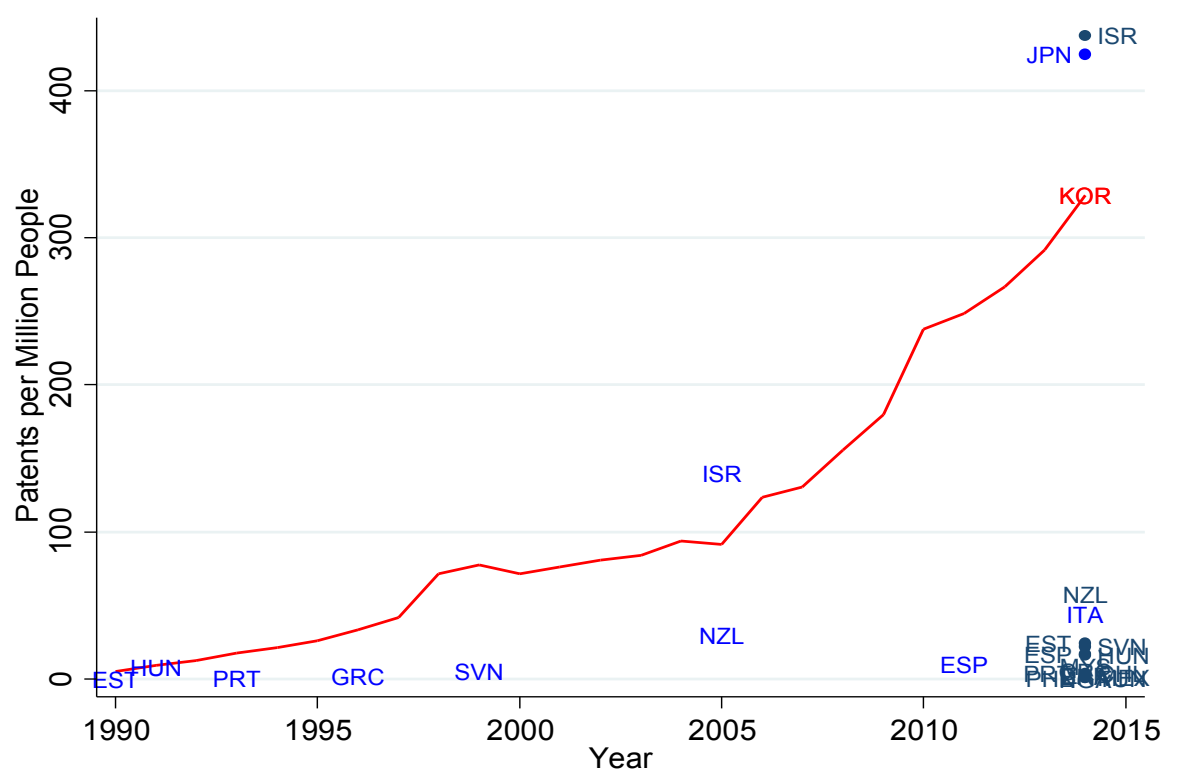

Source: USPTO 
In summary, technology and innovation are key to growth not only at the frontier but also at much lower levels of development. Taiwan Province of China and Korea's experience shows that venturing into the frontier sectors and producing own technology at early stages of development pay off in sustaining high growth. It is a high return-high risk strategy and that is why it is important to support sectors rather than firms as it is not known ex ante which firm would succeed (Aghion 2016). Korea's strategy followed this approach. ${ }^{31}$

We have come a full circle on income convergence toward the frontier and growth at the frontier. Producing sophisticated products provides productivity gains, spillovers, and other positive externalities needed to catch up. At the same time, producing sophisticated products requires high $R \& D$ spending and innovation to keep up with the frontier. High spending on R\&D by large domestic firms in high tech areas early on suggests a path to achieving high and sustained growth.

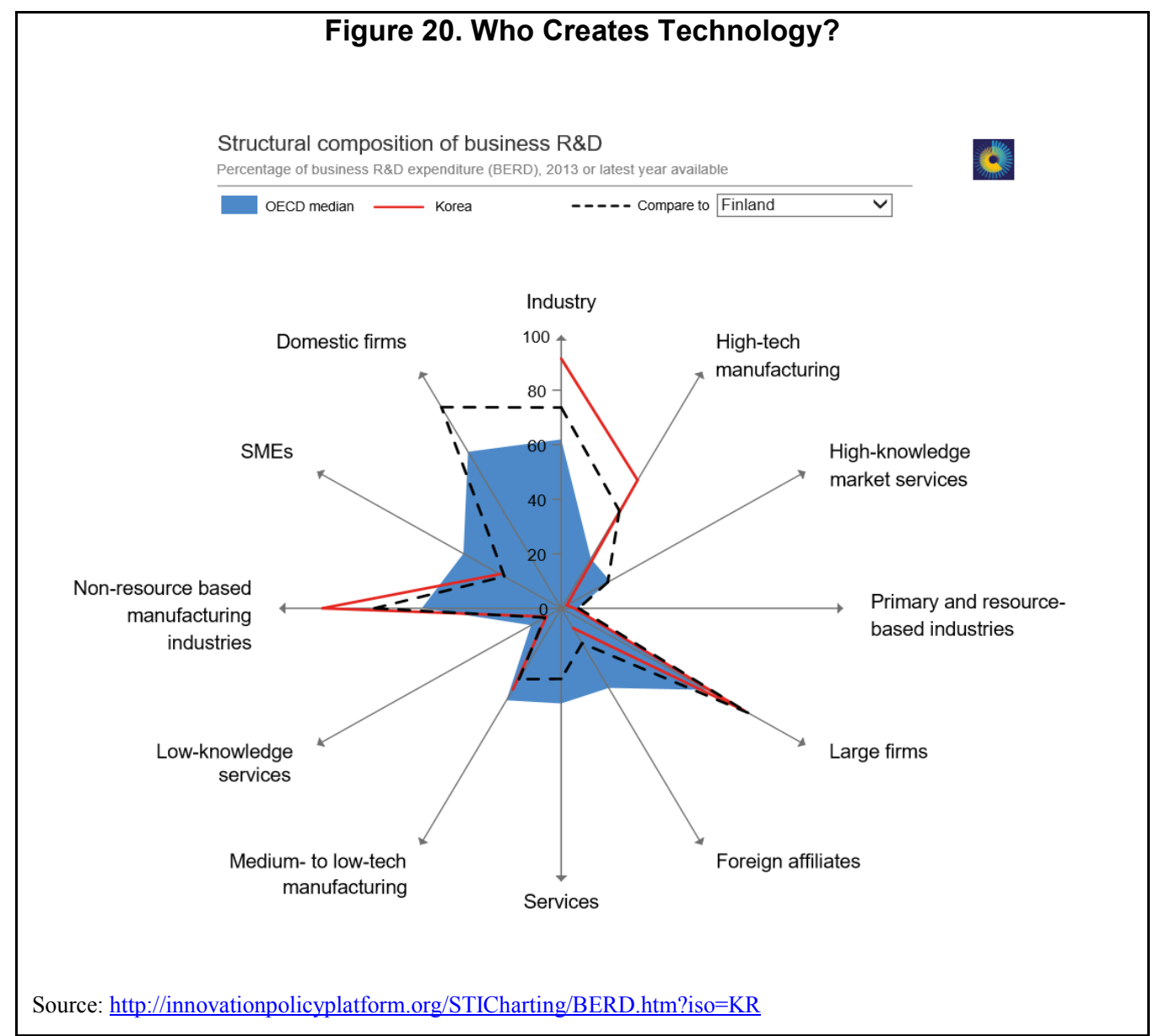

\footnotetext{
${ }^{31}$ As argued by Hausmann and Rodrik (2003), it is optimal to encourage investments in the modern sector ex ante in the presence of uncertainty in terms of the sectors the country is good at.
} 


\section{TIP THROUGH HISTORY}

\section{A. TIP Has Always Failed in the Past...Because It Was Not Tried}

A standard argument against any sort of state intervention to spur the growth of new industries lies in the fact that there have been many failures in the past. On a superficial level it is true that most developing countries somehow attempted to develop new industries and acquire new technologies using some sort of state intervention. The policy tools used were diverse and ranged from subsidies and protection through tariffs all the way to price controls and the use of state enterprise monopolies.

Many public enterprises created in the great wave of industrial policies of the 1960s and 1970s ended up in financial disarray eating up huge amounts of resources. The widespread view is that industrial policy leads to inefficient enterprises which would perpetually live on state handouts mainly benefitting cronies. It is also usually believed that the bad financial situation of many developing economies in the 1980s and 1990s was the direct result of the resource misallocation and inefficiency resulting from "industrial policies". If this is the case, how can it be that TIP was behind the spectacular success of the Asian miracles and how can one draw from it any useful lessons?

We argue that there are very few examples of TIPs in the past according to our definition. One of the pillars of the Asian miracles' policies was export orientation in technologically sophisticated industries. In other words, transport companies such as airline companies, power companies, telecommunication networks or tourism do not qualify as part of TIP. That still leaves a great number of attempts in manufacturing industries such as heavy industries, automobile and electronics. There are a few examples where state intervention had an explicit objective to export immediately. Indeed, the pattern of the industrial policies of the 1960s and 1970s was to create productive capacities, mostly in heavy industries, which were mainly inward looking, i.e., import substitution industrialization.

The first observation is that the golden age of import substitution did yield a sizable increase in manufacturing production although it did not match those of the Asian miracles. We use the Groningen Growth and Development Centre (GGDC) 10-Sector database, which provides comparable data on sectoral productivity performance for 10 broad sectors from 1950 onward for many countries. ${ }^{32}$ Figure 21 shows the average annual growth rate of value added (VA) in manufacturing (in real terms per capita) over two different periods, i.e., 1965-1980 and 19802010. Over the first period, during the height of industrial policies, many developing economies achieved relatively high growth rates in manufacturing spurred by the import substitution policies. Among the best performers, manufacturing value added per capita grew at an average annual rate of about 10 percent in Indonesia, 7 percent in Nigeria and 6 percent in Brazil over 1965-1980. Yet, these performances were still dwarfed by that of the Asian miracles. Korea which started at a level of income per capita comparable to that of Indonesia

\footnotetext{
${ }^{32}$ See Timmer et. al. (2015).
} 
saw its manufacturing VA per capita grow at an annual rate of 15 percent, while those of Taiwan Province of China and Singapore grew by around 12 percent.

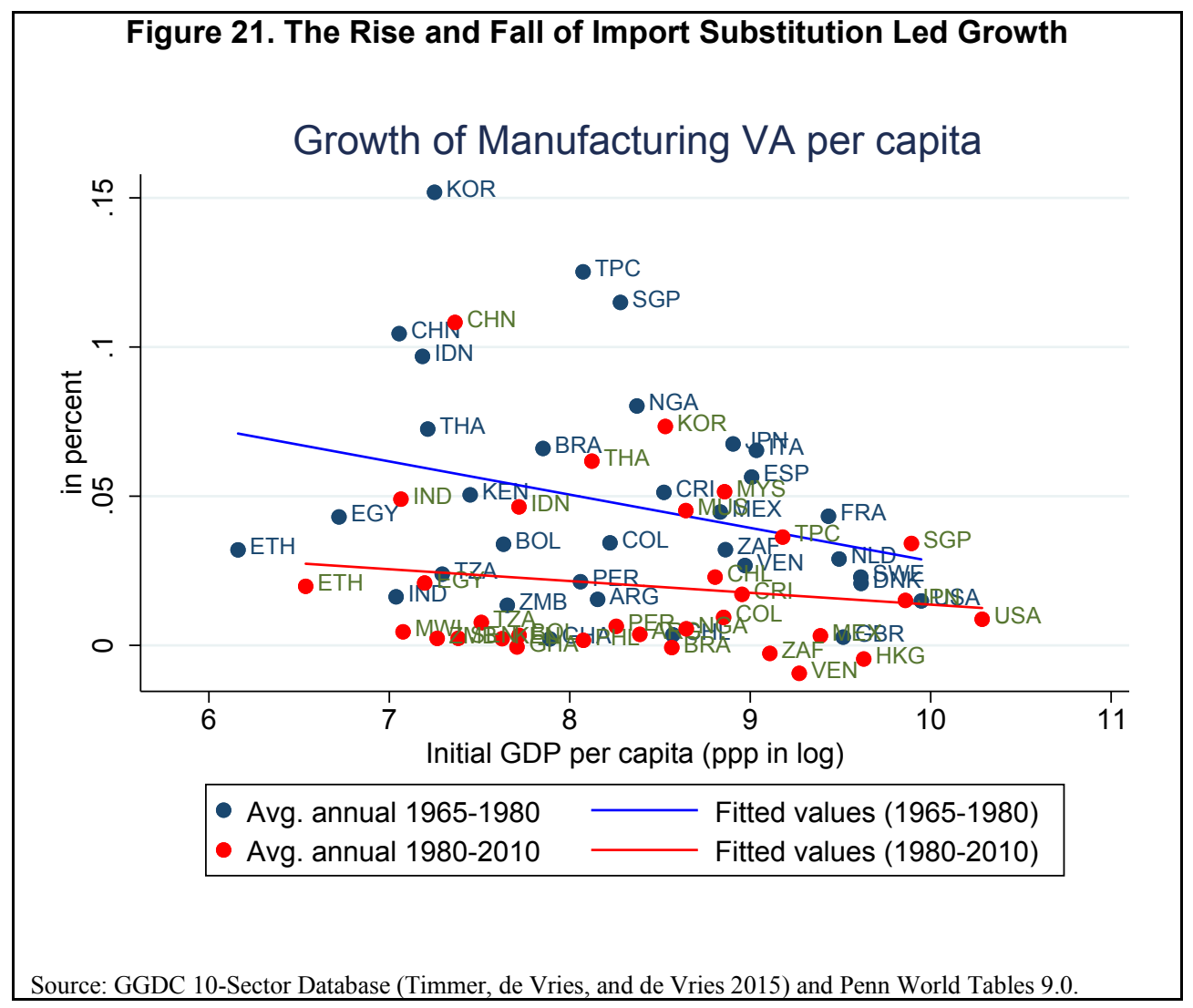

During the later period, 1980-2010, when import substitution policies were rolled back in most developing economies, the average growth rates of manufacturing production dropped significantly, and manufacturing stagnated in many economies. ${ }^{33}$ Meanwhile, manufacturing VA in the Asian miracles kept growing at relatively high rates, especially when controlling for initial income per capita.

We offer evidence that among developing economies, very few pursued an export-oriented industrialization policy on a large scale as it was the case in the Asian miracles. ${ }^{34}$ Inward looking or outward looking could be proxied by the strength of the short-term relationship between the growth of manufacturing value-added and the growth of manufacturing exports. By strength, we mean whether these growth rates are correlated in a significant way and how

\footnotetext{
${ }^{33}$ As shown by the decline in the slope and intercept of the fitted line.

${ }^{34}$ In practice, countries may have mixed export orientation with little state intervention in some sectors with import substitution policies in others. This was the case in Malaysia for example which pursued import substitution in the automotive industry while being export oriented in electronics, heavily relying on MNCs (see Cherif and Hasanov 2015).
} 
large this elasticity is. For example, if the relationship is significant and the elasticity is close to or greater than one, then one could say that such a country is export-oriented.

We use a structural break test to determine whether a break in the relationship happened and if so, the year of the break. ${ }^{35}$ The kernel distribution of the break years (when the null hypothesis that there was no structural break was rejected at a 5 percent level) shows that the distribution has a mode in mid- to late-1970s (Figure 22). Most countries that changed their short-term export/import orientation had already done so by 1990 .

Studying the strength of the short-term relationship (elasticity and R-squared), the Asian miracles are clearly outliers over the 1970-1990 period. Singapore and Korea are among the very few countries with a high R-squared and an elasticity that is both significant and positive (Figure 23). Over 1990-2010, many countries would see the strength of the short-term relationship between exports and manufacturing output change (see Appendix Figure 1).

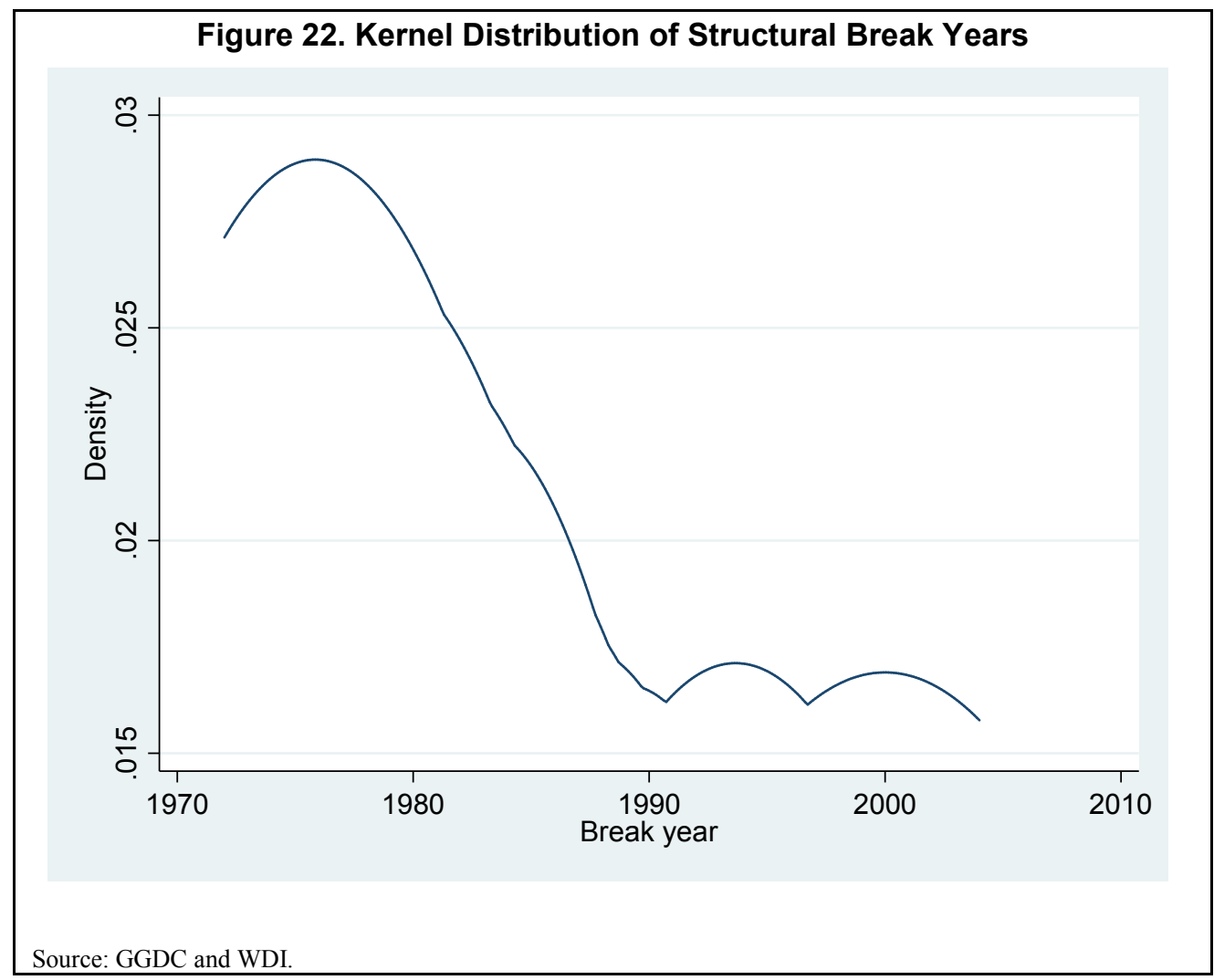

\footnotetext{
35 The regression model is (where all the variables are in real terms): $\Delta \log ($ manufacturing exports $)=c+\alpha \Delta \log ($ manufacturing value added $)+\varepsilon$
} 
The difference between the Asian miracles and other developing economies is even starker in terms of export performance. Figure 24 shows the ratios of manufacturing exports per capita relative to Korea in a large set of countries. While most advanced economies were exporting between 25 and 150 times as much as Korea in 1965, the ratios shrank by an order of magnitude to between twice to 8 times Korea's exports per capita by 1980 (Figure 24a). Figure $24 \mathrm{~b}$ covers the same period zooming on countries that started at less than twice Korea's level of exports in manufacturing encompassing most of the available developing economies in the sample. Korea stands out as no country even remotely kept pace with it in terms of manufacturing exports. At best, countries like Malaysia and Tunisia, which exported more manufactured goods per capita than Korea in 1965, represented about 40 percent and 20 percent of Korea's exports by 1980 . Figure 24c and 24d show that Korea kept catching up with advanced economies, especially those with a comparable population size, while most developing economies kept falling behind (or at best their ratios stagnated at a fraction of Korea's).

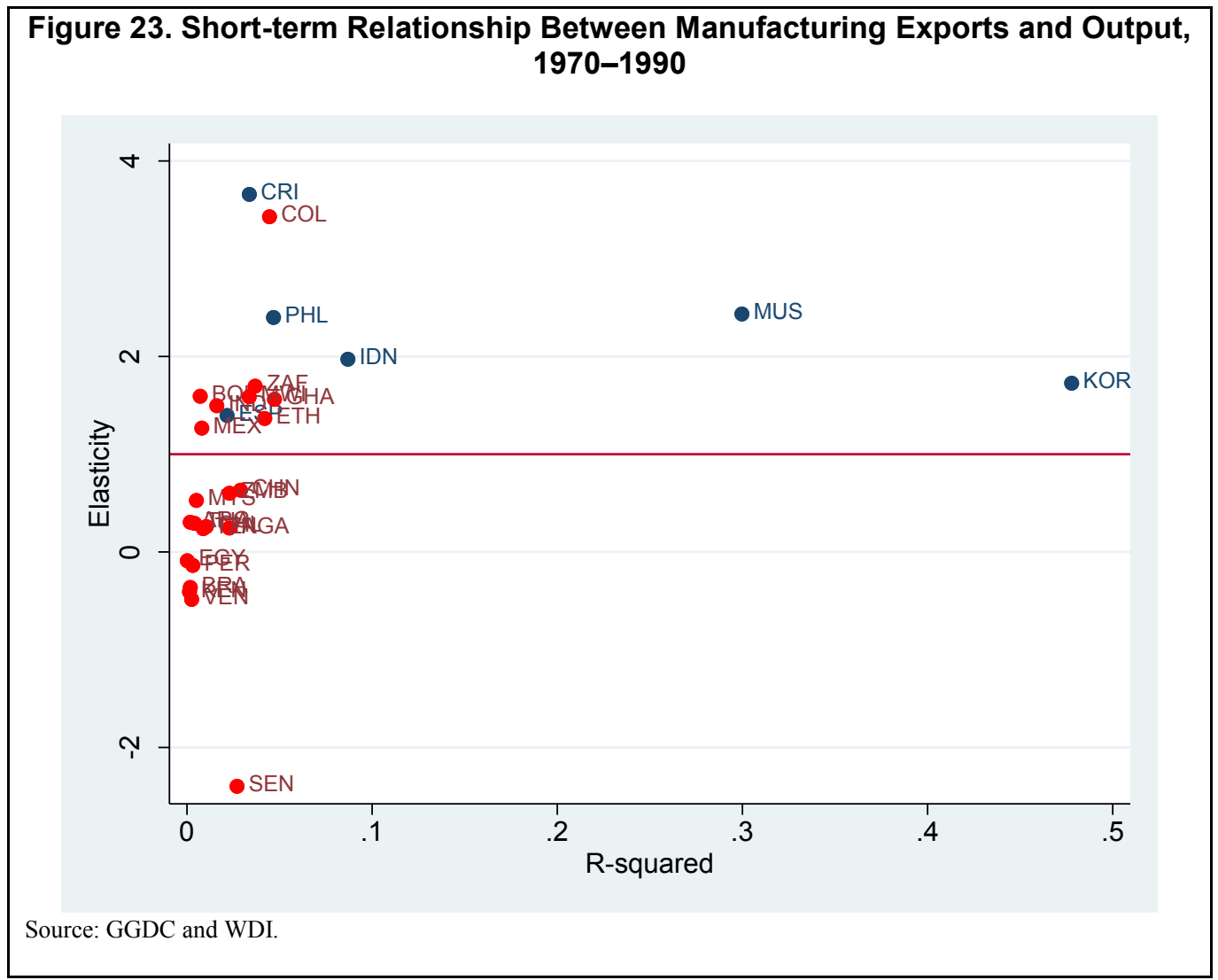




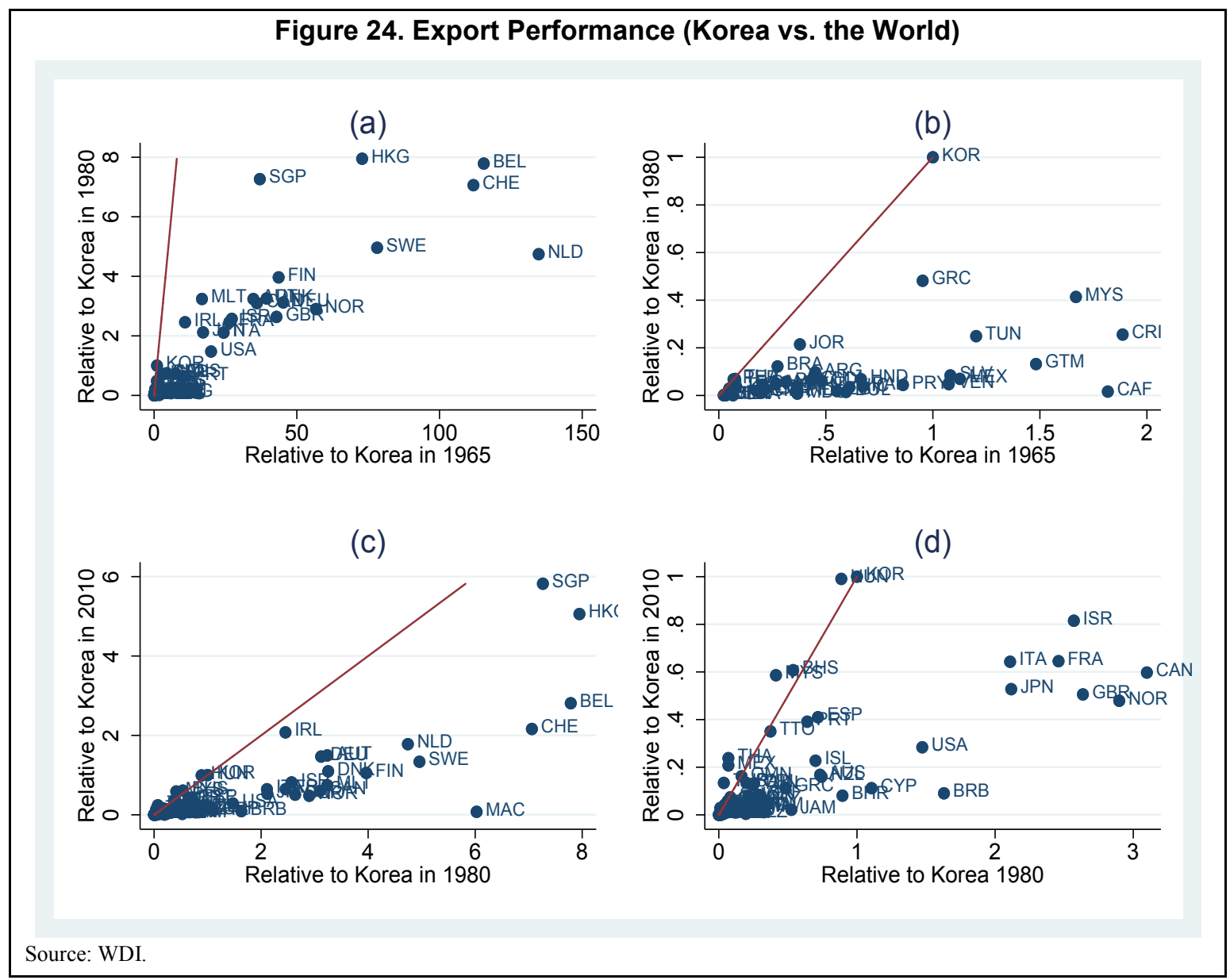

We show further evidence that although most developing economies had tried some sort of industrial policy in the 1960s-1980s, there are very few countries that had achieved sustained growth in their production of manufacturing, especially beyond the 1980s and had a clear export orientation view that was even remotely comparable to Korea's (and other Asian miracles'). In fact, our conjecture is that is it precisely thanks to its export orientation that Korea managed to sustain its growth in manufacturing output. In addition, Cherif, Hasanov, and Wang (2018), using cross-country growth regressions and neighbor-country instruments, find that export sophistication measures such as EXPY (Hausmann, Hwang, and Rodrik 2007), a manufacturing exports share, and manufacturing exports per capita, are all robust determinants of long-run growth.

We further illustrate our point by measuring the level of "manufacturing export intensity" (MEI) of a country by its market share in world manufacturing export (that is a country's exports of manufacturing divided by the world's total exports of manufacturing) normalized by its share in world population. For example, in 2010, Switzerland's weight in world population was about 0.11 percent and its manufacturing export market share was 1.7 percent, producing the level of manufacturing export intensity of about 150 percent, which was 250 times greater than India's (India represented close to 18 percent of world population at the time). In contrast to the growth rate of exports of manufacturing, which can be misleading if 
for example a big country in terms of population starts exporting with almost no initial manufacturing base, a sizable change in this measure captures adequately whether a country is making a serious foray in world markets in relation to its population size over longer periods. The differences between low and middle-income countries and high-income countries according to this variable are stark. In 1970, the median manufacturing export intensity in low and middle-income economies was 5 percent compared to 270 percent in high-income economies. In 2014, it was 8 percent in low and middle-income economies and 370 percent in high-income economies. The gap between poor and rich countries in terms of manufacturing intensity was immense, and it has widened further.

Figure 25 shows the average growth of manufacturing value added per capita (in real terms) in relation to the change in manufacturing export intensity over 1970-1990 in a sample of developing economies (as of the 1970s). ${ }^{36}$ As noted above, these countries started at a very low level of manufacturing export intensity (with a median close to 0.05), and most have not increased it much over the period. Countries such as Korea, and to less extent Malaysia and Thailand, managed to simultaneously grow fast both in terms of manufacturing output and manufacturing export intensity. In fact, by 1990, Korea jumped close to the initial level of export intensity of the median high-income country. Meanwhile, countries such as China and Indonesia achieved particularly high growth rates in manufacturing output (7-10 percent on average in per capita terms) without changing much their manufacturing export intensity. This provides compelling evidence of an import substitution policy that was still largely in place until the late 1980s. Other countries known for their import substitution policies in the 1970s and 1980s, such as Egypt, Nigeria and India, follow the same pattern of relatively high growth of manufacturing output and a negative change in their manufacturing export intensity. The rest of the countries had both small growth rates in manufacturing output and small or negative change in manufacturing export intensity. Chile is a clear outlier as its laissez-faire policy led to an anemic growth in manufacturing output and a collapse in its manufacturing export intensity. In other words, besides Korea and a few other countries, developing economies did not pursue simultaneously a rapid industrialization and an export-oriented policy.

\footnotetext{
${ }^{36}$ The data are taken from de Vries et al. (2015). Appendix Figure 2 uses U.N. statistics data and covers more countries, but the overall picture is similar.
} 


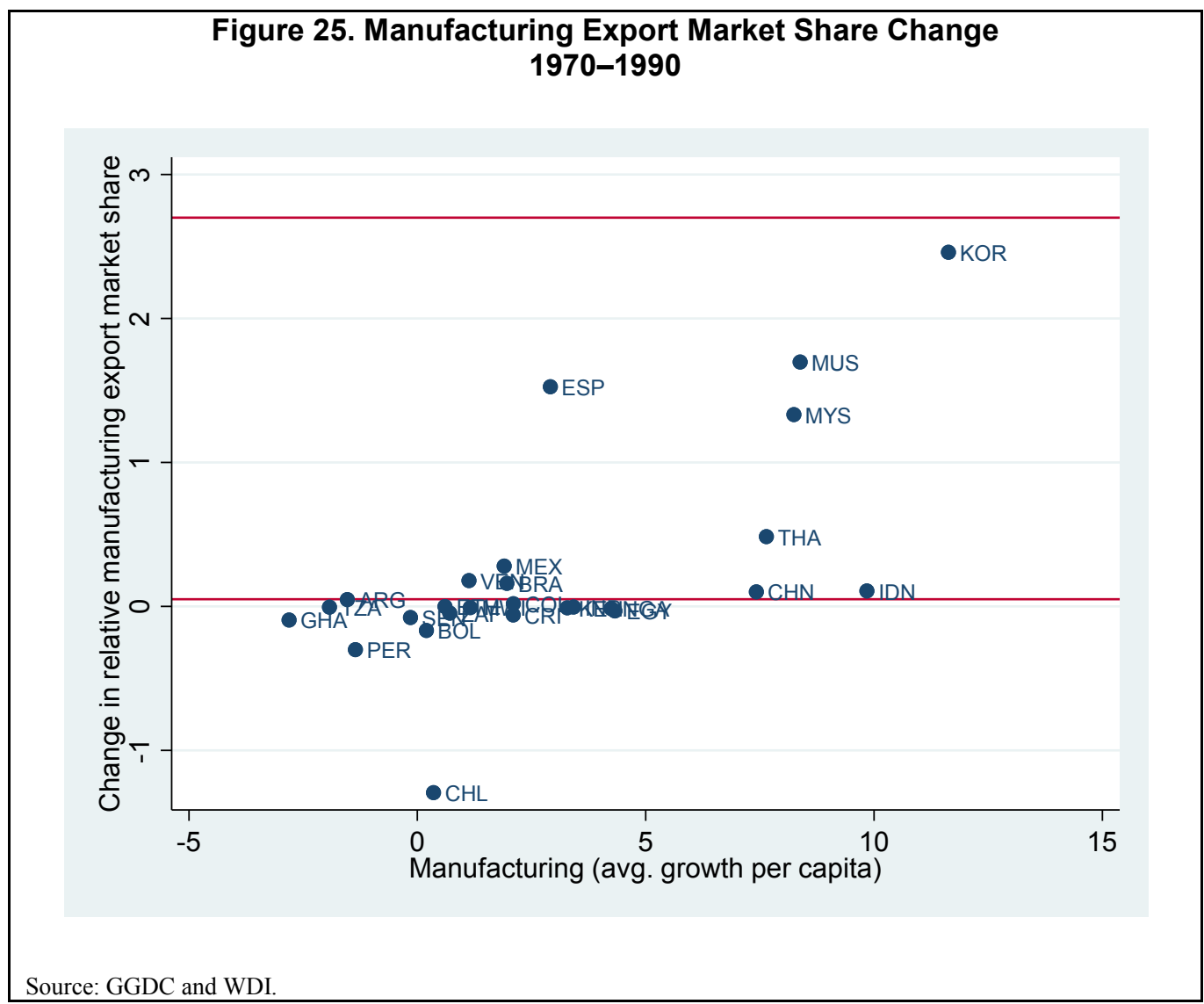

\section{B. ISI in India: The State as a Micromanager}

Although important, economies of scale are not necessarily the only reason behind the failure of ISI policies. The lack of export orientation leads to a lack of productivity improvements, innovation, and dynamism while ISI policies are also usually accompanied by distortions and perverse incentives. India, with its large market, represents a good case that controls for the lack of economies of scale in the failure of ISI policies.

India led a particularly ambitious import substitution policy in the wake of its independence in 1947 and until the late 1970s. Its objective was to produce domestically a high proportion of its consumption of most manufactured goods. By 1970, this goal was achieved to a considerable extent (Krueger 1975). Meanwhile, despite its huge domestic market and relative fast growth in manufacturing output, India has suffered regularly from hard currency shortages and its growth rate in per capita terms was nonetheless anemic. It is worth studying the policy tools and incentives and disincentives put in place at the time and how they distorted economic decisions.

The import substitution goal was achieved through an intricate web of rules and regulations at the center of which was the licensing system. Domestic producers were completely shielded from international competition through restrictions on imports and sometimes import bans. Moreover, domestic firms enjoyed extensive monopoly rents as domestic competition was 
heavily curtailed. In parallel, cumbersome regulations were a constant burden on firms. To be able to produce a certain good (finished or intermediate), an industrialist needed to apply for several licenses including a capacity license allowing to produce a specific good and setting total capacity and yearly production ${ }^{37}$ as well as the number of shifts (and sometimes at the level of specific models in the case of the car industry). To import inputs and machinery, a separate license was needed to secure the foreign exchange needed. Even the technical support associated with some machinery purchase had to be licensed separately as "foreign collaboration" license (see Krueger 1975). Price controls were also applied in many industries and the delays to get licenses approved could be in the order of several years.

These policies resulted in a situation where profits depended more on the ability to secure the adequate licenses than on competition through improved productivity or innovation. ${ }^{38}$ The inability to produce continuously (as a result of power shortage, unavailable spare parts or raw materials, and other administrative hurdles to import intermediate goods) also influenced the type of technology adopted, which did not entail economies of scale and was less conducive to learning-by-doing or R\&D. For example, the automotive industry in 1970 was producing models that were produced in other countries in the early 1950s (Krueger 1975). The policies pursued were also detrimental to many firms that were prevented from integrating vertically and had to rely on inefficient and often expensive suppliers. Some indigenous materials and local machinery makes were banned from imports leading to prices up to tenfold international prices.

Despite rules that forced firms to export some of their production in some industries or to generate enough exports to cover their initial investment in machinery (e.g., firms producing for more than 5 years had to export 5 percent of their output in the automotive industry), exports generated rarely exceeded the minimum requirements, which were small to begin with. Among the reasons cited, the heavy paperwork burden, the costly expansion of capacity, the difficulty to meet continuously the stringent delivery deadlines and volumes in a context of recurrent disruptions ${ }^{39}$, and above all profit margins that were way too low compared to the domestic market.

India's import substitution policy, which is representative of the policies pursued by developing economies in the 1960s and 1970s, contradicts key principles of TIP except for the intervention to create domestic capabilities, which it did with relative success. Krueger (1975) argues that many of the firms supported by ISI policies could compete globally if they had

\footnotetext{
${ }^{37}$ The anecdote of a firm in the automotive industry reaching its production limit before end-year and asking its entire staff to work on building a garden, illustrates the limits of the type of state micromanagement associated with import substitution policies (Krueger 1975).

${ }^{38}$ For example, some firms would strategically aim at over-capacity and the associated oversized rights to intermediate goods imports, to drive out competitors.

${ }^{39}$ A great source of uncertainty for potential exporters is that an input can be added to the list of banned imports, provided a domestic firm justifies that it can ex ante meet local demand. However, firms may still fail to meet the demand quantity and quality standards, costing the exporter several months of disruption while it tries to lift the import ban.
} 
access to raw materials and intermediate inputs, which were heavily restricted (e.g., licensing requirements). She concludes that "By that criterion, import-substitution policies have been highly successful" (Krueger 1975, p. 111). However, pushing domestic firms to compete on international or domestic markets was far from a priority. On the contrary, monopoly rents on the huge domestic market insured that firms had no serious interest in the difficult and risky export markets. More important, achieving self-sufficiency in most tradable final goods did not prevent India from suffering from hard currency shortages as it still relied on key imported inputs such as raw materials and machinery. In other words, import substitution gives an illusion of self-sufficiency while remaining vulnerable to external shocks.

\section{Export Orientation, not Tariffs, is the Secret Ingredient}

As mentioned earlier, export orientation has been a critical ingredient of the Asian miracles' industrial policies. It represented a major departure from the import-substitution policies adopted in most developing economies in the 1960s-1980s. On the surface, these two types of policies, Asian miracles vs. the typical ISI that failed in the past, were similar. Both relied on tariffs to protect their domestic markets and used subsidies to support domestic champions in selected strategic sectors (see Wade 1990, Chang 2002 and Woo 1991). However, these similarities, which are usually downplayed or simply ignored as they do not fit the standard recipe, hide fundamental differences in the approaches taken.

In the typical developing economy, tariffs and other barriers to entry were meant to limit competition on the domestic market, in some cases a public monopoly, and there was no specific incentive to export and compete on international markets. This model can lead to some successes in the sense that production would increase, and capabilities would improve. This is consistent with the evidence shown in the 1970s-80s. However, over time, the lack of competition would mean little investment in R\&D and innovation and quasi-total dependence on imported intermediate goods, especially critical high technologies. In relatively small economies, the protected firms would have to put in place relatively small-scale production units and would not take advantage of economies of scale. In large economies such India, ISI policies would lead to sizable misallocation of factors, where inefficient firms would perpetually survive, and efficient ones prevented from growing as a result of different constraints such as access to imported inputs (see Krueger 1975 and Hsieh and Klenow 2009 for a more recent study). Even if these firms were well managed and were not captured by well-connected individuals, they would perpetually depend on different types of protection from international and domestic competition and on subsidies. In this context, domestic firms would be extremely vulnerable to a combination of devaluation and lifting of tariffs as they would see the cost of their inputs increase without an improvement in their competitiveness in the absence of exports. Although textbook economics would predict a pick-up in exports following a depreciation, in practice, firms cannot start exporting overnight. When eventually these protections and support are lifted, typically in a phase of fiscal consolidation or currency 
crisis, the ISI model becomes suddenly unsustainable and industrial policy ultimately doomed to be a failed experiment. ${ }^{40}$

In contrast, in the Asian miracles, tariffs were only a tool among many to promote exports by ensuring a minimum rent for domestic producers while competition was fierce both at home and abroad. The Asian miracles used all the tools available to ensure as much revenue as possible to the whole sector but not necessarily to specific firms and they managed to get away with it in the context of the cold war. More important, firms receiving support were expected to export and were subject to strict accountability, including export quotas in Korea (see Woo 1991) or preferred credit and tariff conditions in Taiwan Province of China (see Wade 1990). Firms had to invest heavily in R\&D and innovate to compete on international markets. They would also have to set large production capacities, much larger than if they were limited by the domestic market and reap the benefits of economies of scale. An everincreasing level of integration was sought to increase profitability and take advantage of lower wages domestically, which was often the result of state intervention. ${ }^{41}$ Exporting firms would either integrate vertically or they would help create a network of suppliers by sending teams of engineers to train their workers (see Wade 1990 and Chang 2002). Given enough time, and under a strict accountability framework and exposed to intense competition in foreign markets, exporting firms would become immune to lifting barriers and would even benefit from a devaluation as their primary market was outside the country.

Export orientation prevents from falling in an illusion of economic "independence" and tariffs are neither necessary nor sufficient to succeed. The contrast between ISI and export orientation can be illustrated by the different paths followed by Korea's Hyundai and Malaysia's Proton. ${ }^{42}$ While Hyundai became a global brand and a highly successful and innovative car maker, providing demand for a dense network of suppliers, Proton is a less integrated automaker relying on critical imported inputs (e.g., Mitsubishi's engine to this day) with insignificant exports and a domestic market, which is challenged by foreign automakers despite tariffs and subsidies.

In both countries, strong state intervention led to the creation of new capabilities in the 1970s in the automotive industry. A mix of subsidies, tariffs to protect the domestic market as well as joint-ventures and licensing agreements with Japanese and U.S. automakers helped establish the first car makers in both countries. However, there were key differences in terms of policies followed.

Proton never experienced the kind of strong push for exports and competition Hyundai faced in Korea. The Korean conglomerate targeted aggressively foreign markets since the beginning following a strategy described as "move first, then learn and adjust". One of the first factories

\footnotetext{
${ }^{40}$ These firms could even be profitable without subsidies as long as they can import inputs at a favorable exchange rate and sell them on a domestic market with a high markup.

${ }^{41}$ See Wade (1990) for the case of Taiwan Province of China.

${ }^{42}$ See Cherif and Hasanov (2015) for more details and references.
} 
built in the mid-80s had an annual capacity of 300,000 surpassing the total annual domestic demand of Korea of 250,000 and solely dedicated to the U.S. market. It also built early on its own network of car dealerships and advertisement in the U.S. In contrast, Proton remained inward oriented with a modest production capacity compared to global players. When Proton was trying to export to the U.S. market, it relied on local dealerships and could not build a strong brand. It is reported that dealers would use the cheap Proton cars as bait and try to sell more aggressively other more expensive brands. ${ }^{43}$ In terms of local content, to this day Proton still relies on a license from Mitsubishi to produce its engine while Hyundai leapfrogged technologically in the 1980s and managed to design its own engine. Finally, Hyundai is one of the few survivors of many attempts to set up global automotive players by other chaebols.

\section{Can Laissez-Faire Be Worse than Import Substitution?}

In contrast to Norway and most developing economies at the time, Chile followed a literal version of "laissez-faire" policy until the early 1980s with disastrous effects. Among others, it ruled out import substitution policies (e.g., it lifted tariffs unilaterally) and avoided sectoral policies altogether founding its strategy on the expectation that comparative advantage sectors would naturally emerge in the absence of state intervention, provided the business environment and major government failures were tackled. As shown in Figure 25, this strategy made Chile an outlier in a negative way. Over 1970-90, it witnessed a sizable loss in terms of market share in manufacturing exports although it started from a relatively high position compared to other developing economies. For example, in 1970, Chile's manufacturing export intensity was about 200 percent compared to a median of 5 percent in developing economies and much greater than Malaysia's, which was about 80 percent. In 1990, the situation was reversed where Chile's MEI was about 70 percent and Malaysia's 210 percent. More striking, while most developing economies managed to achieve relatively high growth rates in their manufacturing output, Chiles manufacturing per capita grew at a meagre annual rate of 0.35 percent compared to more than 8 percent in Malaysia, for example.

The 1982 crisis triggered a roll back of Chile's laissez-faire experiment when it raised its tariff on imports and re-introduced some sort of state intervention to spur export growth albeit through indirect tools and favoring what it considered comparative advantage sectors such as agroindustry. For example, over 1985-2003, the "reintegro simplificado" (simplified reintegration) program provided an export subsidy to help firms export in non-traditional sectors (Varas 2012). Later, in the 1990s and early 2000s, the Chilean Economic Development Agency (CORFO), which focused on SMEs, helped facilitate funding and technical assistance while Fundación Chile, which was based on a private-public partnership, helped create start-up companies in projects promoting technology transfers. After Fundación Chile helped adopt Norwegian technology in its nascent salmon industry, the industry took off and remained its most successful case. Yet overall Chile still pursued the free market approach, which indirectly translated to less interventionist policies for Fundación Chile

\footnotetext{
${ }^{43}$ This asymmetry in incentives for car dealerships could explain why Tesla, which relies on its own network, has been more successful than other firms in selling fully electric cars (see de Rubens et. al. 2018).
} 
(Varas 2012). Interestingly, the main successes of Chile in non-mineral exports such as salmon and blueberries can be attributed to its state interventions through these agencies.

Despite these successes and Chile's relatively steady real GDP growth and macro-stability, its productivity growth has lagged its peers. Chile's GDP per capita relative to that of the U.S. fluctuated in the range of about 20-30 percent since early 1960s until mid-2000s. This could be explained by its focus on natural resources and low sophistication sectors such as agroindustry in contrast to other natural resource producers such as Malaysia, Mexico and Indonesia. They have outpaced Chile by a large margin in terms of export sophistication for the past two decades. More striking, Chile's total factor productivity has stagnated since 1970 (see Cherif and Hasanov 2015).

\section{E. Earlier Miracles in Advanced Economies and the Forgotten Hand of the State}

"Late late comers", as the Asian miracles are usually described in the development literature (see Amsden 2003), are not the only ones that used state intervention to steer the economy into specific industries. As argued by Chang (2002), there is strong evidence that the catching up of the original "late comers," i.e. Japan, Germany and before them the United States, show similar patterns.

Alexander Hamilton, the first secretary of the Treasury of the United States, outlined a strategy to promote manufacturing to catch up with Britain (Hamilton 1791). Chang (2002) and Cohen and De Long (2016) argue that the economic dominance of the U.S. was the result of a stream of visionary market-distorting state interventions which started with Alexander Hamilton. Among the policies they cite, protectionism and intervention to develop research appear to have played a prominent role to develop infant industries.

High tariffs to protect nascent manufacturing industries had been a landmark of U.S. economic policy since Alexander Hamilton until after Second World War. For example, at the turn of the $20^{\text {th }}$ century, when Argentina and the U.S. had similar levels of income per capita, tariff on manufactured goods were about 45 percent in the former and about 5 percent in Argentina, the highest and the lowest among the advanced countries, respectively. Moreover, state directed research and development to acquire new technologies has also been an integral part of Hamilton's strategy and, although it has changed in its form, the tradition has continued to the present. One would see the same pattern in the development of Germany and Japan (see Chang 2002).

To this day, there are still strong elements of industrial policy in advanced economies albeit in a quite indirect form. Mazzucato (2013) studies the direct contribution of government programs to what is commonly thought of as private innovations. For example, she shows that many components of the Apple iPhone, the product that made Apple one of the biggest companies in the world by market valuation, including its path-breaking touch screen technology, were originally developed thanks to government subsidies and in particular from defense programs. The same applies to what is considered as a key innovation in the last two decades, the internet and computers. O'Mara (2004) shows that the origins of Silicon Valley's 
rise are strongly related to the prodigious defense and space programs during the cold war, in particular through procurement policies.

Other industrial policy tools were used in advanced economies. The German development bank KfW, played a major role in the reconstruction of the country after the Second World War (see Naqvi, Henow, and Chang 2018). The public bank targeted among others sophisticated tools and machinery industries which later became the engine of the German economy. To this day, the bank plays an important role with assets representing 14 percent of GDP in 2016 and about 6 percent of the banking sector (more than 500 billion euros). As an example of its leading role in technological leapfrogging, the public bank financed close to 100 percent of all the projects in renewable energy between 2007 and 2009 in the early stages of the "Energiewende" drive. The private sector has since gradually increased its share of financing but only after the government undertook most of the risky initial investment.

\section{CONCLUding REMARKS}

We argue that the success of the Asian Miracles was not a matter of luck but the result of TIP. Although they were not hit with severe negative shocks or possessed some intrinsic characteristics for success, their high sustained growth was the outcome of the implementation of an ambitious technology and innovation policy over decades that kept adapting to changing conditions and moving to the next level of sophistication. The state set ambitious goals, managed to adapt fast, and imposed accountability for its support to industries and firms. We argue that first, TIP was based on the state intervention to facilitate the move of domestic firms into sophisticated sectors beyond the existing comparative advantage. Second, export orientation since the onset played a key role in sustaining competitive pressure and pushing firms to innovate. This strategy contrasts with import substitution industrialization strategies, prevalent until the late 1980s among developing economies, that led to inefficiencies, lack of innovation, and persistent dependence on key imported inputs. Finally, the discipline of the market and accountability were enforced in a strict manner.

We interpret the various degrees of success of developing economies in achieving a higher income status as corresponding to different levels of ambition and policies pursued in conducting TIP. The more a country was willing to leap technologically beyond comparative advantage and the more this technology was produced by domestic firms, the higher the chances were to sustain high growth.

Most countries in the middle-income trap have followed some elements of TIP, notably by attracting MNCs and joining GVCs of sophisticated products, but they have mostly failed in developing their own technology at the frontier or moving away from low R\&D intensity sectors such as natural resource extraction. Relatively successful countries such as Chile and Malaysia have managed to solve a great deal of government failures while developing new exports such as salmon and blueberries in Chile and rubber and palm oil in Malaysia, but mostly relying on foreign technologies. Meanwhile, the Asian miracles were moving to the 
frontier, undertaking long-term and risky projects in automotive and electronics while developing own technologies in these fields.

For the other countries stagnating or falling behind, we argue that either the policies they followed do not qualify as TIP, given the criteria we have established, or it is difficult to disentangle bad luck from bad policies. Most developing countries have attempted some type of industrial policy in the past and there are many examples of failures. For example, industrial policy in the automotive industry in Malaysia and India failed in the past but they were conducted within an ISI framework, which was the rule rather than the exception in the 1960s-1980s. Other examples such as the aircraft industry in Indonesia in the past do not provide sufficient evidence against TIP. Perhaps Indonesia was hit with bad luck with the Asian crisis of 1998 and could have emulated the success of EMBRAER in Brazil if given more time.

We gave a broad definition of TIP, but it would be useful to clarify what it is not. Our argument is not that TIP succeeds in every sector every time or that it does not entail risks. Rather, we argue that TIP offers broad concepts of a growth strategy, the modalities (e.g., tools) of which are yet to be defined. We also do not argue that the tools traditionally associated with industrial policy, such as subsidies, tariffs and the use of SOEs ${ }^{44}$, are necessarily effective ways to pursue TIP. Some of these policies could in fact explain the failures of industrial policy in the past. In terms of the role of state, TIP is the exact opposite of centralized planning, as it favors more competition and autonomy of the private sector, not less. The role of the state to intervene is to correct market failures where they exist and enforce a strict market discipline. As such, it is the exact opposite of indefinite support for under-performing, under-innovating and rent-seeking firms. We are not arguing that TIP is easy to pursue or that there is a cookbook recipe. For example, how to select sectors or enforce a strict market discipline is still an uncharted territory, but it is an important area to explore.

More important, TIP is not in opposition to the standard recipe of macro-stability, improving institutions and business environment, or investing in infrastructure and human capital. All these ingredients are necessary, but not necessarily sufficient for high sustained growth. Through the lens of TIP, policymakers can set clearer priorities for their growth strategies, and we argue that higher and more sustained growth is more probable. The Asian Miracles correspond to the most ambitious version of TIP, which led them from low-income to highincome status in a couple of generations. But there is a spectrum of possibilities depending on domestic and external conditions and how ambitious the authorities are and how willing they are to implement TIP.

\footnotetext{
44 The public sector is not necessarily unfit for the task as the example of Singapore shows, where the government-linked companies played a significant role in the economy since independence and are run efficiently on a competitive and commercial basis (Ramirez and Tan 2004).
} 
To apply the principles of TIP, one would need to specify the strategies that countries can use depending on their own circumstances. This entails addressing questions such as what specific sectors to focus on, what type of institutions to build, and what types of skills and infrastructure to acquire, and how to do so. Cherif and Hasanov (forthcoming) attempt to address these issues in a follow-up paper. 


\section{REFERENCES}

Abramovitz, Moses. 1986. “Catching Up, Forging Ahead, and Falling Behind.” Journal of Economic History 46(2): 385-406.

Acemoglu, Daron, Philippe Aghion, and Fabrizio Zilibotti, 2006. "Distance to Frontier, Selection, and Economic Growth," Journal of the European Economic Association, 4(1): 37-74.

Acemoglu, Daron, and James A. Robinson. 2012. Why Nations Fail: The Origins of Power, Prosperity and Poverty. 1st ed. New York: Crown.

Aghion, Philippe and Peter Howitt. 1992. "A Model of Growth Through Creative Destruction" Econometrica 60: 323-51.

Aghion, Philippe. 2016. "Growth Policy Design for Middle-Income Countries." In Cherif, Reda, Fuad Hasanov, and Min Zhu (editors), Breaking the Oil Spell: The Gulf Falcons' Path to Diversification. Washington, DC: International Monetary Fund Press.

Amsden, Alice. 1989. Asia's Next Giant: South Korea and Late Industrialization. Oxford: Oxford University Press.

Amsden, Alice. 2003. The Rise of "The Rest": Challenges to the West from LateIndustrializing Economies. Oxford: Oxford University Press.

Arezki, Rabah, Reda Cherif, and John Piotrowski. 2009. "Tourism Specialization and Economic Development: Evidence from the UNESCO World Heritage List," IMF Working Paper 09/176. (Washington, DC: International Monetary Fund)

Arrow, Kenneth. 1962. "The Economic Implications of Learning by Doing." The Review of Economic Studies 29(3): 155-73.

Balassa, Bela and Marcus Noland, 1989. "Revealed Comparative Advantage in Japan and the United States," Journal of International Economic Integration 2 (2): 8-22.

Bartelme, Dominick and Yuriy Gorodnichenko. 2015. "Linkages and Economic Development.” BEHL Working Paper WP2015-07.

Bazzi, Samuel and Michael A. Clemens. 2013. "Blunt Instruments: Avoiding Common Pitfalls in Identifying the Causes of Economic Growth," American Economic Journal: Macroeconomics 5(2): 152-86.

Benhassine, Najy and Gael Raballand. 2009. "Beyond Ideological Cleavages: A Unifying Framework for Industrial Policies and Other Public Interventions." Economic Systems 33(4): 293-309. 
Berg, Andrew, Jonathan D. Ostry, and Jeromin Zettelmeyer. 2012. "What Makes Growth Sustained?" Journal of Development Economics 98(2): 149-66.

Berger, Suzanne. 2011. "Why Manufacturing Matters." MIT Technology Review July 1. Available: https://www.technologyreview.com/s/424554/why-manufacturing-matters/.

Best, Michael. 2007. "Cluster Dynamics in Malaysian Electronics,” in Jomo K. S. (ed.), Malaysian Industrial Policy, Singapore: National University of Singapore Press, 24976.

Boulton, William. 1997. "Hong Kong-South China Electronics Industry." In Electronics Manufacturing in the Pacific Rim, Michael Kelly and William Boulton (eds). WTEC Panel Report, Loyola College in Maryland.

Bulman, David, Maya Eden, and Ha Nguyen, 2012. "Transitioning from Low-Income Growth to High-Income Growth: Is there a Middle-Income Trap?" World Bank, background paper for G-20 Meeting, June.

Callen, Tim, Reda Cherif, and Fuad Hasanov. 2016. "Introduction." In Cherif, Reda, Fuad Hasanov, and Min Zhu (editors), Breaking the Oil Spell: The Gulf Falcons' Path to Diversification. Washington, DC: International Monetary Fund Press.

Cermeño, Alexandra L. 2018a. "The driving forces of service localization during the twentieth century: evidence from the United States." European Review of Economic History, Online.

Cermeño, Alexandra L. 2018b. "The transformation of the Manufacturing Belt: How market size drove the localisation of knowledge hubs." VoxEU. 23 May. Available: https://voxeu.org/article/how-market-size-drove-localisation-knowledge-hubs-us.

Chang, Ha-Joon. 2002. Kicking Away the Ladder: Development Strategy in Historical Perspective. London: Anthem Press.

Chang, Ha-Joon. 2009. "Industrial Policy: Can We Go Beyond an Unproductive Confrontation?" Annual World Bank Conference on Development Economics, Seoul, South Korea, June 22-24.

Chang, Ha-Joon. 2013. "Industrial Policy: From Ideology to Pragmatism," presentation at the World Bank conference on Making Growth Happen: Implementing Policies for Competitive Industries, October.

Chang, Ha-Joon and Antonio Andreoni. 2016. "Industrial Policy in a Changing World: Basic Principles, Neglected Issues and New Challenges," 40 Years of the Cambridge Journal of Economics Conference, Cambridge, July 13.

Chang, Ha-Joon and Justin Lin. 2009. "Should Industrial Policy in Developing Countries Conform to Comparative Advantage or Defy it? A Debate Between Justin Lin and HaJoon Chang," Development Policy Review, 27, September: 483-502. 
Chen, Edward K.Y. 1987. "Foreign Trade and Economic Growth in Hong Kong: Experience and Prospects." In NBER's Trade and Structural Change in Pacific Asia, Colin I. Bradford, Jr. and William H. Branson (eds). Chicago, IL: University of Chicago Press, $333-78$.

Cherif, Reda. 2013. "The Dutch Disease and the Technological Gap.” Journal of Development Economics 101(C): 248-55.

Cherif, Reda, and Fuad Hasanov. 2013. “Oil Exporters' Dilemma: How Much to Save and How Much to Invest." World Development 52 (C): 120-31.

Cherif, Reda and Fuad Hasanov. 2015. "The Leap of the Tiger: How Malaysia can Escape the Middle-Income Trap,” IMF Working Paper 15/131. (Washington, DC: International Monetary Fund)

Cherif, Reda and Fuad Hasanov. 2016. "Soaring of the Gulf Falcons: Diversification in GCC Oil Exporters in Seven Propositions." In Cherif, Reda, Fuad Hasanov, and Min Zhu (editors), Breaking the Oil Spell: The Gulf Falcons' Path to Diversification. Washington, DC: International Monetary Fund Press.

Cherif, Reda and Fuad Hasanov. Forthcoming. "The Return of the Policy that Shall Not Be Named: Strategies of Industrial Policy.” Working paper.

Cherif, Reda, Fuad Hasanov, and Alfred Kammer. 2016. "Lessons for Today and the Way Forward." In Cherif, Reda, Fuad Hasanov, and Min Zhu (editors), Breaking the Oil Spell: The Gulf Falcons' Path to Diversification. Washington, DC: International Monetary Fund Press.

Cherif, Reda, Fuad Hasanov, and Lichen Wang. 2018. "Sharp Instrument: A Stab at Identifying the Causes of Economic Growth." IMF Working Paper WP/18/117. (Washington, DC: International Monetary Fund)

Clauset, A., C.R. Shalizi, and M.E.J. Newman. 2009. "Power-law Distributions in Empirical Data" SIAM Review 51(4): 661-703.

Cohen, Stephen and Bradford DeLong. 2016. Concrete Economics: The Hamilton Approach to Economic Growth and Policy. Harvard Business Review Press.

Criscuolo, Chiara, Ralf Martin, Henry G. Overman, and John Van Reenen. 2019. "Some Causal Effects of an Industrial Policy," American Economic Review 109(1): 48-85.

De Rubens, G. Z., L. Noel, and B. K. Savacool. 2018. "Dismissive and Deceptive Car Dealerships Create Barriers to Electric Vehicle Adoption at the Point of Sale," Nature Energy 3: 501-07.

Devan, Janamitra. 2011. "Strengthening Industrial Competitiveness to Promote Job Creation." A speech delivered at the conference organized by Trade and Industrial Policies Strategies (TIPS) and World Bank in Pretoria, South Africa, October 27. 
Diao, Xinshen, Margaret McMillan, and Dani Rodrik. 2017. "The Recent Growth Boom in Developing Economies: A Structural Change Perspective.” NBER Working Paper No. 23132.

Easterly, William. 1995. "Explaining Miracles: Growth Regressions Meet the Gang of Four," In Growth Theories in Light of the East Asian Experience, NBER-EASE Volume 4: National Bureau of Economic Research, Inc., 267-99.

Eichengreen, Barry, Donghyun Park, and Kwanho Shin, 2013. "Growth Slowdowns Redux: New Evidence on the Middle-Income Trap,” NBER Working Paper No. 18673.

Eichengreen, Barry. 2016. "Confronting the Fiscal Bogeyman.” Project Syndicate column, March 11.

Fallows, James. 1995. Looking at the Sun: The Rise of the New East Asian Economic and Political System. Vintage (first published in 1994).

Feenstra, Robert and John Romalis. 2014. "International Prices and Endogenous Quality." The Quarterly Journal of Economics 129(2): 477-527.

Feenstra, Robert C., Robert Inklaar and Marcel P. Timmer. 2015. "The Next Generation of the Penn World Table." American Economic Review 105(10): 3150-3182. Available for download at www.ggdc.net/pwt.

Felker, Greg. 2001. "The Politics of Industrial Investment Policy Reform in Malaysia and Thailand," in Jomo K. S. (ed.), Southeast Asia's Industrialization: Industrial Policy, Capabilities and Sustainability, New York: Palgrave, 129-82.

Gabaix, Xavier. 2009. "Power Laws in Economics and Finance," Annual Review of Economics 1(1): 255-94.

Gerschenkron, Alexander, 1962. Economic Backwardness in Historical Perspective, Harvard University Press.

Ghani, Ejaz, Arti Grover Goswami, and Homi Kharas. 2011. "Can services be the next growth escalator?” VoxEU. December 12. Available: https://voxeu.org/article/can-servicesbe-next-growth-escalator.

Ghani, Ejaz and Homi Kharas. 2010. The Service Revolution. Economic Premise No 14. World Bank. (Washington, DC: World Bank Group)

Ghani, Ejaz and Stephen O'Connell. 2014. "Can Service be a Growth Escalator in LowIncome Countries?”, World Bank Policy Research Working Paper Series 6971.

Hall, Frederic S. 1902. "The Localization of Industries.” Bulletin of the Twelfth Census of the United States.

Hallegatte, Stéphane, Marianne Fay, and Adrien Vogt-Schilb. 2013. "Green Industrial Policies: When and How.” World Bank Policy Research Working Paper 6677. 
Hallward-Driemeier, Mary and Gaurav Nayyar. 2017. Trouble in the Making? The Future of Manufacturing-Led Development. Washington, DC: World Bank.

Hamilton, Alexander. 1791. Report on the Subject of Manufactures. Presented to Congress on December 5.

Harrison, Ann and Andrés Rodríguez-Clare. 2010. "Trade, Foreign Investment, and Industrial Policy for Developing Countries.” In Dani Rodrik and Mark Rosenzweig, editors: Handbook of Development Economics 5, The Netherlands: North-Holland, pp. 4039-214.

Harrison, Ann, Leslie A. Martin, and Shanthi Nataraj. 2017. "Green Industrial Policy in Emerging Markets.” Annual Review of Resource Economics 9:253-274.

Hausmann, Ricardo, Jason Hwang, and Dani Rodrik, 2007. "What You Export Matters," Journal of Economic Growth, 12(1), March: 1-25.

Hausmann, Ricardo, Lant Pritchett, and Dani Rodrik. 2005. "Growth Accelerations" Journal of Economic Growth 10(4): 303-29.

Hausmann, Ricardo. 2015a. "The Role of Productive Development Policies." Presentation at the Inter-American Development Bank’s Policy Dialogue, Washington, DC, May 14.

Hausmann, Ricardo. 2015b. "What are the Challenges of Economic Growth?" Available: http://growthlab.cid.harvard.edu/publications/what-are-challenges-economic-growth.

Hausmann, Ricardo, Luis Espinoza, and Miguel Angel Santos. 2015. "The Low Productivity Trap: Growth Diagnostics of Chiapas.” Executive Summary. Center for International Development Working Paper 304, Harvard University.

Henry, Peter Blair and Conrad Miller. 2009. "Institutions versus Policies: A Tale of Two Islands.” American Economic Review 99(2): 261-67.

Herrendorf, Berthold and Akos Valentinyi. 2012. "Which Sectors Make Poor Countries So Unproductive?" Journal of the European Economic Association 10(2): 323-41.

Heum, P. 2008. "Local Content Development - Experiences from Oil and Gas Activities in Norway," SNF, Bergen.

Hirschman, Albert, 1958. The Strategy of Economic Development. New Haven, Conn.: Yale University Press.

Hlatshwayo, Sandile and Michael Spence. 2014. "Demand and Defective Growth Patterns: The Role of the Tradable and Non-Tradable Sectors in an Open Economy." American Economic Review: Papers \& Proceedings 104(5): 272-77.

Hsieh, Chang-Tai. 2002. "What Explains the Industrial Revolution in East Asia? Evidence from the Factor Markets," American Economic Review 92(3): 502-26. 
Hsieh, Chang-Tai and P. Klenow. 2009. "Misallocation and Manufacturing TFP in China and India." The Quarterly Journal of Economics 124(4): 1403-48.

Inter-American Development Bank. 2014. Rethinking Productive Development: Sound Policies and Institutions for Economic Transformation. IDB: Washington, DC.

International Monetary Fund. 2016. Central, Eastern, and Southeastern Europe: How to Get Back on the Fast Track. Regional Economic Issues, May.

International Monetary Fund. 2018. "Manufacturing Jobs: Implications for Productivity and Inequality," World Economic Outlook, Chapter 3, April.

Johnson, Chalmers. 1982. MITI and the Japanese Miracle: The Growth of Industrial Policy, 1925-1975. Stanford, CA: Stanford University Press.

Johnson, Paul and Chris Papageorgiou. Forthcoming. "What Remains of Cross-Country Convergence?" Journal of Economic Literature.

Jomo K. S., Chen Yun Chung, Brian Folk, Irfan ul-Haque, Pasuk Phongpaichit, Batara Simatupang, and Mayuri Tateishi. 1997. Southeast Asia's Misunderstood Miracle: Industrial Policy and Economic Development in Thailand, Malaysia, and Indonesia. Westview Press, Oxford.

Juhász, Réka. 2018. "Temporary Protection and Technology Adoption: Evidence from the Napoleonic Blockade," American Economic Review 108(11): 3339-76.

Kalouptsidi, Myrto. 2018. "Detection and Impact of Industrial Subsidies: The Case of Chinese Shipbuilding." Review of Economic Studies 85(2): 1111-58.

Kang, Joonkyu. 2001. "A Study of the DRAM Industry.” Massachusetts Institute of Technology Sloan School of Management. Master's thesis.

Kavlaka, Goksin, James McNerneya, and Jessika E. Trancik. 2018. "Evaluating the Causes of Cost Reduction in Photovoltaic Modules." Energy Policy 123: 700-10.

Knowledge@Wharton. 2017. “DowDuPont’s Andrew Liveris: How America Can Bring Back Manufacturing." October 12. Available:

http://knowledge.wharton.upenn.edu/article/dowduponts-andrew-liveris-america-canbring-back-manufacturing/.

Krueger, Anne. 1975. The Benefits and Costs of Import Substitution in India. St. Paul, MN: University of Minnesota Press.

Krugman, Paul. 1987. "The Narrow Moving Band, the Dutch Disease, and the Competitive Consequences of Mrs. Thatcher: Notes on Trade in the Presence of Dynamic Scale Economies," Journal of Development Economics 27(1-2): 41-55.

Krugman, Paul. 1994. “Competitiveness: A Dangerous Obsession.” Foreign Affairs 73(2): $28-44$. 
Krugman, Paul. 1994. “The Myth of Asia's Miracle,” Foreign Affairs 73: 62-78.

Lane, Nathan. 2017. "Manufacturing Revolutions: Industrial Policy and Networks in South Korea." Working paper, Institute for International Economic Studies, Stockholm.

Leskinen, Olivia, Paul Klouman Bekken, Haja Razafinjatovo, and Manuel García 2012. "Norway Oil and Gas Cluster: A Story of Achieving Success through Supplier Development," Harvard Business School.

Lin, Justin. 2012. The Quest for Prosperity: How Developing Economies Can Take Off. Princeton, NJ: Princeton University Press.

List, Friedrich. 1885. The National System of Political Economy, translated from the original German edition published in 1841 by Sampson Lloyd. London: Longmans, Green, and Company.

Liu, Ernest. 2017. "Industrial Policy in Production Networks.” Working paper, Princeton University.

Low, Linda. 2001. "The Role of the Government in Singapore's Industrialization," in Jomo K. S. (ed.), Southeast Asia's Industrialization: Industrial Policy, Capabilities and Sustainability, New York: Palgrave, 113-28.

Lucas, Robert Jr., 1988. “On the Mechanics of Economic Development.” Journal of Monetary Economics 22, 3-42.

Lucas, Robert Jr., 1993. “Making a Miracle,” Econometrica, 61(2), March: 251-72.

Marshall, Alfred. 1880. Principles of Economics. Chapter 10, London, U.K.: MacMillan.

McMillan, M., and D. Rodrik. 2011. "Globalization, Structural Change, and Productivity Growth.” NBER Working Paper 17143.

Mazzucato, Mariana, 2013. The Entrepreneurial State: Debunking Public vs. Private Sector Myths. New York: Public Affairs.

Monnery, Neil. 2017. Architect of Prosperity: Sir John Cowperthwaite and the Making of Hong Kong. London: London Publishing Partnership.

Murphy, Kevin M., Andrei Shleifer, Robert W. Vishny. 1989. "Industrialization and the Big Push,” Journal of Political Economy 97(5): 1003-26.

Naqvi, Natalya, Anne Henow, and Ha-Joon Chang. 2018. "Kicking Away the Financial Ladder: German Development Banking under Economic Globalisation.” Review of International Political Economy, Online.

Newman, M. E. J., A. Reggiani, and P. Nijkamp. 2005. "Power Laws, Pareto Distributions and Zipf's Law." Cities 30: 323-51. 
Ocampo, Jose Antonio, Lance Taylor and Codrina Rada. 2009. Growth and Policy in Developing Countries: A Structuralist Approach. New York: Columbia University Press.

O’Mara, Margaret. 2004. Cities of Knowledge: Cold War Science and the Search for the Next Silicon Valley. Princeton, NJ: Princeton University Press.

Ramalingam, Ben. 2013. Aid on the Edge of Chaos: Rethinking International Cooperation in a Complex World. Oxford: Oxford University Press.

Ramírez, Carlos and Ling Hui Tan. 2004. "Singapore Inc. versus the Private Sector: Are Government-Linked Companies Different?” IMF Staff Papers 51(3): 510-28.

Rasiah, Rajah. 2004. "Foreign Ownership, Technological Intensities, and Network Strengths: Electronics Firms in East Asia," OECD conference paper on The Impact and Coherence of OECD Country Policies on Asian Developing Economies.

Rasiah, Rajah. 2007. "R\&D and Export Intensities in Automotive Parts Firms in China, Malaysia, Philippines and Taiwan: Does Ownership Matter?” RIETI Discussion Paper Series.

Rodrik, Dani. 2005. "Growth Strategies," in Philippe Aghion \& Steven Durlauf (ed.), Handbook of Economic Growth, edition 1, volume 1, chapter 14, Oxford: Elsevier, 967-1014.

Rodrik, Dani. 2012. "Why We Learn Nothing from Regressing Economic Growth on Policies," Seoul Journal of Economics 25(2): 137-51.

Rodrik, Dani. 2013. "Unconditional Convergence in Manufacturing," The Quarterly Journal of Economics 128(1), February, pp. 165-204.

Rodrik, Dani. 2016. "Premature Deindustrialization," Journal of Economic Growth 21(1), pp.1-33.

Romer, Paul. 1990. "Endogenous Technological Change," Journal of Political Economy 98(5), pp. S71-102.

Rumbelow, Helen. 2017. "Don't Mess with Mariana Mazzucato, the World's Scariest Economist." The Times, November 17.

Sasson, Amir and Atle Blomgren 2011. "Knowledge Based Oil and Gas Industry," Knowledge-based Norway, March, Report No. 4.

Senhadji, Abdelhak. 2000. "Sources of Economic Growth: An Extensive Growth Accounting Exercise.” IMF Staff Papers 47(1): 129-57.

Stiglitz, Joseph and Bruce Greenwald. 2014. Creating a Learning Society. New York, NY: Columbia University Press. 
The Economist. 2016. "The End of the Line.” February 6. Available: https://www.economist.com/international/2016/02/06/the-end-of-the-line.

Timmer, M. P., G. J. de Vries, and K. de Vries. 2015. "Patterns of Structural Change in Developing Countries.” In J. Weiss and M. Tribe (Eds.), Routledge Handbook of Industry and Development Routledge: 65-83.

Trade and Industry Department. 2018. "Support to Hong Kong Industries." The Government of the Hong Kong Special Administrative Region. Online. Accessed November 2018. Available:

https://www.tid.gov.hk/english/smes industry/industry/industry content.html.

Tran, Van Tho. 2013. "The Middle-Income Trap: Issues for Members of the Association of Southeast Asian Nations,” Asian Development Bank Institute Working Paper 421.

Wade, Robert. 2018. "The Development State: Dead or Alive? Development and Change 49(2): 518-46.

Wade, Robert. 1990. Governing the Market. Princeton, NJ: Princeton University Press.

Warwick, K. 2013. "Beyond Industrial Policy: Emerging Issues and New Trends," OECD Science, Technology and Industry Policy Papers, No. 2, OECD Publishing, Paris.

Weiss, John. 2005. "Export Growth and Industrial Policy: Lessons from the East Asian Miracle Experience.” ADB Institute Discussion Paper No. 26.

Woo, Meredith. 1991. Race to the Swift: State and Finance in Korean Industrialization. New York: Columbia University Press.

Varas, Maria Elena. 2012. "Economic Diversification: The Case of Chile," Revenue Watch Institute.

Young, Alwyn. 1991. "Learning by Doing and the Dynamic Effects of International Trade," The Quarterly Journal of Economics 106(2): 369-405.

Young, Alwyn. 1995. "The Tyranny of Numbers: Confronting the Statistical Realities of the East Asian Growth Experience," The Quarterly Journal of Economics 110 (August 1995): 641-80. 
APPENDiX I. TABLES

Table 1. Taiwan Province of China: Machinery and Transport Equipment Top RCAs Industries 1970

\begin{tabular}{|c|c|c|c|}
\hline sitc4 & Description & RCA & Expport share \\
\hline 7241 & Textile and leather machinery, and parts thereof, nes & 9.0 & $2.7 \%$ \\
\hline 7242 & Textile and leather machinery, and parts thereof, nes & 8.3 & $3.2 \%$ \\
\hline 7231 & Civil engineering, contractors plant and equipment and parts, nes & 3.4 & $0.9 \%$ \\
\hline 7173 & Parts, nes, of rotating electric plant & 3.1 & $0.5 \%$ \\
\hline 7331 & Metalworking machinery & 2.9 & $0.3 \%$ \\
\hline $72 X X$ & Parts, nes of machines in headings 72348,72721 , and $72842-72848$ & 2.8 & $0.0 \%$ \\
\hline 7293 & Parts, nes of machines in headings 72348,72721 , and $72842-72848$ & 2.7 & $1.4 \%$ \\
\hline 7292 & Parts, nes of machines in headings 72348,72721 , and $72842-72848$ & 2.3 & $0.3 \%$ \\
\hline 7299 & Parts, nes of machines in headings 72348,72721 , and $72842-72848$ & 2.2 & $1.1 \%$ \\
\hline 7249 & Machinery for preparing, tanning, working leather, etc; parts nes & 2.0 & $1.8 \%$ \\
\hline 7291 & Parts, nes of machines in headings 72348,72721 , and $72842-72848$ & 1.7 & $0.2 \%$ \\
\hline 7329 & Metalworking machinery & 1.5 & $0.4 \%$ \\
\hline 7221 & Tractors (other than those falling in heading 74411 and 7832) & 1.1 & $0.6 \%$ \\
\hline \multicolumn{4}{|c|}{  } \\
\hline 72348 & Machines and mechanical appliance for public works, nes & & \\
\hline 72721 & Machines, appliances for animal, vegetable fats and oils industry & & \\
\hline 72842 & Machines for the rubber and plastics materials industries, nes & & \\
\hline 72843 & Machines and mechanical appliances for the tobacco industry, nes & & \\
\hline 72844 & Machines and mechanical appliances for treating wood, nes & & \\
\hline 72845 & Machines and mechanical appliances for treating metals, nes & & \\
\hline 72846 & Machines and mechanical appliances for treating metals, nes & & \\
\hline 72847 & Machines and mechanical appliances for treating metals, nes & & \\
\hline 72848 & Other machinery, mechanical appliances having individual functions & & \\
\hline
\end{tabular}

Table 2. Taiwan Province of China: Machinery and Transport Equipment Top Export Industries 1990

\begin{tabular}{clcc} 
sitc4 & \multicolumn{1}{c}{ Description } & RCA & Expport share \\
\hline 7525 & Peripheral units, including control and adapting units & 3.9 & $3.2 \%$ \\
7599 & Parts, nes of and accessories for machines of headings 7512 and 752 & 2.4 & $3.1 \%$ \\
7764 & Electronic microcircuits & 1.6 & $2.2 \%$ \\
7523 & Complete digital central processing units; digital processors & 3.0 & $1.8 \%$ \\
7649 & Parts, nes of and accessories for apparatus falling in heading 76 & 2.2 & $1.6 \%$ \\
7852 & Cycles, not motorized & 20.2 & $1.4 \%$ \\
7788 & Other electrical machinery and equipment, nes & 2.4 & $1.3 \%$ \\
7731 & Insulated electric wire, cable, bars, etc & 2.8 & $1.1 \%$ \\
7721 & Switches, relays, fuses, etc; switchboards and control panels, nes & 1.3 & $1.0 \%$ \\
7284 & Machinery for specialized industries and parts thereof, nes & 1.1 & $1.0 \%$ \\
7522 & Complete digital data processing machines & 3.6 & $1.0 \%$ \\
7528 & Off-line data processing equipment, nes & 3.8 & $0.9 \%$ \\
7853 & Invalid carriages; parts, nes of articles of heading 785 & 6.2 & $0.8 \%$ \\
\hline Note & & & \\
7512 & Calculating, accounting, cash registers, ticketing, etc, machines & & \\
752 & Automatic data processing machines and units thereof & & \\
76 & Telecommunications, sound recording and reproducing equipment & & \\
785 & Cycles, scooters, motorized or not; invalid carriages & & \\
\hline
\end{tabular}

Source: UN COMTRADE and World Trade Flows (Feenstra and Romalis 2014).

(C)International Monetary Fund. Not for Redistribution 


\begin{tabular}{|cccc}
\hline \multicolumn{2}{c}{ Table 3. Korea: Machinery and Transport Equipment Top RCAs Industries 1970} \\
sitc4 & \multicolumn{1}{c}{ Description } & RCA & Expport share \\
\hline 7242 & Textile and leather machinery, and parts thereof, nes & $0.6 \%$ \\
7292 & Parts, nes of machines in headings 72348, 72721, and 72842-72848 & 1.8 & $0.2 \%$ \\
7293 & Parts, nes of machines in headings 72348, 72721, and 72842-72848 & 6.8 & $3.4 \%$ \\
\hline Note & & & \\
\hline 72348 & Machines and mechanical appliance for public works, nes & \\
72721 & Machines, appliances for animal, vegetable fats and oils industry & \\
72842 & Machines for the rubber and plastics materials industries, nes & \\
72843 & Machines and mechanical appliances for the tobacco industry, nes & \\
72844 & Machines and mechanical appliances for treating wood, nes & \\
72845 & Machines and mechanical appliances for treating metals, nes & \\
72846 & Machines and mechanical appliances for treating metals, nes & \\
72847 & Machines and mechanical appliances for treating metals, nes & \\
\hline
\end{tabular}

Table 4. Korea: Machinery and Transport Equipment Top Export Industries 1990

\begin{tabular}{lllc}
\multicolumn{1}{c}{ sitc4 } & & RCA & Expport share \\
\hline 7764 & Electronic microcircuits & 4.5 & $5.9 \%$ \\
7932 & Ships, boats and other vessels & 5.2 & $2.4 \%$ \\
7525 & Peripheral units, including control and adapting units & 2.3 & $1.9 \%$ \\
7611 & Television receivers, colour & 3.8 & $1.9 \%$ \\
7638 & Other sound recording and reproducer, nes; video recorders & 3.9 & $1.7 \%$ \\
7649 & Parts, nes of and accessories for apparatus falling in heading 76 & 1.8 & $1.4 \%$ \\
7761 & Television picture tubes, cathode ray & 7.4 & $1.0 \%$ \\
7621 & Radio receivers for motor-vehicles & 7.7 & $1.0 \%$ \\
7758 & Electro-thermic appliances, nes & 3.7 & $0.9 \%$ \\
7861 & Trailers and transports containers & 7.8 & $0.9 \%$ \\
\hline Note & & & \\
\hline 76 & Telecommunications, sound recording and reproducing equipment & &
\end{tabular}

Source: UN COMTRADE and World Trade Flows (Feenstra and Romalis 2014). 


\section{APPENDIX II. FIGURES}

Figure 1: Short-term Relationship Between Manufacturing Exports and Output, 1990-2010

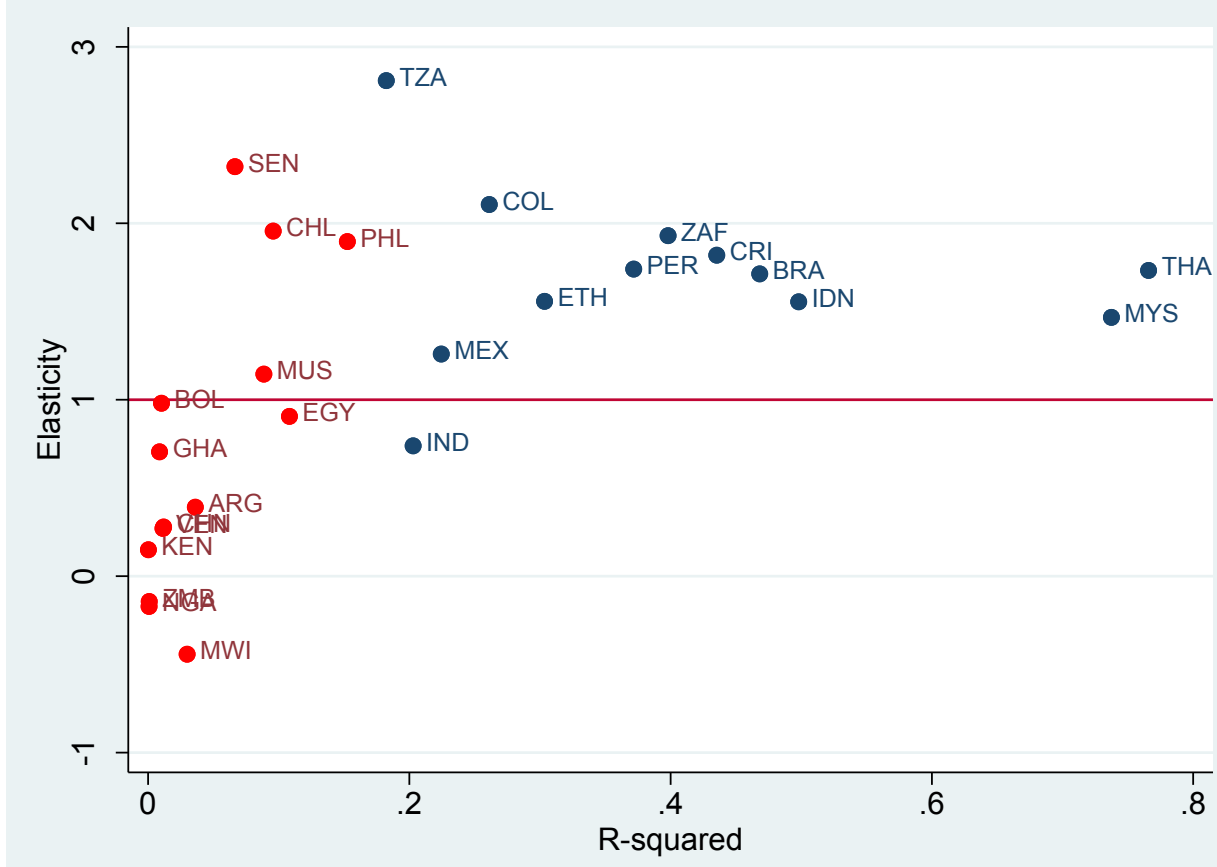

Source: GGDC and WDI.

Figure 2. Manufacturing Export Market Share Change, 1970-1990

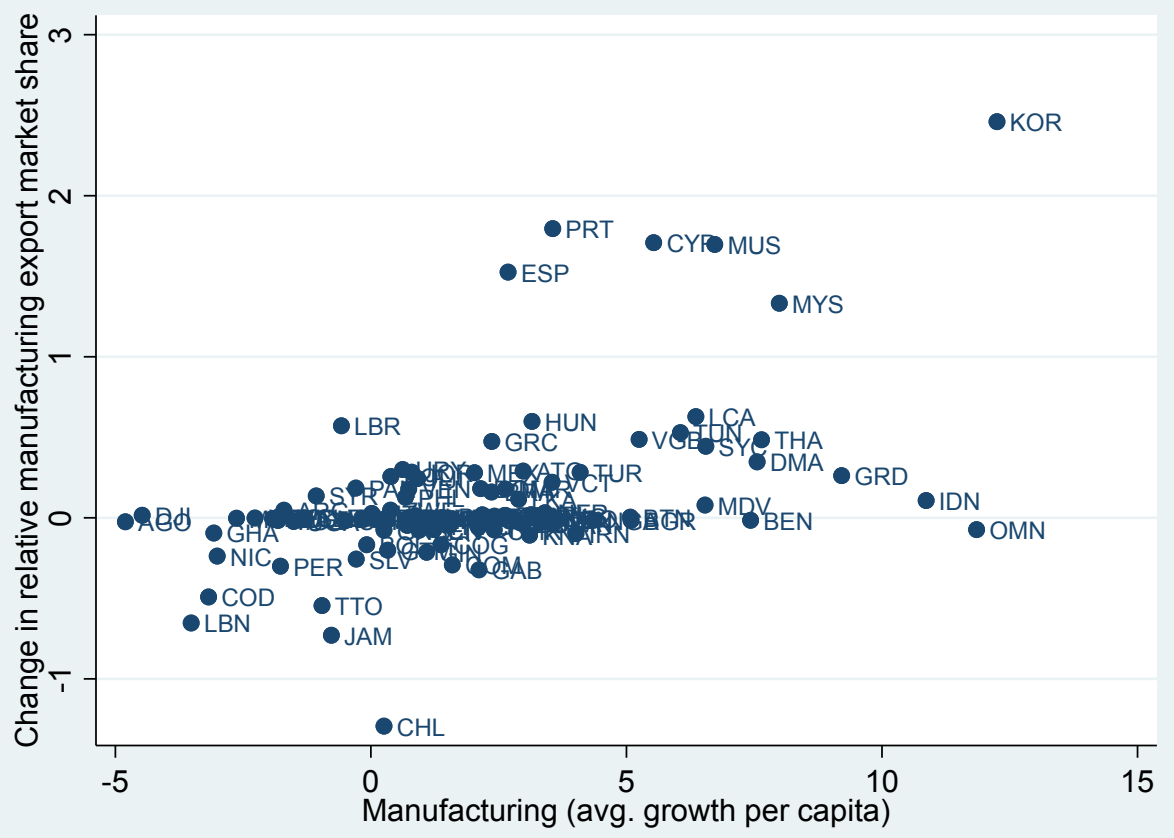

Source: UN and WDI.

CInternational Monetary Fund. Not for Redistribution 
Figure 3. Manufacturing Export Market Share Change, 1990-2010

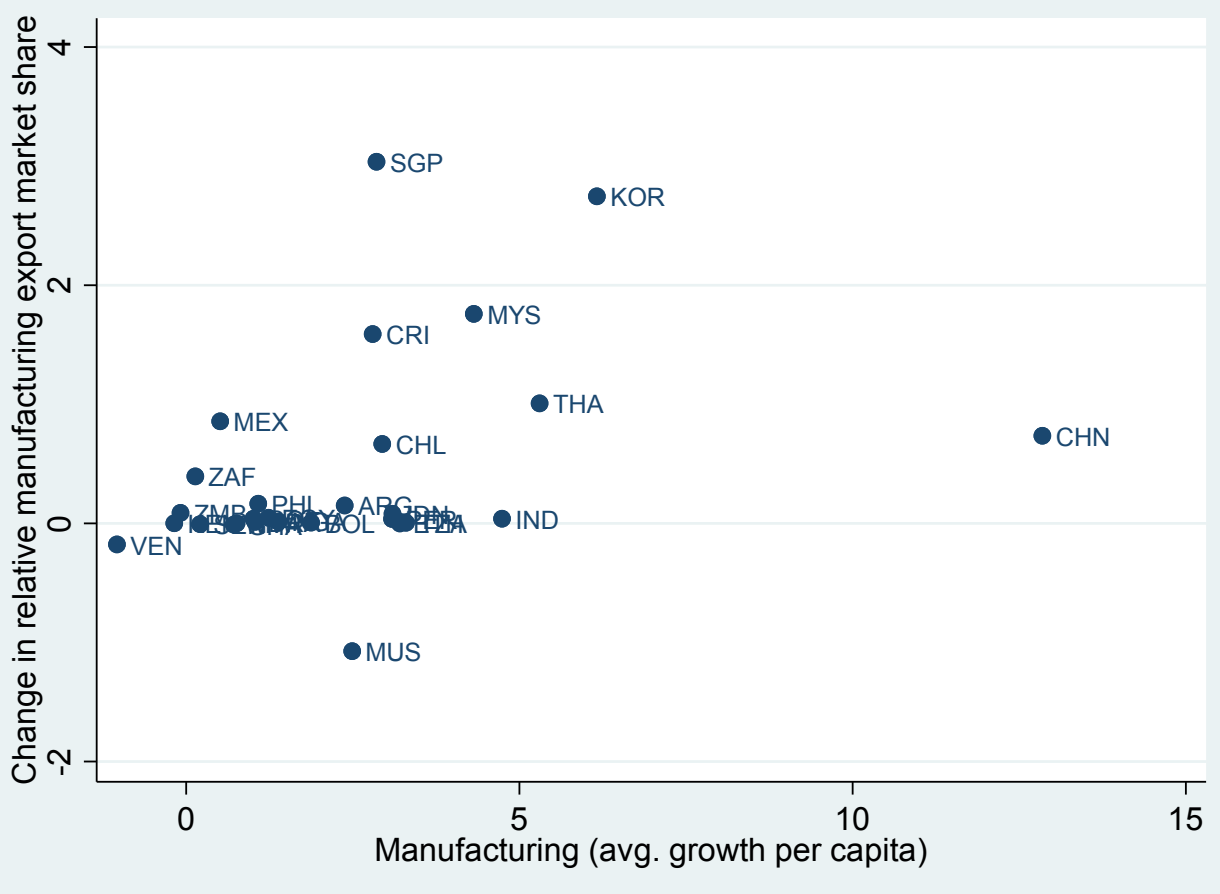

Source: GGDC and WDI.

Figure 4. Manufacturing Export Market Share Change, 1990-2010

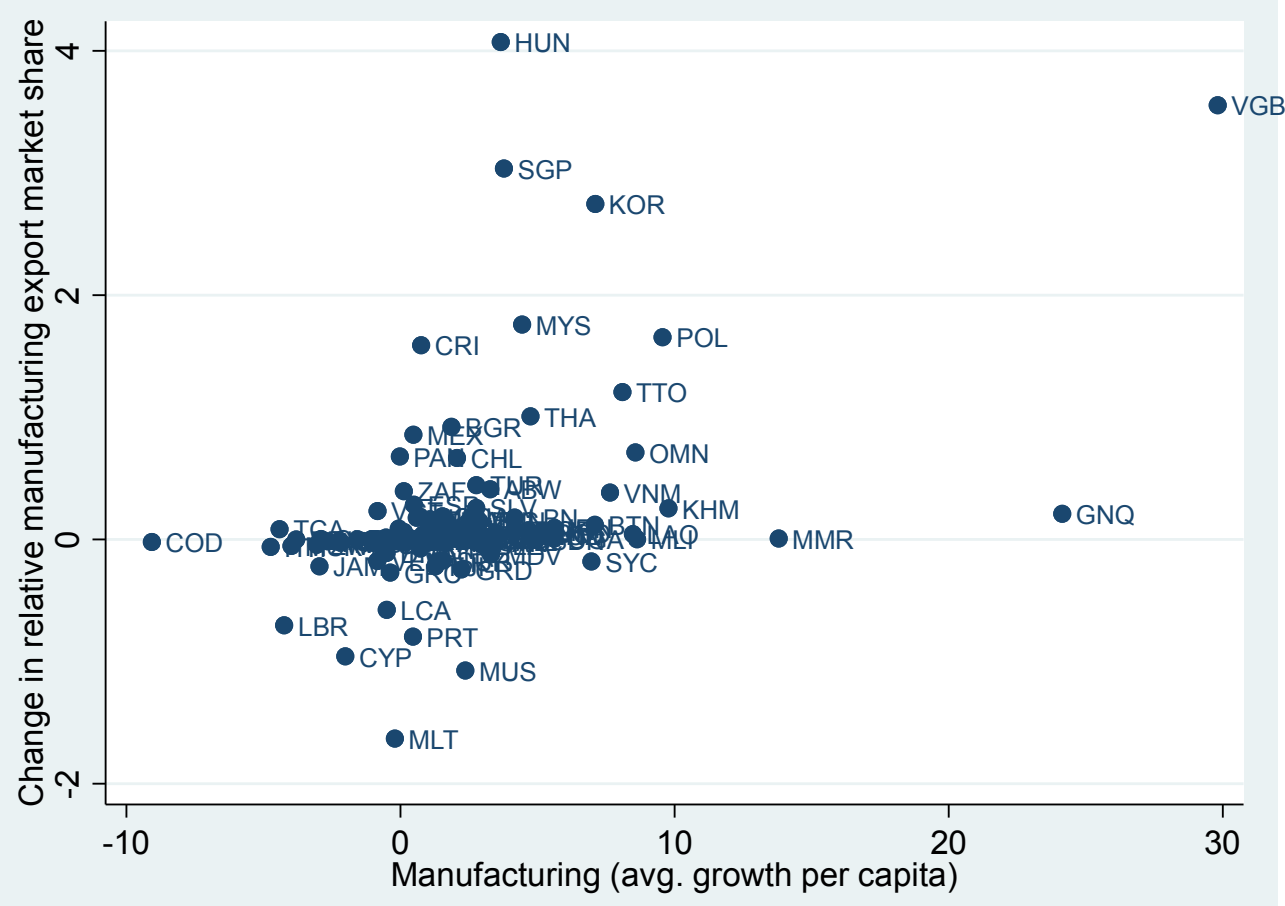

Source: UN and WDI. 


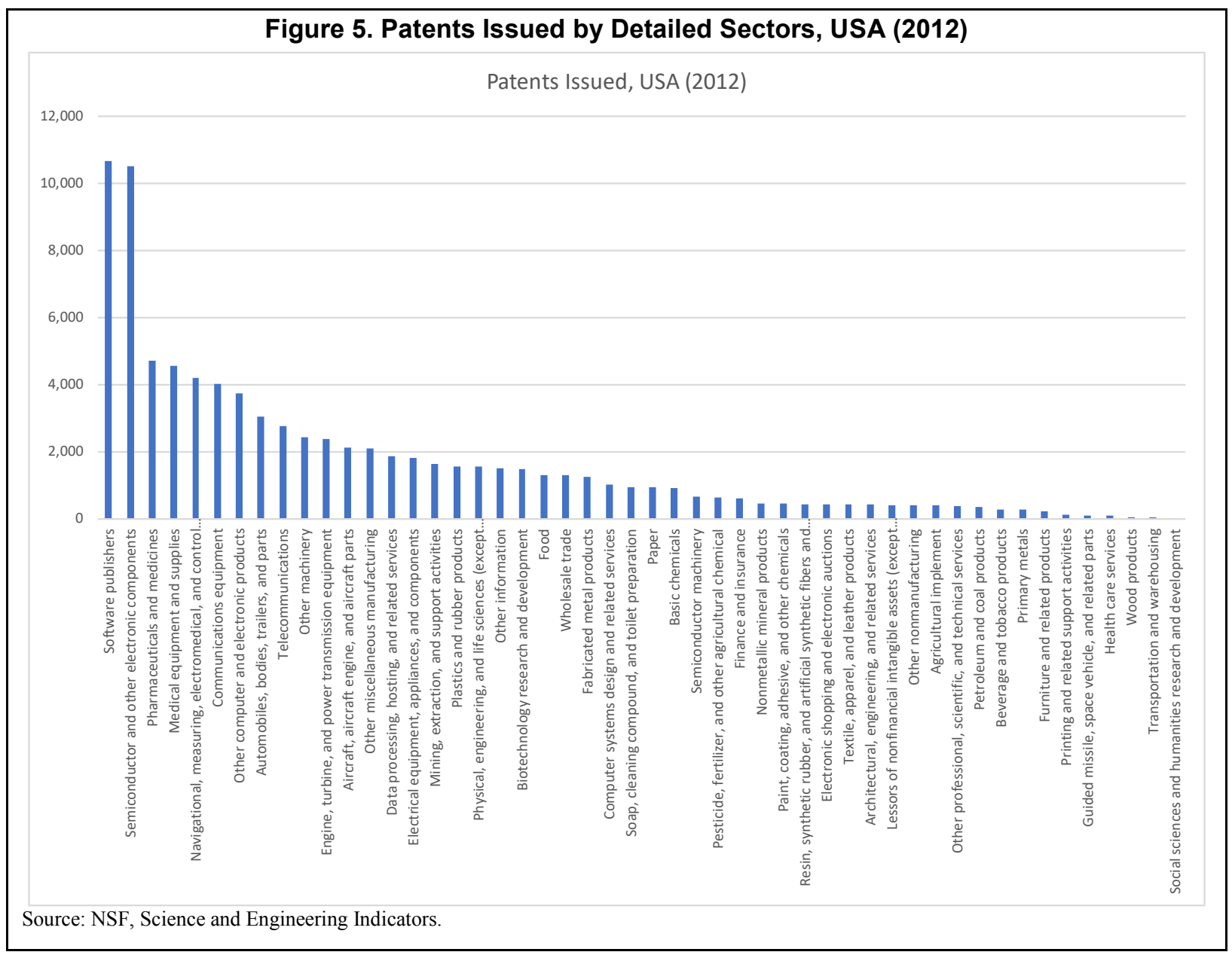

